\title{
Core Analysis for the Development and Constraint of Physical Models of Geothermal Reservoirs
}

\author{
G. N. Boitnott \\ New England Research, Inc.
}

\begin{abstract}
Final Report:
Covering Period: June 1, 1999 - June 12003

Date of Report: December 14, 2003

Recipient: New England Research, Inc. 331 Olcott Drive, Suite L1 White River Junction, VT 05001
\end{abstract}

Award Number: DE-FG07-99ID13761

PI/Contact(s): $\quad$ Greg N. Boitnott, 802-296-2401, boitnott@ner.com

This material is based upon work supported in part by the U S. Department of Energy under Award No. (DE-FG0799ID13761). Any opinions, findings, and conclusions or recommendations expressed in this material are those of the author and do not necessarily reflect the views of the Department of Energy. 

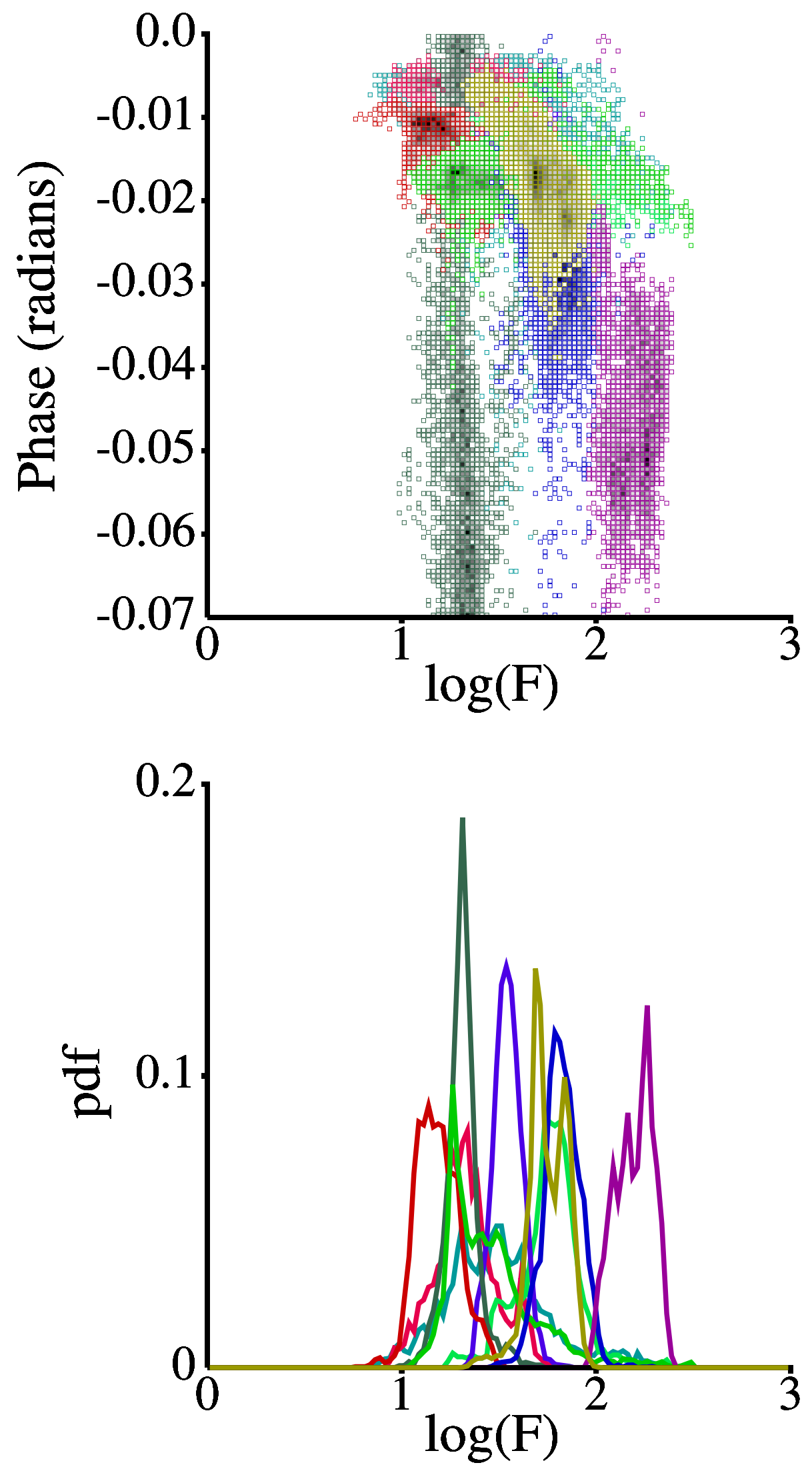

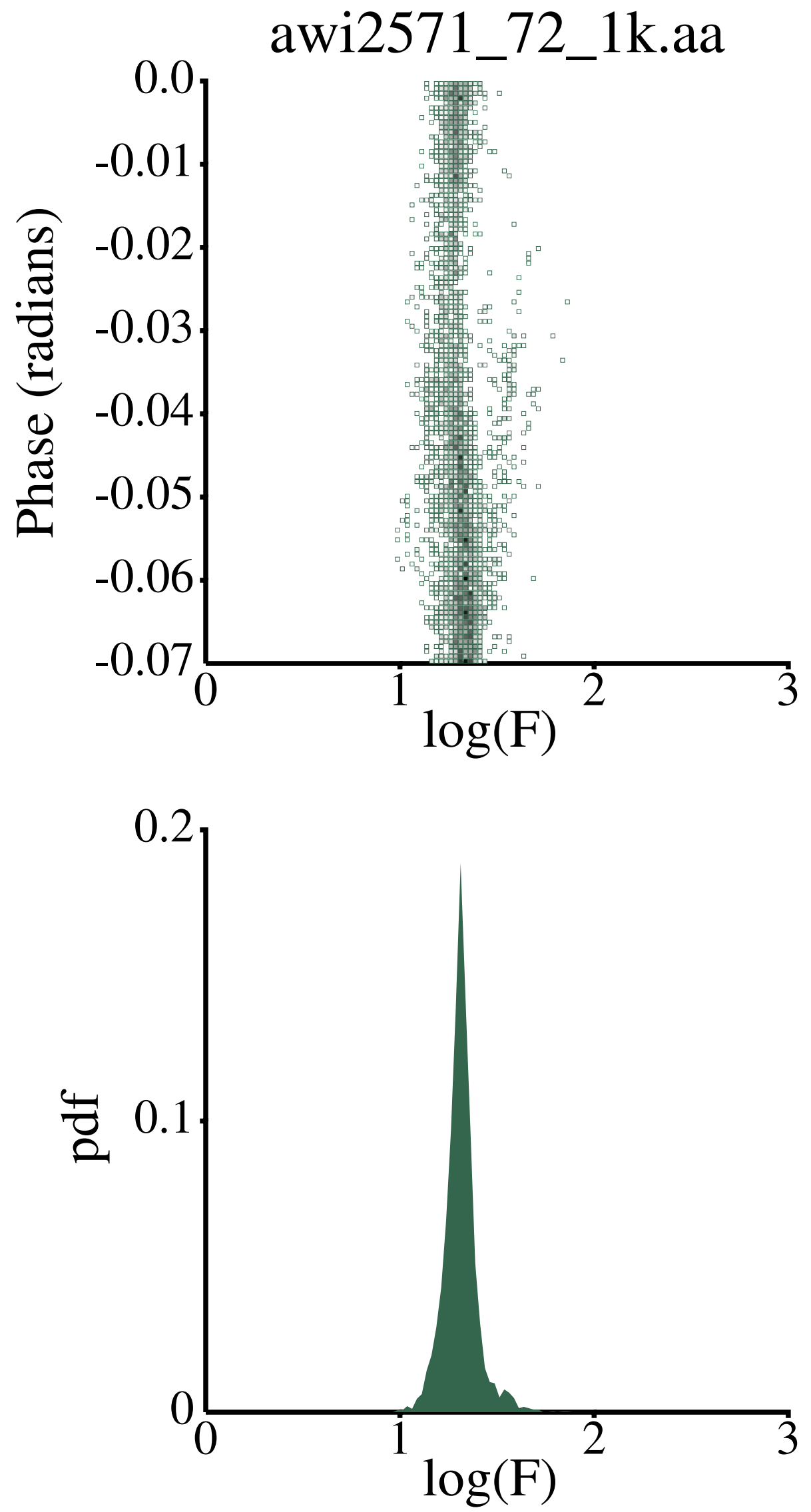

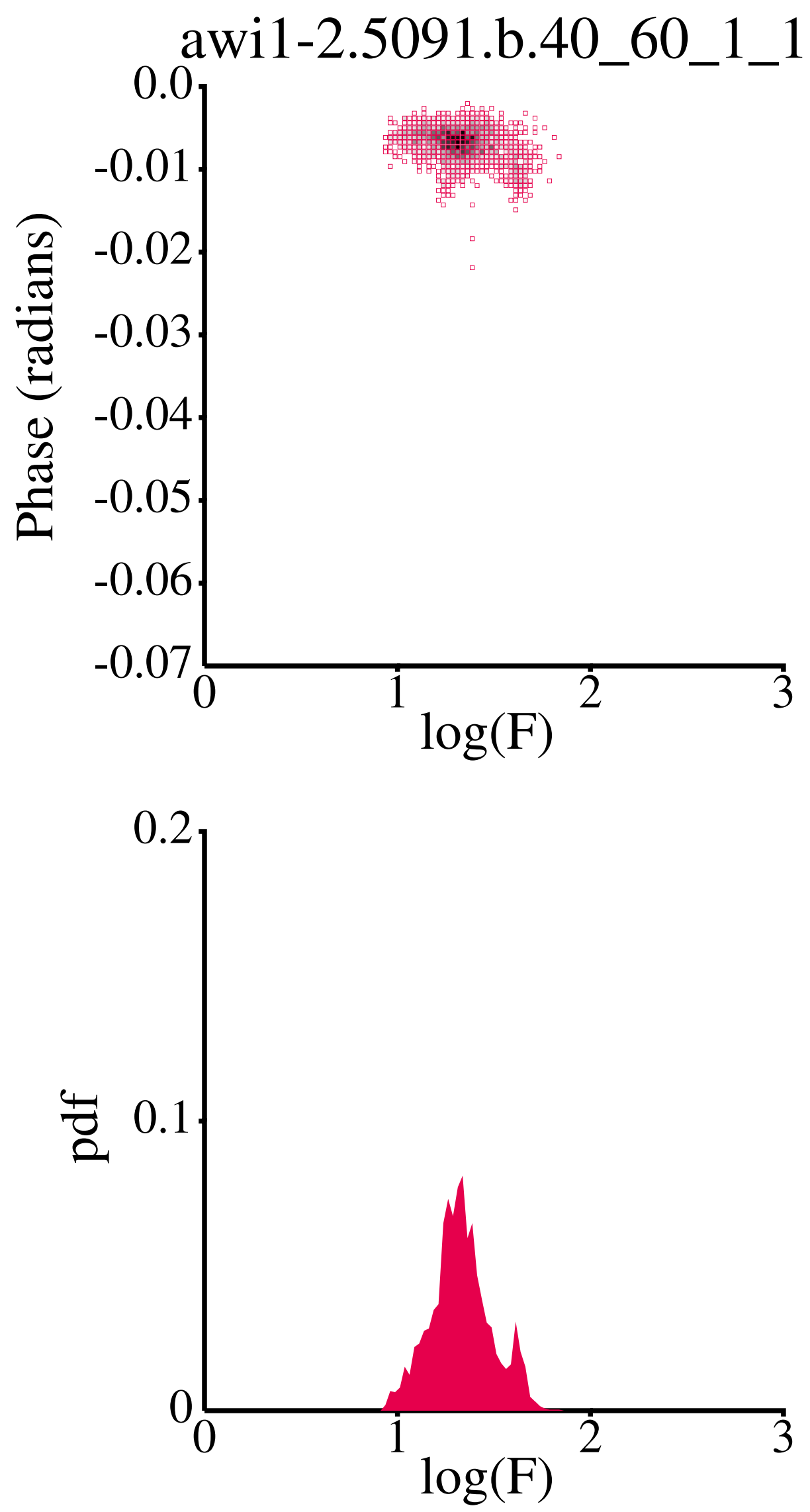

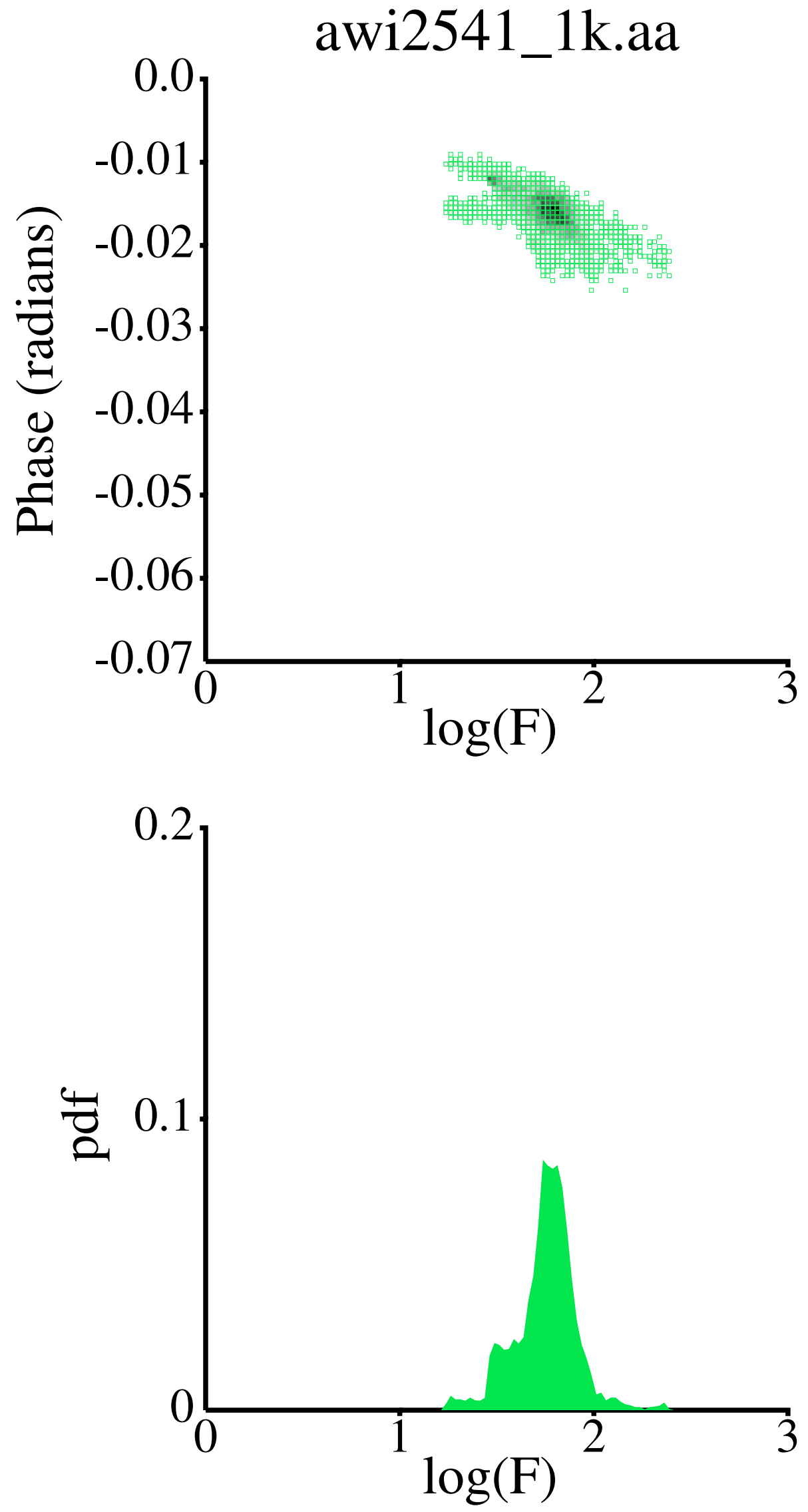

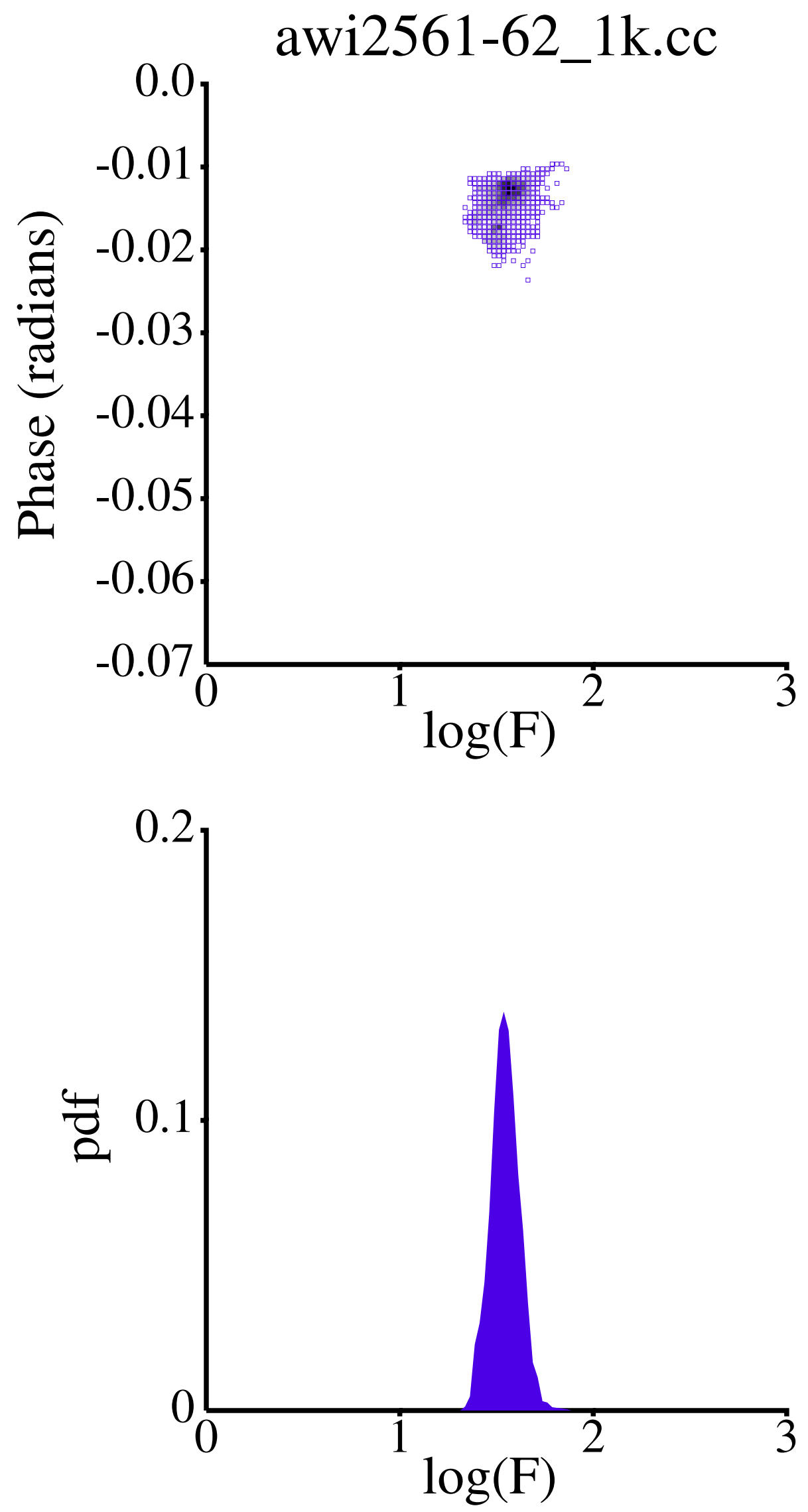

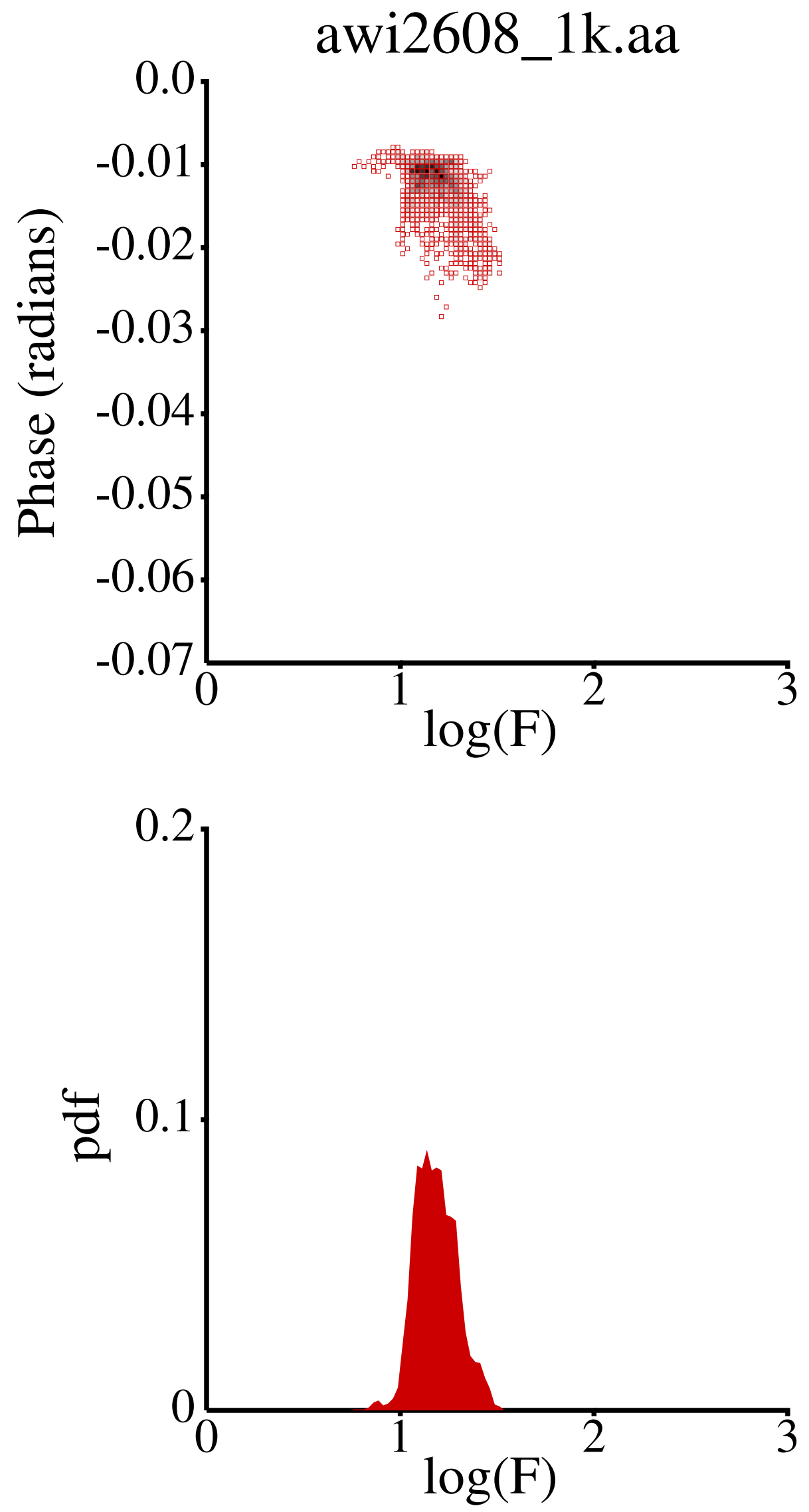

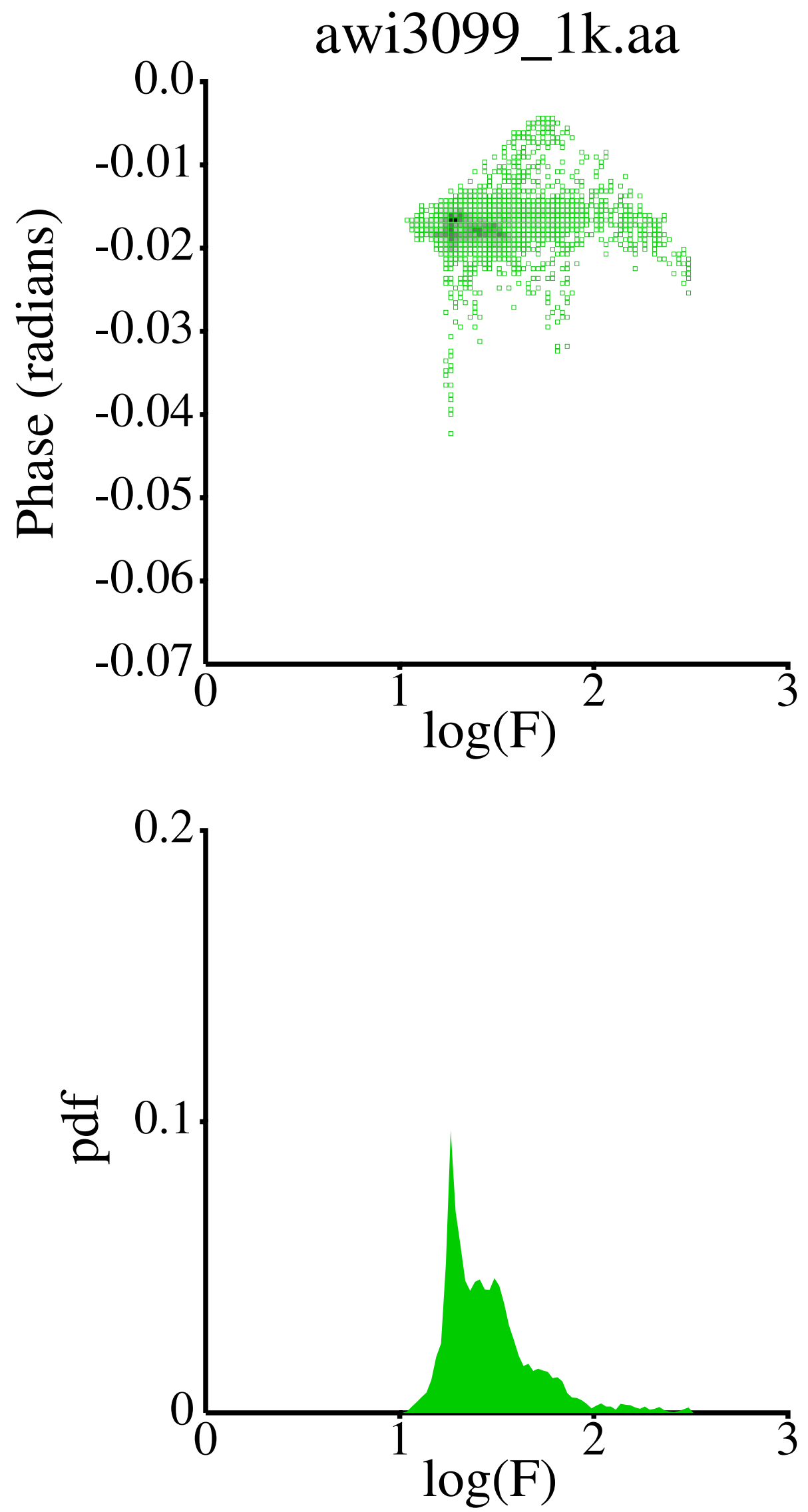

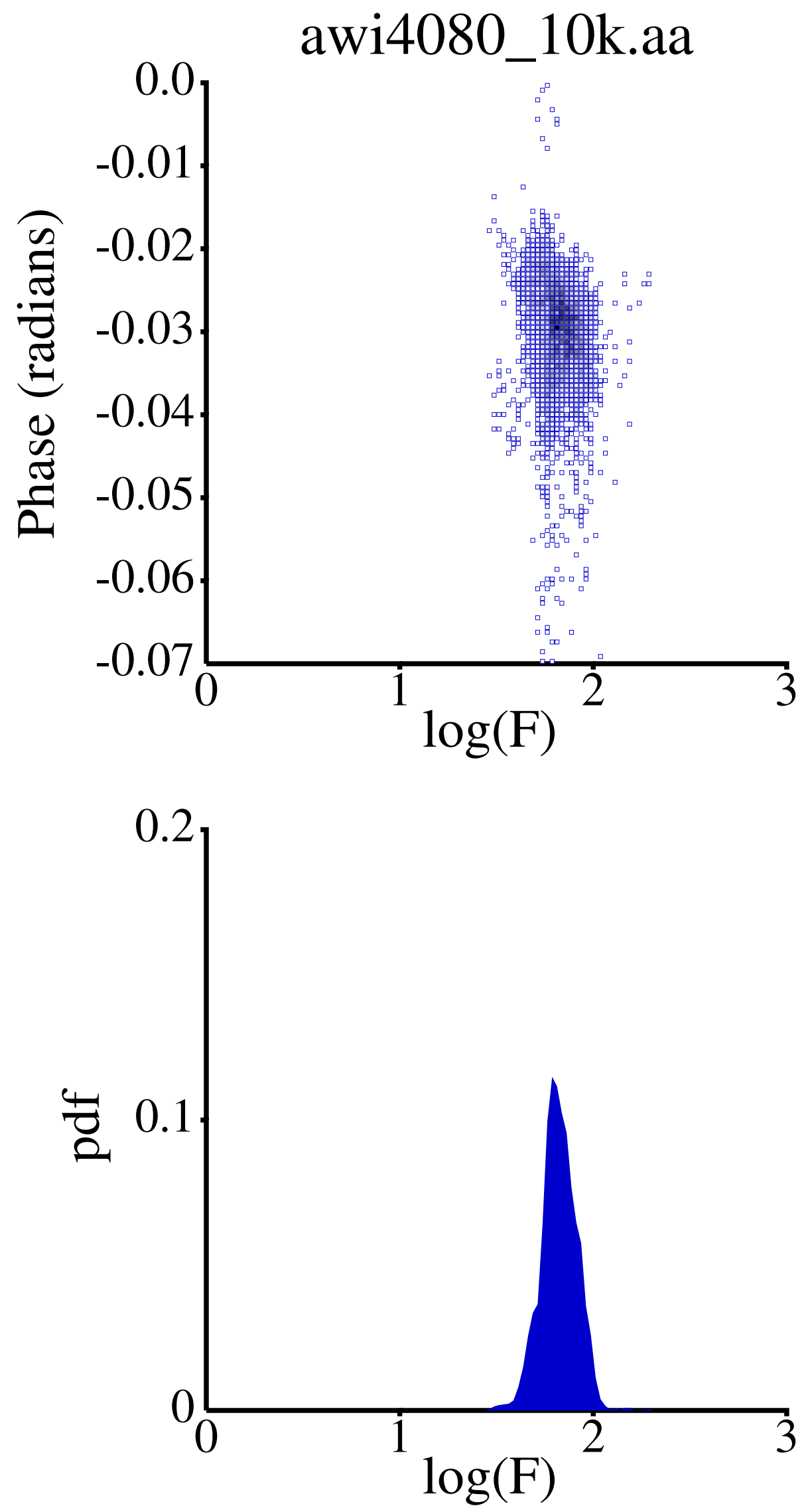

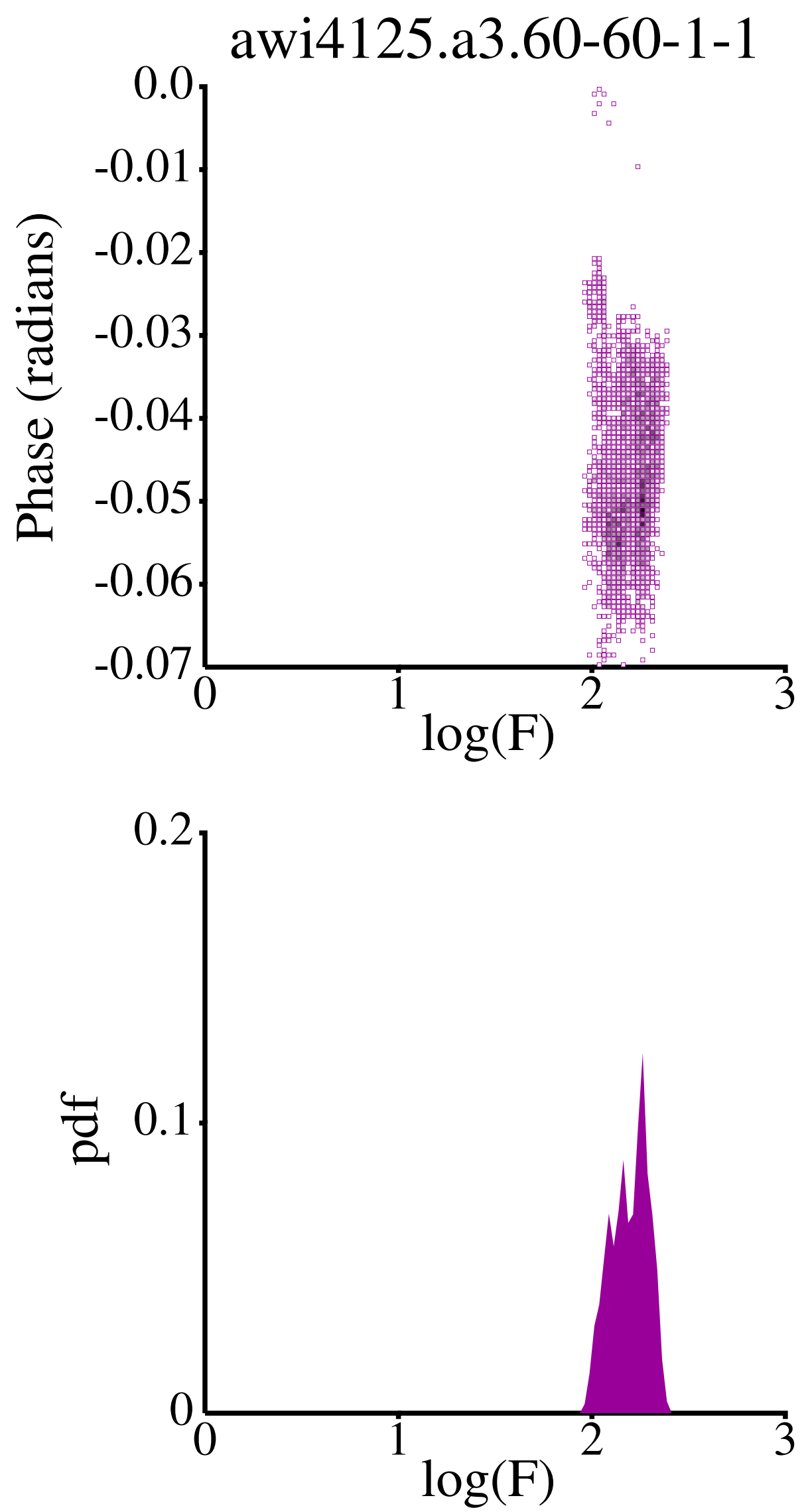

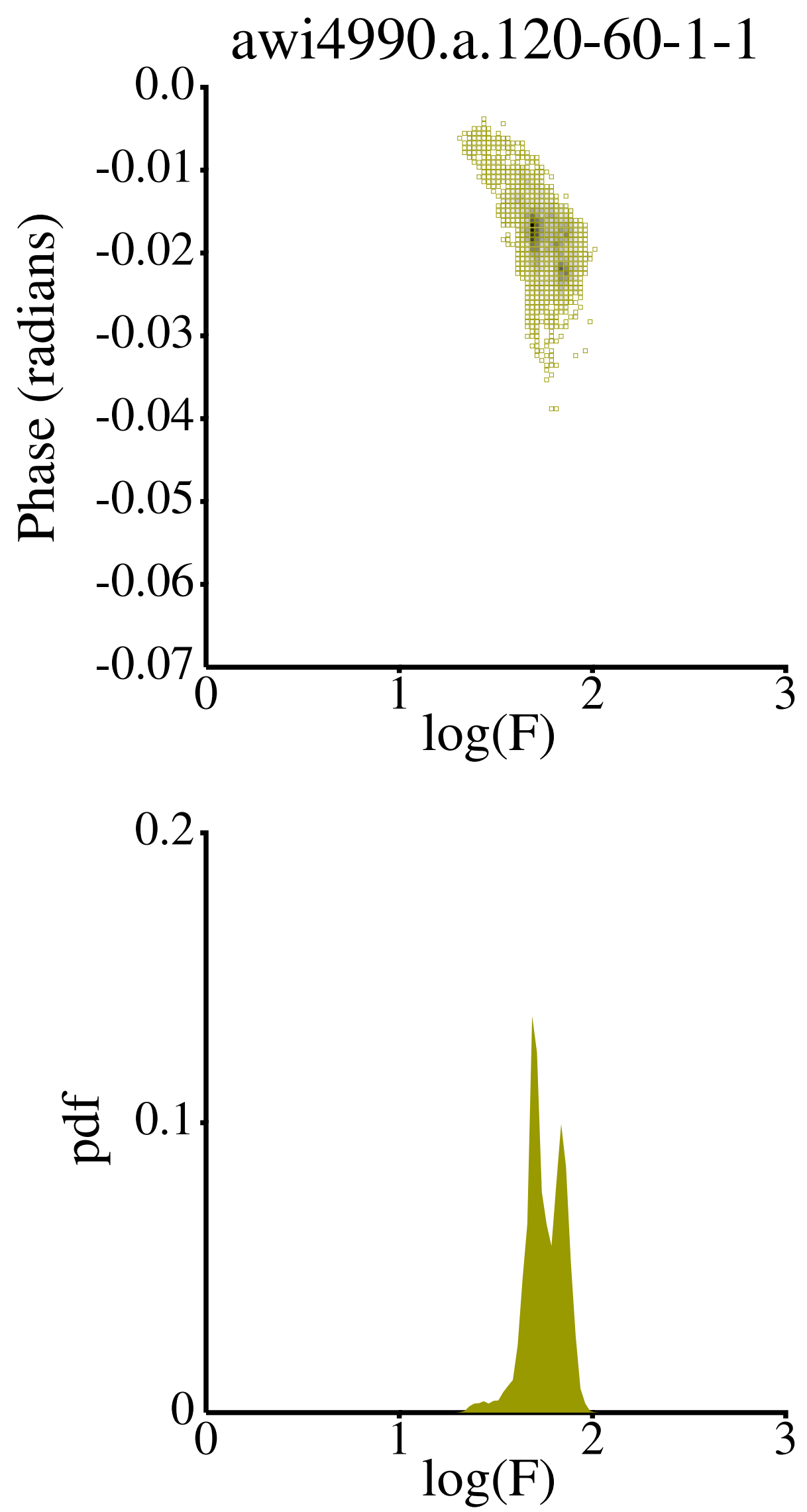

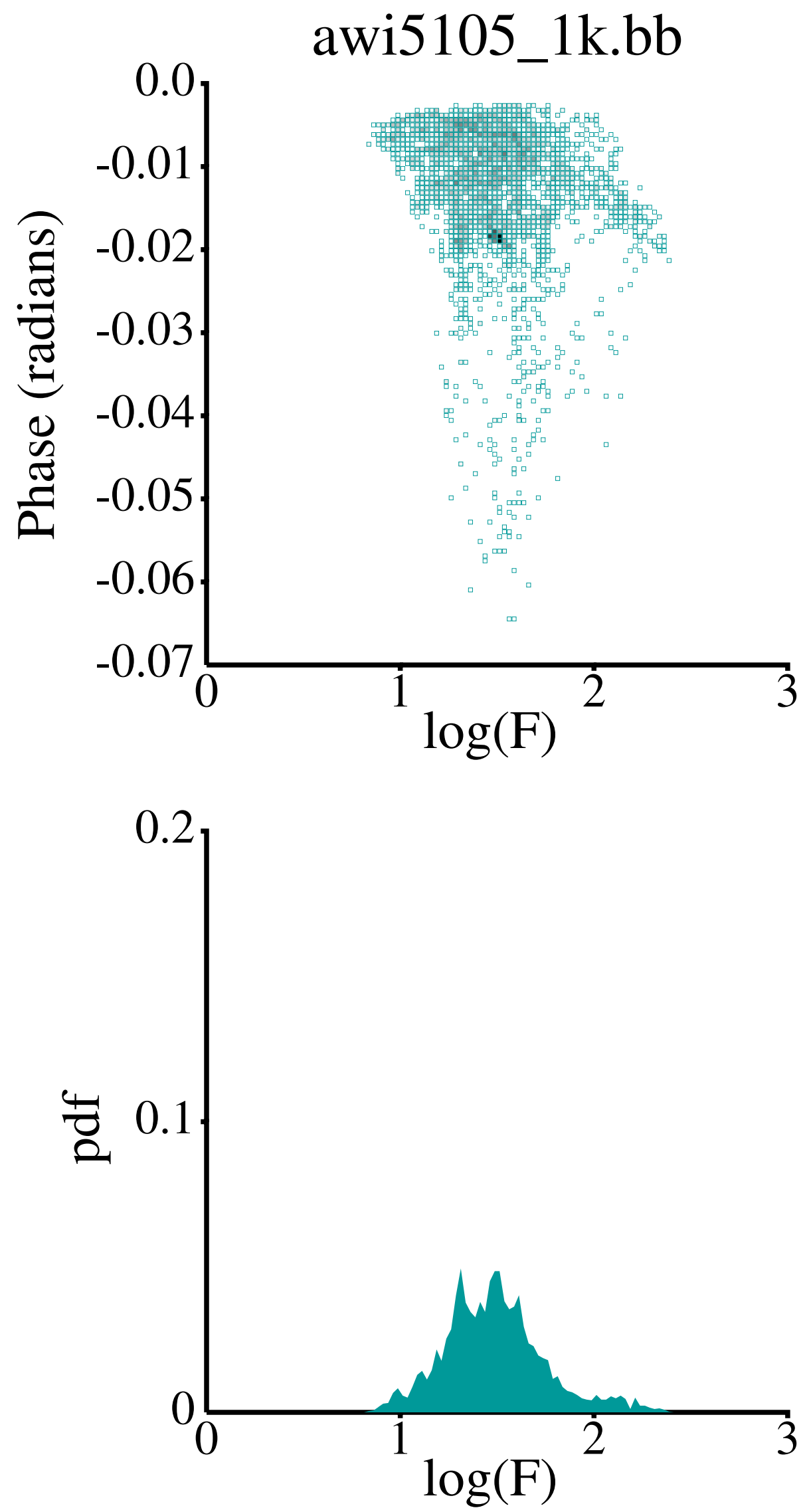

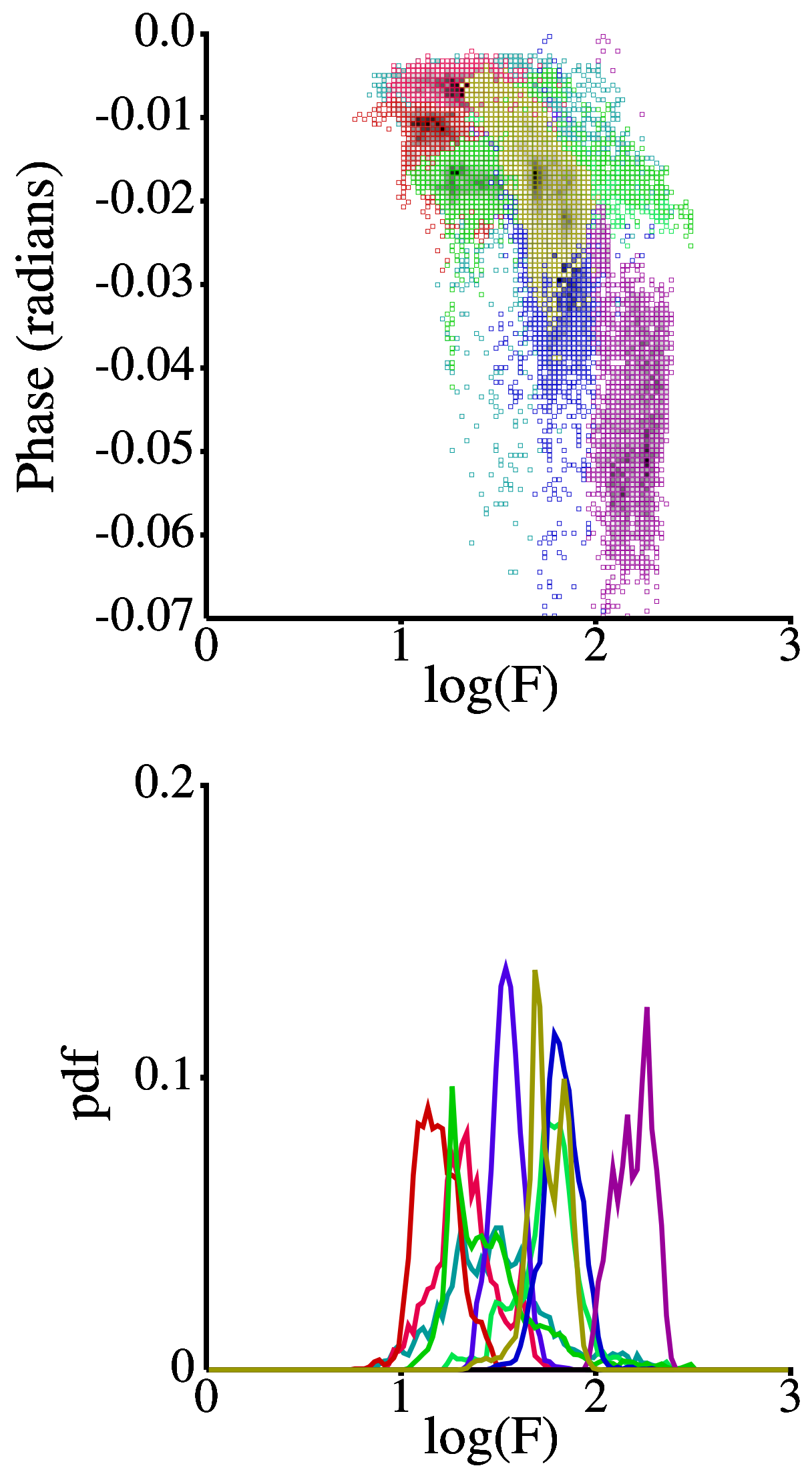


\section{Executive Summary}

\section{Contents}

1.1. Purpose

1.2. Background and Technical Approach

1.3. Summary of Findings and Accomplishments

1.4. Project Benefits

1.5. Key Findings

1.6. Accomplishments

1.7. Technology Transfer Activities

1.8. Project History

1.8.1. Deviations from Project Plan

\section{Technical Report}

2.1. Abstract

2.2. Velocities and Moduli of Awibengkok Cores

2.2.1. Laboratory Testing and Observations

2.2.2. Implications to Seismic Exploration and Monitoring

2.2.3. Development of an Empirical model for velocities

2.2.4. Physical Significance of the Empirical Model

\subsection{Electrical Properties}

2.3.1. Overview

2.3.2. Electrical Impedance of Awibengkok Cores

2.3.2.1. Depth and Lithology

2.3.2.2. Pressure and Temperature

2.3.2.3. Frequency Dependence

2.3.2.4. The Effect of Brine Chemistry on Electrical Properties

2.3.3. Empirical Models of Electrical Properties

2.3.3.1. Mineralogic Controls

2.3.3.2. Electrical Properties of the Geysers Matrix

2.3.3.3. Summary of Findings

2.4. Joint Interpretation of Electrical Properties

2.5. Core Scale Heterogeneity

2.6. Some Thoughts Concerning Field Scaling

2.7. References

2.8. Appendix A: Resistivity Maps 


\section{Executive Summary}

\subsection{Purpose:}

Effective reservoir exploration, characterization, and engineering require a fundamental understanding of the geophysical properties of reservoir rocks and fracture systems. Even in the best of circumstances, spatial variability in porosity, fracture density, salinity, saturation, tectonic stress, fluid pressures, and lithology can all potentially produce and/or contribute to geophysical anomalies. As a result, serious uniqueness problems frequently occur when interpreting anomalies. Under such circumstances, interpretation of geophysics must be guided by realistic assumptions based on a knowledge base founded in validated rock physics models of reservoir material.

Unfortunately, fundamental rock properties data on rocks recovered from geothermal reservoirs is lacking. While the extensive and advanced knowledge base of the oil and gas industry is typically applied in geothermal exploration and production workflows, many problems arise due to fundamental differences between geothermal and hydrocarbon reservoirs. This problem is compounded by the fact that in comparison to heavily studied oil and gas reservoirs, geothermal reservoirs are commonly complex, fractured systems with architectures unlike those encountered by the petroleum industry. To overcome these problems, an accurate physical understanding of rocks from geothermal reservoirs must be established as a prerequisite to geophysical interpretation.

To help meet these needs, measurements and analysis of core scale properties from two geothermal reservoirs was performed to identify the role of mineralogy, pore structure, rock type, degree and type of alteration, and core scale heterogeneity on key physical properties (electrical, mechanical, and seismic). Through the use of laboratory measurements in conjunction with model development, physically based models of key geophysical properties are constrained and important ties to mineralogy and texture unique to geothermally altered rocks are established. Areas of technical focus include: a systematic study of shear weakening phenomena (rock/water interaction); quantification of core scale heterogeneity of electrical properties; and development of models for field scaling of seismic, electrical, and flow properties.

\subsection{Background and Technical Approach}

Prior to this study, core studies have identified important phenomena which may be uniquely characteristic of rocks recovered from geothermal reservoirs. One observation is the general lack of pressure dependence of the matrix material. This characteristic allows for important simplifying assumptions to be made when interpreting field seismic and electrical data. In addition, the observation of dramatic shear modulus reduction due to rock water chemical reactions in geothermal rocks [see Boitnott, 1995; Boitnott and Boyd, 1996] requires a re-evaluation of traditional assumptions used in interpreting seismic anomalies. This work was initiated as an extension of these efforts in order to extend the laboratory data set and evaluate, quantify, and further study these phenomena.

This study was structured around a four point plan developed to address the identified technical issues: (1) data was collected to further develop a database of the basic measurements of mechanical, electrical and flow properties of the matrix to establish a representative data-set of physical properties and relate those properties to rock type and degree of alteration; (2) specialized measurements were performed to study in detail the variables, such as temperature, brine chemistry, and saturation, which control and/or influence the important geophysical 
properties; (3) equipment and techniques were developed to characterize core scale heterogeneity to improve understanding of how the measured matrix and borehole scale properties are related to core scale fabrics and variations; and (4) empirical models were formulated to allow application of the results through integrating physical models of the matrix with models of fractured rock.

In this study, velocities and electrical properties where measured on core plugs from the Awibengkok Geothermal field in Indonesia and The Geysers Geothermal field in California, providing results from a suite of cores which are mineralogically similar but texturally quite variable. The data set is used to identify processes which control the fundamental geophysical properties of the matrix. General empirical models are used to quantify those factors in order to provide practical descriptions of seismic and electrical properties of geothermal reservoir matrix. The resulting models provide a means by which one can study and understand the relative importance of different variables (e.g. porosity, mineralogy, and texture) on the core scale physical properties.

\subsection{Summary of Findings and Accomplishments}

Measured formation factors, ultrasonic velocities, and dynamic bulk and shear moduli all exhibit normal trends with porosity. However scatter in these relationships is relatively large. The laboratory measurements, evaluated in the context of routine porosity determinations as well as petrographic and modal-mineralogic analysis, have enabled the identification of compositional and textural factors affecting the seismic and electrical characteristics of these rocks. Systematic evaluation indicates that, with the exception of the bulk modulus, illite plays an important role in influencing all of the measured properties.

These results confirm that despite the relatively high porosities of the Awibengkok samples, the effect of pressure on the velocities is weak and the depth dependence is small compared to the variations from core to core. This observation may greatly simplify interpretation of field scale velocity profiles by effectively removing (or minimizing) a variable from consideration when interpreting depth and/or production dependent trends in geophysical properties. This in turn provides an opportunity to probe and monitor spatial and temporal variations in the processes influencing the fracture system, since the geophysical expression of the fracture system is expected to be strongly pressure dependent.

The results also provide important information concerning the interpretation of seismic anomalies. As found previously on core samples from the Geysers, laboratory velocity measurements on core from the Awibengkok reservoir demonstrate that brine saturation causes an increase in the $\mathrm{Vp} / \mathrm{Vs}$ and decrease in Vs (enhanced by shear weakening due to rock-water interactions), with little resulting effect on $\mathrm{Vp}$. The net result is that a high $\mathrm{Vp} / \mathrm{Vs}$ anomaly associated with a low Vs anomaly is indicative of a saturation anomaly while a high Vp/Vs anomaly associated with a high $\mathrm{Vp}$ is indicative of another phenomenon (such as lithology or fracture density variations). This is contrary to traditional interpretations of seismic anomalies, which typically assume $\mathrm{Vp} / \mathrm{Vs}$ and high $\mathrm{Vp}$ are indicators of saturation.

Electrical impedance measurements, performed as a function of pressure, temperature, and brine chemistry, are used to quantify the amount of surface conduction, identify the causes of frequency dependence, and establish empirical relationships describing the porosity and mineralogic controls on electrical properties. The results indicate that porosity, illite, chlorite, and electrically conductive minerals all contribute significantly to electrical properties, and thus can lead to significant uncertainties in interpreting resistivity anomalies. 
A unique aspect of the measurement program is the characterization of spatial heterogeneity of electrical properties. A micro-resistivity mapping apparatus has been developed and the resulting images are rich in information, illustrating a wide variety of "anomalies" ranging from conductive or resistive clasts to fractures and porous veins. Importantly, the results illustrate that the samples have intrinsic variability on the order of a factor of three or more with significant correlations at length scales of a few centimeters This suggests that core scale heterogeneity (and its structural details) may give rise to significant resistivity signatures, and may explain much of the scatter in the laboratory scale data. Work was initiated to correlate the observed anomalies with detailed petrographic observations. For example, areas of high conductivity and low phase shift are found to indicate regions dominated by ionic conduction through pores, while regions of high phase shift are found to be associated with concentrations of electrically conductive minerals such as pyrite and hematite. With further study, a better understanding of the electrical heterogeneity should lead to improved interpretations of FMI, induction log, and ERT data.

\subsection{Project Benefits}

This work supports basic reservoir characterization, including applications in exploration (electrical and seismic), engineering (simulation and EGS design), and log analysis. Geophysical exploration, characterization, and monitoring of geothermal reservoirs requires considerable effort and expense. The DOE geothermal program spends a considerable amount of its research funding in direct support of geophysically based interpretations of geothermal reservoirs, including seismic data analysis, electrical resistivity tomography, and development of advanced borehole logging tools. The geothermal industry relies on DOE funded research and technology development to make operational decisions, design new reservoir engineering practices, and to determine the economic viability of geothermal resources.

The value of efforts to advance our understanding of the basic physical properties of geothermal reservoir rocks should not be underestimated. The effectiveness of both geophysical application and research is contingent on proper assumptions with regard to variables that control reservoir properties. Historically, very little emphasis has been placed on core studies, in part limited by the lack of publicly available core material, but also influenced by the erroneous assumption that the current state of the art in rock physics is suitable to guide assumptions with regard to geophysical interpretation in geothermal environments. This has lead to significant errors in the past, such as the erroneous assumption that simple poroelasticity can be used to interpret compressional wave anomalies for characterization of saturation. The results of this project serve to illustrate that studies of basic rock properties can lead to fundamental changes in geophysical interpretations.

\subsection{Key Findings}

With the exception of the bulk modulus, illite plays an important role in influencing all of the measured properties, both with regards to intrinsic variation, and with respect to processes related to saturation (rock/water interaction).

$>$ A single linear dependence on illite content is sufficient to describe the rock/water interaction on the dynamic shear modulus of the matrix at both Awibengkok and the Geysers. Understanding and quantification of this phenomenon is critical to proper interpretation of field data.

$>$ The role of porosity in affecting the saturation dependence on the dynamic bulk modulus is 
well described by low frequency Biot-Gassmann theory.

$>$ Scatter in the bulk modulus with respect to the first order porosity trend appears to be influenced by two yet to be identified mineralogical/textural variables.

$>$ The same variables controlling scatter in dynamic bulk modulus also control intrinsic variation in $\mathrm{Vp} / \mathrm{Vs}$ ratio, a key saturation indicator used for exploration and reservoir monitoring. Key samples which should provide end-member values of these variables have been identified.

$>$ Pressure and temperature dependence of electrical resistivity is in general relatively small, indicating that straightforward temperature corrections based on brine conductivity can be used to correct field data. Frequency dependence of resistivity is variable and can lead to relatively strong dispersions at logging frequencies. The observed dispersion, which can lead to a $20 \%$ reduction in resistivity between $1 \mathrm{~Hz}$ and $10 \mathrm{kHz}$, is relatively insensitive to changes in temperature and pressure.

$>$ Porosity and illite concentration are found to be the most important petrographic variables that control electrical properties.

$>$ A simple physical model that results is that of a porous matrix with brine conductivity defined by an Archie relationship $\mathrm{F}^{*}=\phi^{\mathrm{m}^{*}}$ with $\mathrm{m}^{*}$ weakly dependent on porosity in parallel with a secondary conductance which is proportional to the abundance of illite in the sample. While surface conduction enhanced by the presence of illite appears to be an important conduction mechanism, there also appears to be a textural component to the illite dependence that plays a significant role in influencing the formation factor as well.

$>$ Unlike with velocities, for electrical properties the Awibengkok and Geysers data sets cannot be combined in a single empirical model. Fitting the data sets separately, the Awibengkok data set indicates an Archie exponent of -2.1 , while the Geysers data set favors an Archie exponent of -1.75. Illite appears to appears associated with decreased electrical resistivity in both cases, but the functional form or this relationship (and its underlying physical model) is poorly understood.

$>$ Detailed resistivity mapping of slabbed core indicates that core scale heterogeneity (and its structural details) may give rise to significant resistivity signatures, and may explain much of the remaining scatter in the laboratory scale data.

$>$ Resistivity maps of lahar samples with conspicuous heterogeneity in the form of clasts of various rock types, illustrate that the clasts are not resolved well by resistivity alone. This indicates that resistivity variation is a poor indicator of lithology, an observation corroborated by the plug data.

$>$ Complex impedance (i.e. combined interpretation of both the real and imaginary components of the electrical impedance) appears to do a reasonable job in identification of discrete clasts and/or beds in some cases. As resitivity logging tools become more advanced, complex impedance may prove a useful reservoir characterization tool.

\subsection{Accomplishments}

* Quantification of mineralogy and porosity controls on electrical and acoustic properties of matrix material from geothermal reservoirs.

* Establishment of a model and supporting data set for electrical and seismic properties of geothermal reservoir matrix which incorporates saturation, temperature, pressure, brine concentration, porosity, and illite content.

* Demonstration that rock water interactions related to illite content are important in controlling matrix shear velocity, a key physical phenomenon that needs to be considered 
when interpreting seismic and borehole acoustic data.

* Identification of important clues concerning underlying petrographic controls on intrinsic variation in $\mathrm{Vp}$ and $\mathrm{Vp} / \mathrm{Vs}$ ratios, both critical unknowns in interpretation of seismic and acoustic data.

* Development of an electrical resistivity probe which augments laboratory equipment that enables routine detailed logs of acoustic, flow, and electrical properties of whole or slabbed core at the mm to meter scales.

* Collection and analysis of a catalog of detailed complex resistivity maps of slabbed core samples from the Awibengkok Geothermal Reservoir, a unique data set for studying heterogeneity and petrographic controls on electrical properties.

\subsection{Technology Transfer Activities}

During the course of this project, results were presented and published as part of technical meetings. Results were also reported via NER's web site, with a page devoted to technical results and publication of all reports and proceedings papers.

In addition to publication of technical results and findings, laboratory equipment and data analysis techniques were developed, most notably the 4 electrode resistivity probe used for making electrical impedance maps of slabbed samples. The work contributed to the commercialization of this probe, which is now part of NER's AutoScan II product line. Data analysis techniques developed for interpretation of the electrical impedance maps have also formed the basis for DataMiner, a new software product for analysis of core scale scale heterogeneity.

In addition to DOE reports and publications, the following presentations and publications were made:

Boitnott, G. N.. and J. Johnson, (1999) Laboratory measurements of ultrasonic velocities on core samples from the Awibengkok geothermal field, Indonesia, GRC Transactions, vol. 23, p. 9-12.

Boitnott, G. N., (2000) Core Analysis for the Development and Constraint of Physical Models of Geothermal Reservoirs, Poster Ptresentation, GRC Annual Meeting, unpublished.

Boitnott, G. N., and J. B. Hulen, (2001), Petrographic controls on electrical properties of core samples from the Awibengkok geothermal field, GRC Transactions, vol 25, p-391394.

Boitnott, G. N., (2002) Core Analysis for the Development and Constraint of Physical Models of Geothermal Reservoirs, GRC Transactions, vol 26, p. 387-392*

Boitnott, G. N., (2002) Resistivity Mapping of Core: Core Scale Heterogeneity at the Awibengkok Geothermal Field, Poster presentation, GRC Annual Meeting, unpublished.

\footnotetext{
* An award for best paper in the Geophysical Measurements session was received for the oral presentation and paper.
} 


\subsection{Project History}

\subsubsection{Deviations from Project Plan}

Due to funding limitations, this project was scaled back significantly midway into the project. Unfortunately, as a result, many lines of investigation have been left incomplete and significant portions of the data set never adequately analysed. Despite these difficulties, the project has produced a number of key findings and has lead to the development of novel laboratory equipment and data analysis procedures. These results will no doubt find future applications, both in support of geothermal reservoir characterization and engineering, and in other fields, such as environmental and oil and gas applications.

Initial plans were to extend the data set where needed (partial saturation and temperature), and to begin adding data from other geothermal reservoirs. More work was planned in the areas of integrating petrography, physical properties maps, and core data to further investigate textural controls on seismic and electrical properties. Emphasis on physical models was also planned, guided by the results of empirical models which identify the variables which control key properties. A key aspect of this physical modeling was to be the integration of fractured rock models with matrix models to make the work applicable to field scale geophysical measurements. Also planned was development of methods of mechanical properties mapping of core scale heterogeneity. These activities all address fundamental physical modeling issues that should be an integral part of the DOE geothermal program. 


\section{Technical Report}

\subsection{Abstract}

Laboratory measurements of velocities and electrical properties on core plugs from the Awibengkok Geothermal field in Indonesia and The Geysers Geothermal field in California are analysed in order to establish models of matrix material from geothermal reservoirs. The hightemperature $\left(240-315^{\circ} \mathrm{C}\right)$, Awibengkok geothermal system is hosted by porous, felsic to intermediate-composition, late Cenozoic volcanic rocks intensely altered to a variety of hydrothermal assemblages. In contrast, The Geysers system is composed of low porosity metagreywackes and metashales, which are mineralogically similar to the Awibengkok reservoir rocks, but texturally quite different. Thus, the data set provides a diverse suite of samples with which to develop petrophysical models applicable to a wide variety of geothermal reservoirs.

The measured formation factors, ultrasonic velocities, and dynamic bulk and shear moduli all exhibit normal trends with increasing porosity, however scatter in these relationships is relatively large. The laboratory measurements, evaluated in the context of routine porosity determinations as well as petrographic and modal-mineralogic analysis, have enabled the identification of compositional and textural factors affecting the seismic and electrical characteristics of these rocks. These factors are found to produce much of the observed scatter in the porosity relationships. In this study, we quantify these factors in order to produce generalized models of seismic and electrical properties of geothermal reservoir matrix. The resulting models provide a means with which one can study and understand the relative importance of different variables (namely porosity, mineralogy, and texture) on the core scale physical properties. Systematic evaluation indicates that, with the exception of the bulk modulus, illite plays a significant role in influencing all of the measured properties.

\subsection{Velocities and Moduli of Awibengkok Cores}

\subsubsection{Laboratory Testing and Observations}

The Awibengkok reservoir consists of a sequence of hydrothermally altered lahars, tuffs and flow units. Over $1 \mathrm{~km}$ of continuous core was recovered from AWI 1-2, providing a unique resource for studying the reservoir rock. The sampling strategy for this study was motivated by the desire to develop a baseline dataset encompassing the major rock types and spanning the entire depth range of the AWI 1-2 corehole.

Ultrasonic compressional and shear velocities were measured as a function of effective confining pressure, in both dry and brine saturated conditions. In general, the velocities are found to be relatively insensitive to pressure and exhibit little correlation with depth or lithology and only a weak dependence on porosity (see Figures 1-3). Despite this lack of correlation with other properties, the compressional and shear velocities are strongly correlated with one another. Also notable is the positive correlation between $\mathrm{Vp}$ and $\mathrm{Vp} / \mathrm{Vs}$.

While the overall velocity/porosity trend in weak, it is interesting to note that the different lithologies studied show deferent trends in their velocity/porosity relationships. For example, tuffs span a wide range of velocities but are confined to a relatively narrow range of porosities, lahars span a wide range of porosities but are confined to a narrow range in velocities, and andesites exhibit a well defined dependence of velocities on porosity. These results indicate 
that the velocities, while sensitive to porosity and rock-type, are influenced by other variables such as textural and mineralogic variations between the samples.

Data illustrating the effect of pressure and saturation on the velocities for three different samples are shown in Figure 3. The three samples encompass a range of alteration textures and rock types. Note that phenomenologically, the data from each sample are similar. In all cases, the effect of pressure on the velocities is notably weak. Saturation with brine has little effect on the compressional velocities and produces a modest reduction in the shear velocities. The reduction in shear velocities appears relatively insensitive to pressure, persisting to high effective pressures. The results in Figure 3 are representative of the Awibengkok samples in general. They are also quite similar in character to results from previous studies on core from The Geysers geothermal field in California (e.g. Boitnott and Bonner, 1994, Boitnott and Boyd, 1996) as well as unpublished results on hydrothermally altered basalts from Iceland. The similarity between the results from these widely varying samples is quite remarkable, suggesting that the behavior is associated with textures and mineralogies produced by hydrothermal alteration.

Physical insight into the processes leading to this behavior is gained by viewing the results in terms of dynamic elastic constants (assuming isotropy and homogeneity). Results for two samples are shown in Figure 4. Note that the effect of saturation is to increase the dynamic bulk modulus and reduce the dynamic shear modulus. The increase in the dynamic bulk modulus is understood to result from poroelastic stiffening of the matrix due to the introduction of a relatively incompressible fluid, and is generally consistent with low frequency Biot-Gassmann theory. The decrease in shear modulus is understood to result from rock-water interaction, as will be discussed shortly 

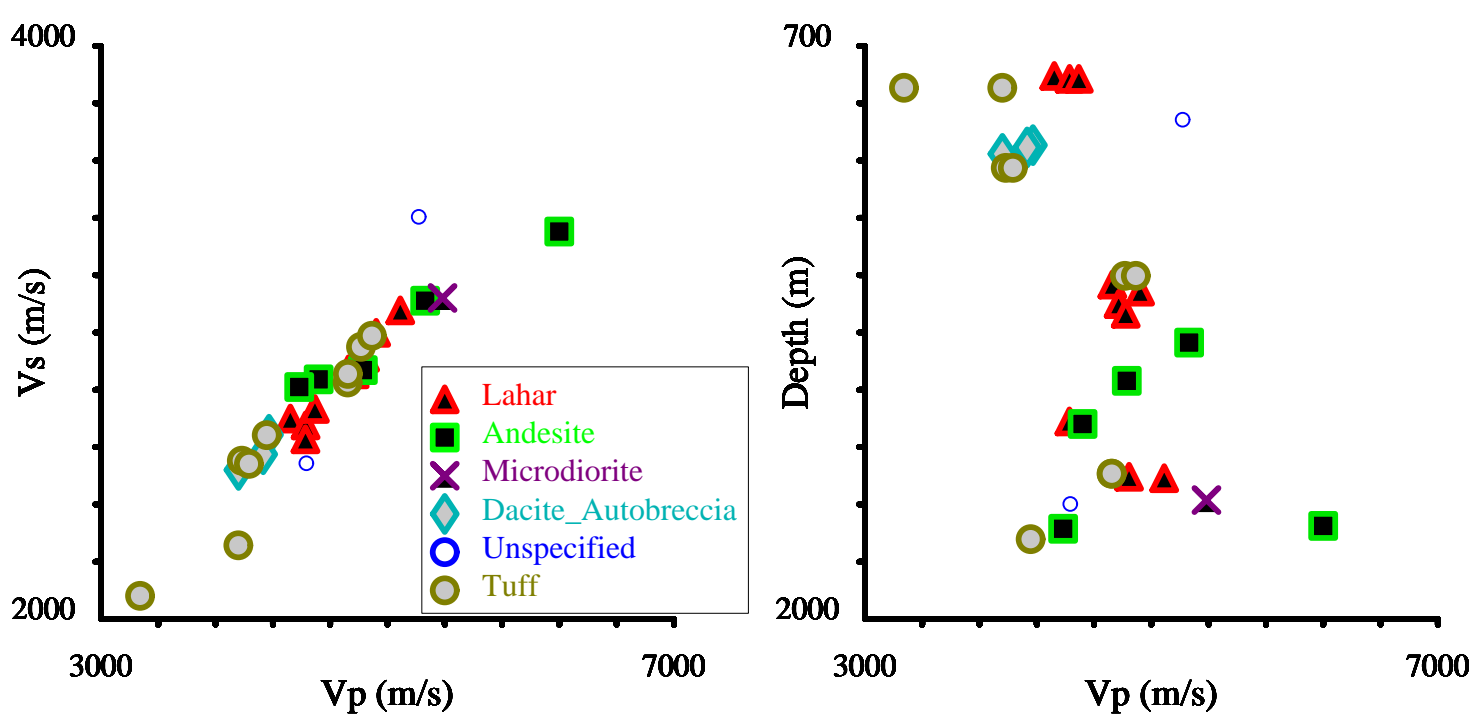

Figure 1: Summary of dry velocities for all samples tested. Note that Vp correlates well with Vs . There is no clear separation between lithologies and no apparent signature with depth.
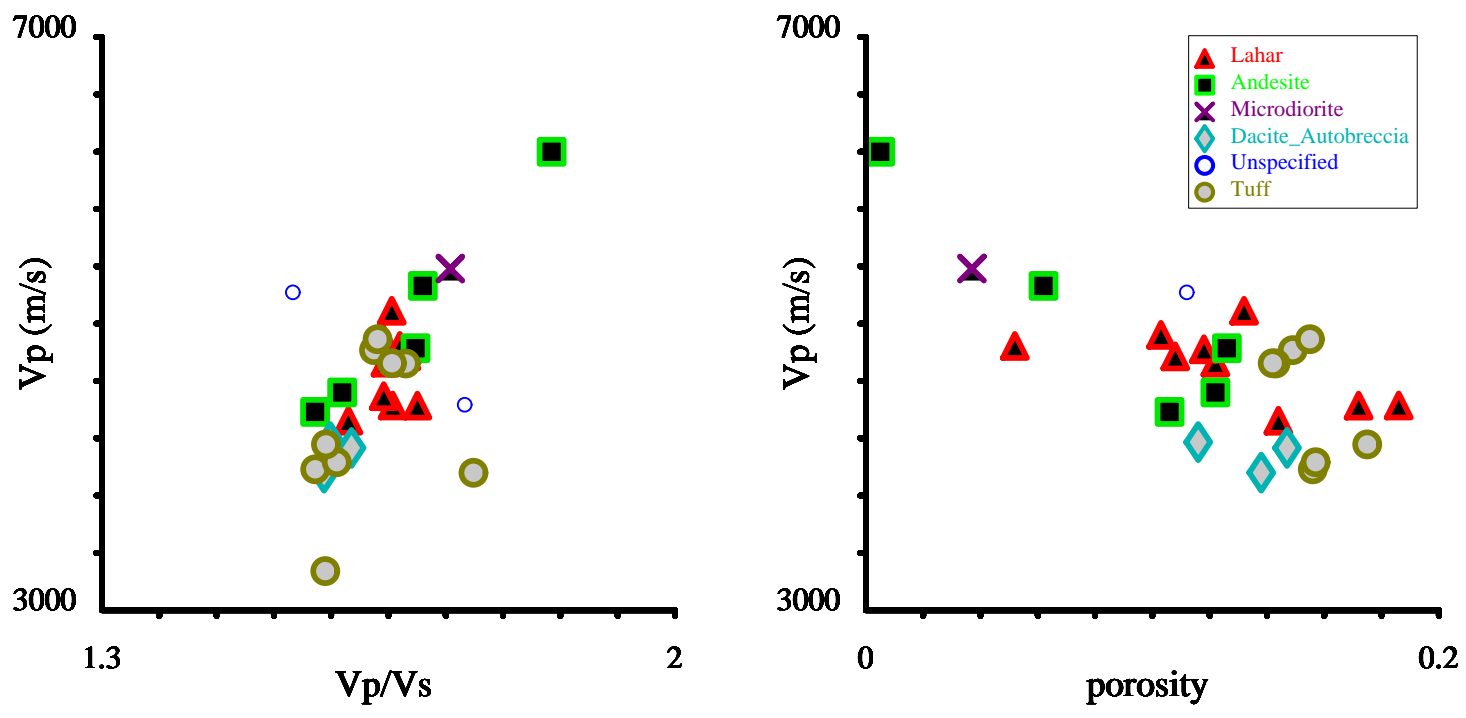

Figure 2: Summary of dry velocities for all samples tested. Note that Vp exhibits a positive correlation with $\mathrm{Vp} / \mathrm{Vs}$ and a negative correlation with porosity. 

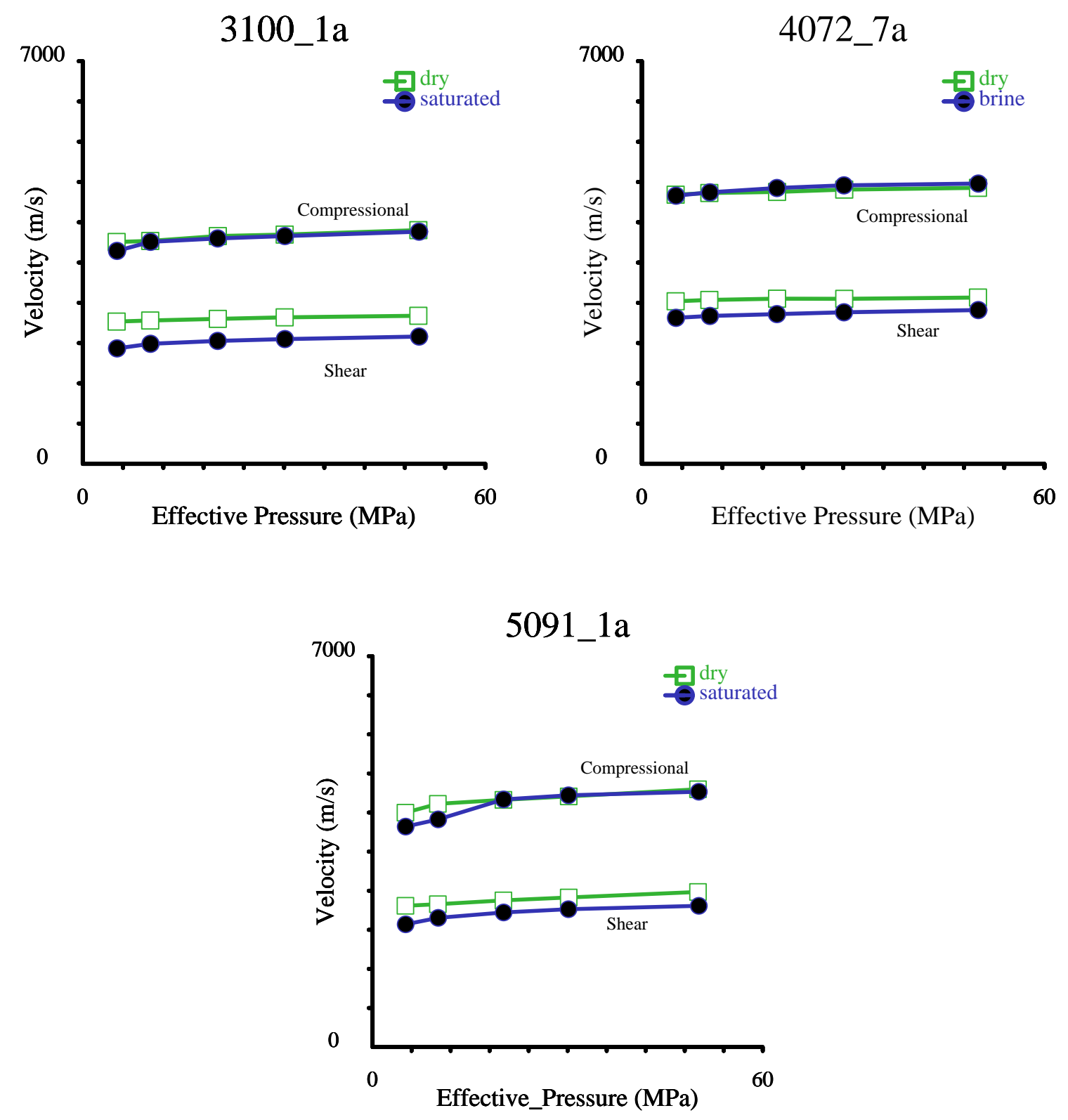

Figure 3: Ultrasonic velocity data plotted as a function of effective confining pressure for dry and brine saturated samples from AWI 1-2. 


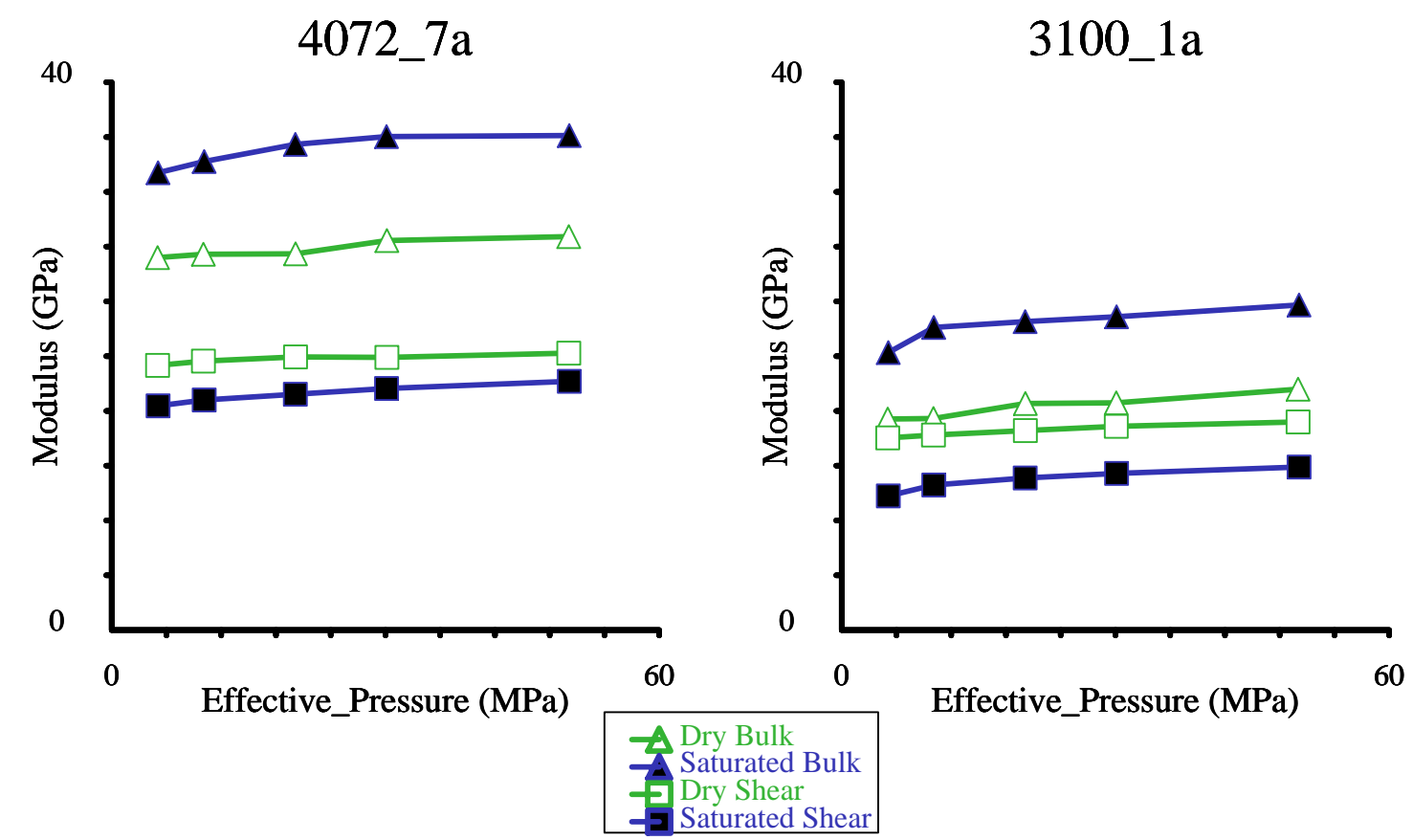

Figure 4: The effect of pressure and brine saturation on the inferred dynamic bulk and shear moduli. Saturation causes an in crease in the dynamic bulk modulus and a decrease in the dynamic shear modulus.

Following previous work on core from The Geysers, the effect of saturation on the velocities of these and related cores is modeled using a modified low frequency Biot-Gassmann poroelastic theory. The required modification from traditional theory is the addition of a shear modulus weakening term which is found to be independent of stress. The model can be described by the following equations, which describe the effect of saturation on the elastic moduli of the matrix material.

$$
\begin{aligned}
& \text { (1a) } \mathrm{K}_{\text {sat }}=\mathrm{K}_{\text {dry }}+\Delta \mathrm{K} \quad ; \quad \text { (1b) } \mathrm{G}_{\text {sat }}=\mathrm{G}_{d r y}+\Delta \mathrm{G} \\
& \text { (1c) } \Delta \mathrm{K}=\frac{\left(\mathrm{K}_{\text {soild }}-\mathrm{K}_{d r y}\right)^{2}}{\left[\mathrm{~K}_{\text {solid }}\left(1-\phi-\left(\mathrm{K}_{\text {dry }} / \mathrm{K}_{\text {solid }}\right)+\phi\left(\mathrm{K}_{\text {solid }} / \mathrm{K}_{f}\right)\right)\right]}
\end{aligned}
$$

$\Delta \mathrm{K}$ represents the increase in bulk modulus due to saturation as described by Biot's low frequency poroelastic theory, where $\phi$ is the porosity, $\mathrm{K}_{\text {soild }}$ is the bulk modulus of the solid grains, $\mathrm{K}_{d r y}$ is the bulk modulus of the dry frame (i.e. the rock in its dry state), and $\mathrm{K}_{f}$ is the bulk modulus of the saturating fluid. In this modified model, the shear modulus $G$ is assumed to weaken with saturation by an amount $\Delta \mathrm{G}$. Using this model, we are lead to a physical understanding of the effect of saturation resulting from three basic mechanisms: fluid density, fluid compressibility, and shear weakening (see Table 1). Other mechanisms such as inertial coupling and local flow which are commonly observed in similar data on crystalline rocks, sandstones, and carbonates, cannot be ruled out, but do not appear necessary to explain the results. This likely results in part from the fine grained nature of the pore space in hydrothermally altered rock. 


\begin{tabular}{|c|c|c|c|c|}
\hline \multicolumn{5}{|c|}{ Table 1: Effect of Saturation on Velocities } \\
\hline Mechanism & Description & $\mathrm{Vp}$ & Vs & $\mathrm{Vp} / \mathrm{Vs}$ \\
\hline Fluid Density & $\begin{array}{l}\text { Saturation causes a increase in bulk density, } \\
\text { resulting in a decrease in velocities. }\end{array}$ & decreases & decreases & No change \\
\hline Fluid Compressibility & $\begin{array}{l}\text { Adding an incompressible fluid stiffens the pores } \\
\text { to compression, increasing the bulk modulus of } \\
\text { the rock }\end{array}$ & increases & No change & increases \\
\hline Shear Weakening & $\begin{array}{l}\text { The presence of liquid water acts to weaken the } \\
\text { shear modulus of the rock. }\end{array}$ & decreases & decreases & increases \\
\hline Local Flow* & $\begin{array}{l}\text { Fluid pressures in compliant pores are unable to } \\
\text { reach equilibrium with the stress conditions, } \\
\text { resulting in a stiffening of the dynamic bulk and } \\
\text { shear moduli. }\end{array}$ & increases & increases & increases \\
\hline Inertial Coupling* & $\begin{array}{l}\text { Inertial coupling between motion of the solid and } \\
\text { fluid phases can lead to increased stiffening of } \\
\text { both the bulk and shear moduli as fluid density } \\
\text { and viscosity is increased }\end{array}$ & increases & increases & increases \\
\hline
\end{tabular}

A number of additional exploratory experiments were performed in an attempt to identify the mechanism causing shear weakening and to further refine our understanding of the poroelastic effects. These experiments include varying pore fluid properties and making measurements as a function of temperature. One such experiment which has been performed was to measure velocities on a kerosene saturated sample. Kerosene has similar physical properties to that of water, but is chemically not reactive with the mineral phases present. Data on a lahar sample, compared with dry and brine saturated data on the same sample is shown in Figure 5.

The experiment was performed to test the hypothesis that a chemical rock-water interaction was responsible for the shear weakening mechanism. The test results appear to confirm this idea, as no shear weakening is evident in the kerosene data. Exploratory experiments were also performed on two brine saturated samples as a function of temperature (Figure 6). These experiments were performed in order to determine the sensitivity of the shear weakening term to temperature. As expected, the amount of shear weakening was observed to increase modestly with temperature in both samples. Unexpectedly however, the inferred dynamic bulk modulus was also found to reduce with increasing temperature. This observation needs to be reproduced and studied further.

Recommendations: More experiments along the lines of these exploratory tests are needed to better understand the poroelastic behavior of the matrix material. Experiments like these should be used to address the role of fluid properties on the poroelastic mechanisms affecting the velocities, attempting to test for the presence or absence of other mechanisms such as local flow and inertial effects, and in so doing providing better constraint of $\mathrm{K}_{\text {solid }}$ and its relationship to mineralogy. Additional experiments and more detailed analyses are needed to identify the mechanisms leading to bulk and shear modulus reduction with temperature. Testing as a function of partial saturation, originally intended but cut from the program due to lack of funds, remains a critical missing data set on rocks from geothermal reservoirs. 

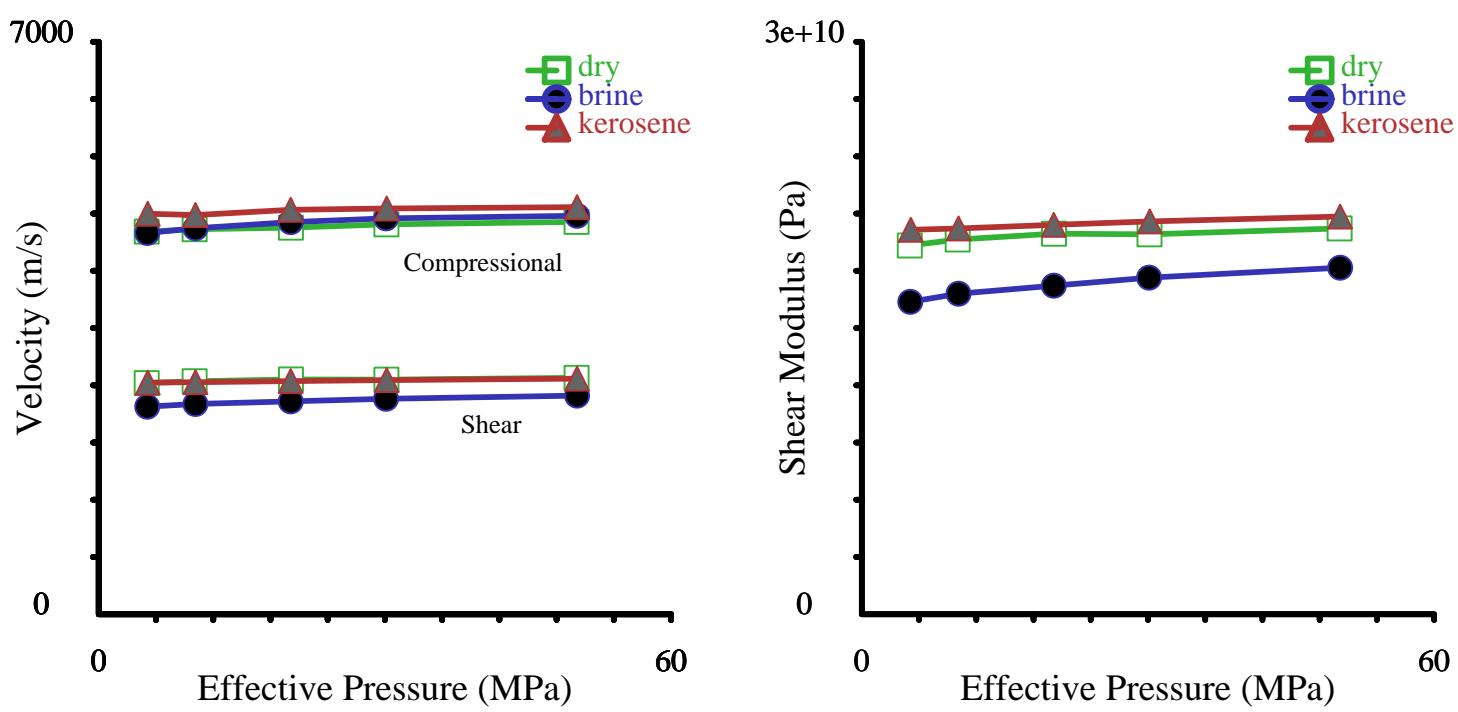

Figure 5: Velocity results on sample 4072_7 for dry, brine saturated, and kerosene saturated conditions. Note that the shear weakening does not occur with kerosene as the pore fluid, indicating that the shear weakening results from a chemical rock-water interaction.
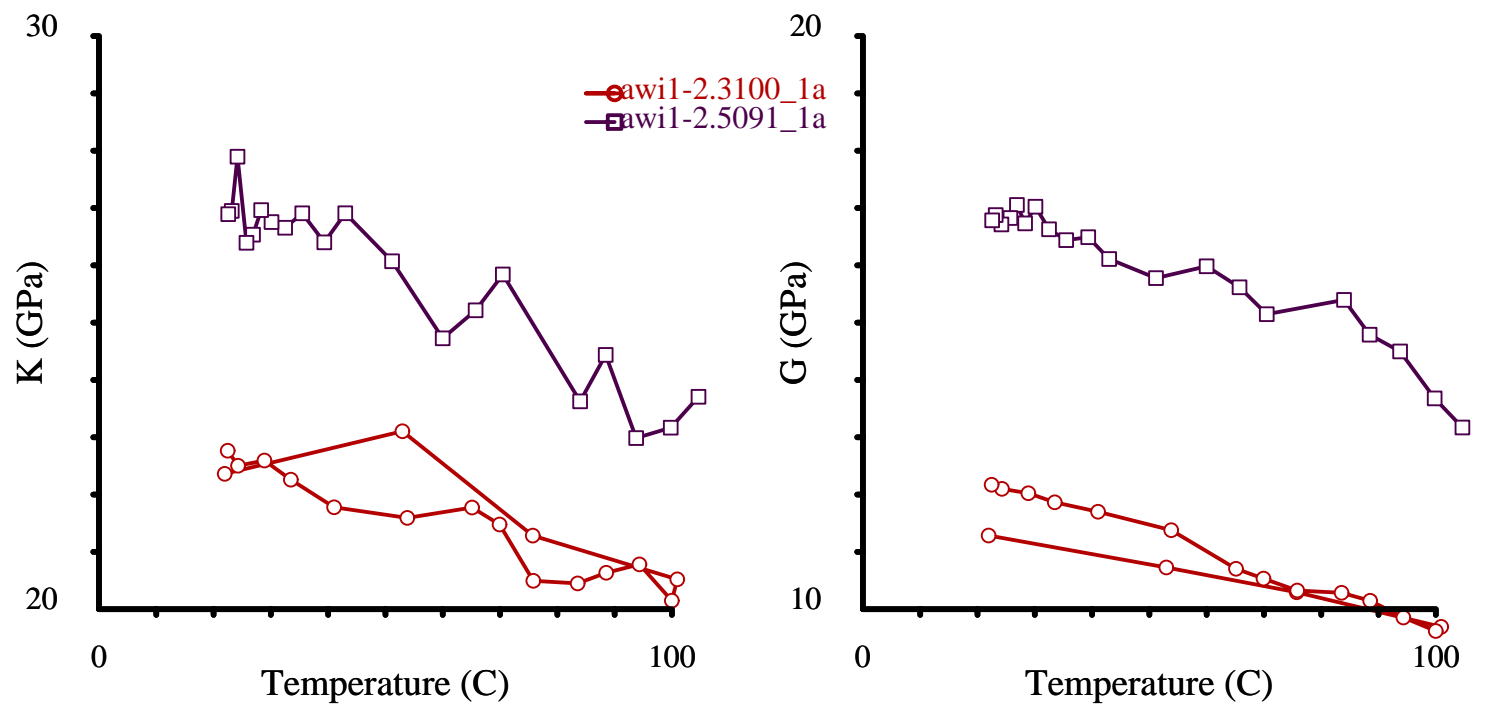

Figure 6: Effect of temperature on the dynamic elastic constants. Note that both the shear and bulk moduli appear to reduce with temperature. The reduction in the shear modulus was not unexpected since the shear weakening was thought to result from rock-water interactions which are likely to be thermally activated. The reduction in dynamic bulk modulus is not expected. 


\subsubsection{Implications to Seismic Exploration and Monitoring}

The implications of these results to geophysical exploration are significant. We have found that despite the relatively high porosities of these samples, the effect of pressure on the velocities is weak and the depth dependence is small compared to the variations from core to core. This fact simplifies interpretation of field scale velocity profiles, by making it easier to the remove the effect of the matrix properties on the field scale velocities, essentially removing stress dependence of the matrix as a variable to be concerned with when interpreting field scale anomalies. This in turn provides an opportunity to probe and monitor spatial and temporal variations in the processes influencing the fracture system, which is expected to be sensitive to stress. The results also provide some input concerning interpretation of seismic anomalies due to saturation. The net effect of brine saturation (at room temperature) is illustrated in Figure 7. Note that saturation causes a increase in the $\mathrm{Vp} / \mathrm{Vs}$ and decrease in Vs, with little effect on $\mathrm{Vp}$. This is a similar behavior to that found on core from The Geysers. The effect of saturation can be broken down into the different mechanisms, shown graphically in Figure 8. Note that the Vp/Vs signature of saturation results from two mechanisms, being equally influenced by the fluid compressibility and shear weakening mechanisms. The net result is that a high $\mathrm{Vp} / \mathrm{Vs}$ anomaly associated with a low Vs anomaly is a candidate for a saturation anomaly while a high Vp/Vs anomaly associated with a high $\mathrm{Vp}$ anomaly is indicative of another phenomenon (such as lithology or fracture density). This is contrary to traditional interpretations of seismic anomalies, which typically look to for high $\mathrm{Vp} / \mathrm{Vs}$ and high $\mathrm{Vp}$ as an indicator of saturation.

Evidence that this same phenomenology is active at the field scale has been discussed previously in the context of The Geysers by Boitnott and Kirkpatrick (1997). The fact that this same phenomenology is evident in the Awibengkok cores (which have considerably higher porosity and are texturally quite different) indicates that this may be a fundamental result applicable to many geothermal reservoirs.

Recommendations: Additional laboratory data, along with modeling efforts toward scaling these results to the field scale should be emphasized in future work. With the core measurements as a foundation, specialized experiments aimed the physical properties of joints and fractures in geothermal matrix should be performed to constrain model development incorporating field scaling issues. 

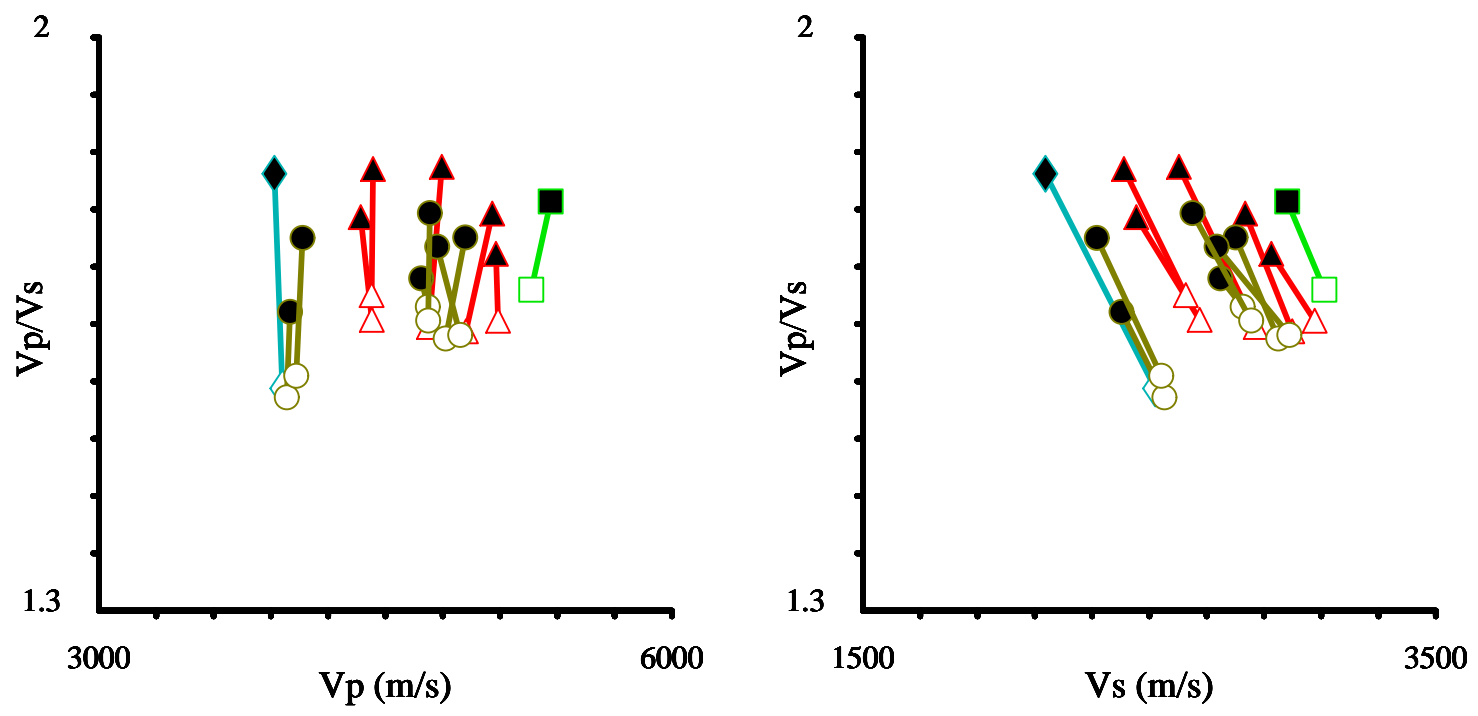

Figure 7: Net effect of saturation on $\mathrm{Vp}, \mathrm{Vs}$, and $\mathrm{Vp} / \mathrm{Vs}$ at room temperature. Filled symbols represent brine saturated results and open symbols represent dry values.
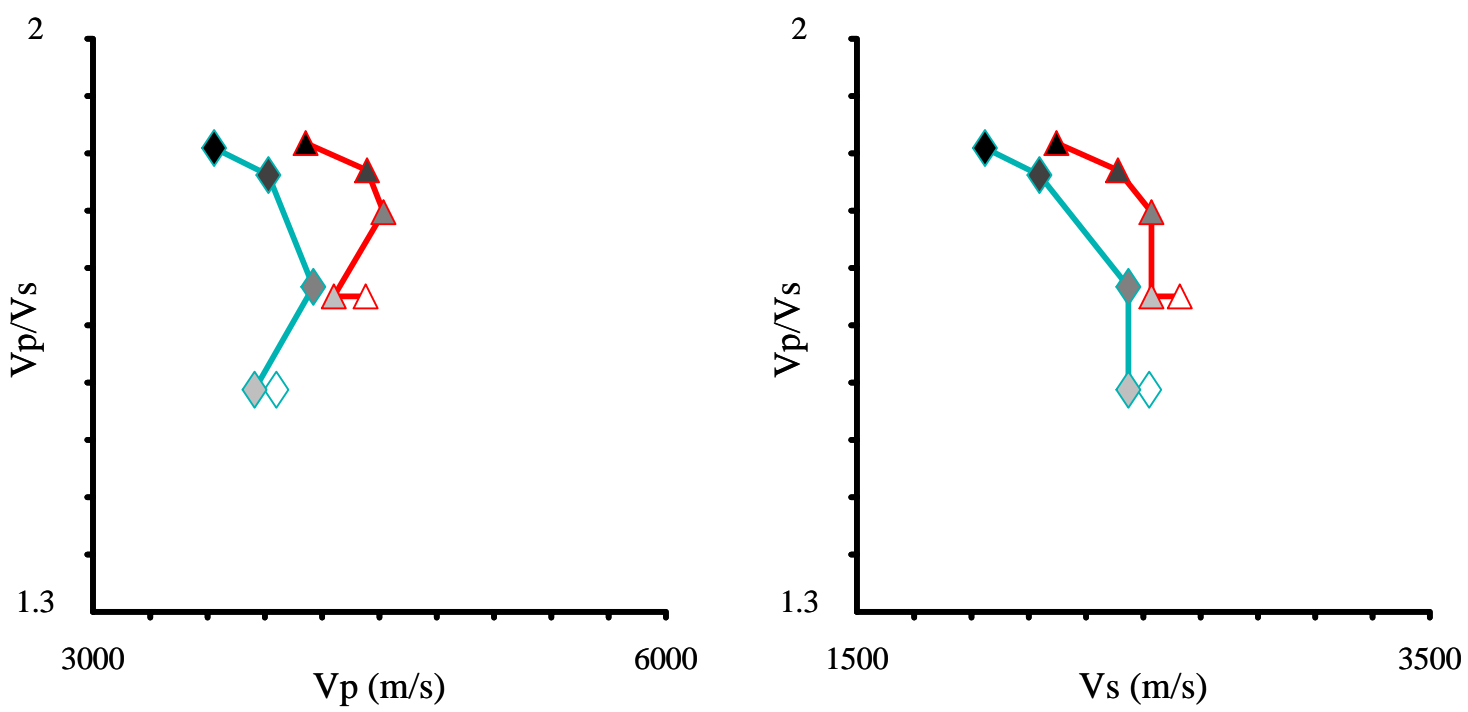

Figure 8: Effect of saturation on $\mathrm{Vp}, \mathrm{Vs}$, and $\mathrm{Vp} / \mathrm{Vs}$, broken down into the different mechanisms contributing to the effect. Open symbols represent dry conditions. Increased shading represents the progressive introduction of the different mechanisms in the following order: increased density, fluid compressibility, shear weakening, and increase in temperature.

\subsubsection{Development of an Empirical Model for Velocities}

In order to develop general models for acoustic properties of geothermal reservoir matrix, the Awibengkok data set was combined with a similar, previously collected data set from The Geysers coreholes NEGU-17 and SB15D (Boitnott and Boyd, 1996). Ultrasonic velocities measured on both dry and saturated plugs exhibit a relatively weak correlation with porosity. The Geysers cores, spanning the porosity range from 1 to 4 percent, fall on the same general trend 
with porosity as do the more variable Awibengkok cores which range in porosity from a fraction of a percent to nearly 20 percent (Figure 9). Also of notice is that the velocity/porosity relationship does not distinguish different lithologies from one another. Based on mineralogic analyses from adjacent pieces of core (courtesy of Jeff Hulen at EGI), it is found that the velocities of the high porosity Awibengkok cores (i.e. cores with porosity greater than 10 percent) exhibit a suggestive relationship with illite content. In general, high illite content correlates with low velocities.

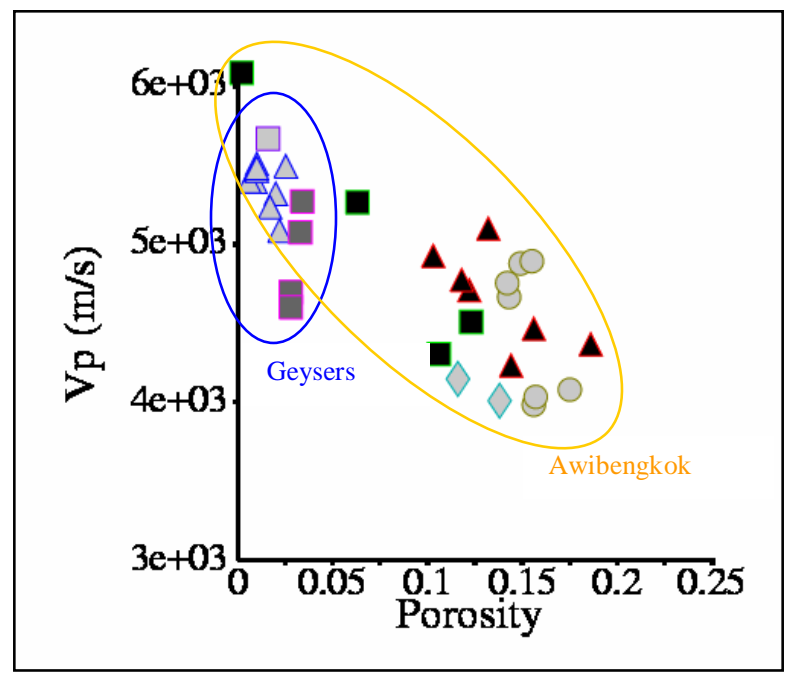

Figure 9: Cross plot of Dry Vp versus porosity for the Awibengkok and Geysers data sets at 10 MPa effective pressure. Different sysmbols indicate different rock types.

These observations motivated the use of an empirical model for velocities which consists of a linear combination of porosity, illite, and chlorite concentration. Similar relationships are justified for shear velocity (Vs), dynamic bulk modulus (K), and dynamic shear modulus (G). Thus we adopted a generic model of velocities and moduli of the general form

$$
\text { (2a) } \mathrm{P}=\mathrm{A} \phi+\mathrm{B} \mathrm{I}+\mathrm{CX}+\mathrm{D}
$$

where $\mathrm{P}$ is the property being studied, $\phi$ is the volume fraction of porosity, $\mathrm{I}$ is the weight fraction illite, and $\mathrm{X}$ is the weight fraction of chlorite. Fits to the data were derived using an iterative search method to find the coefficients that minimize $\Sigma\left(\mathrm{P}_{\mathrm{m}}-\mathrm{P}_{\mathrm{p}}\right)^{2}$, where $\mathrm{P}_{\mathrm{m}}$ is the measured property and $\mathrm{P}_{\mathrm{p}}$ is the predicted property from equation $2 \mathrm{a}$. The relative significance of the different parameters was systematically studied by fitting the data to models with certain terms removed, such as

$$
\begin{aligned}
& \text { (2b) } \mathrm{P}=\mathrm{A} \phi+\mathrm{B} I+\mathrm{D} \\
& \text { (2c) } \mathrm{P}=\mathrm{A} \phi+\mathrm{D}
\end{aligned}
$$

Best fitting parameter sets are shown in Table 2. Comparative measures of goodness of fit are made by computing the RMS error in predicted porosities for each relationship, where the predicted porosity is derived from equations 2 re-written with $\phi$ as the unknown. An example comparison of these errors for the various properties is shown in Figure 10. From this analysis, 
we see that in general both the velocities and moduli are fit equally well by the simple empirical model (i.e. the RMS porosity errors are comparable for each property). For the velocities and the shear modulus, the addition of illite dependence reduces the RMS porosity error by nearly a factor of two, while the addition of chlorite produces only marginal improvements. In contrast, the bulk modulus, which exhibits the strongest correlation with porosity alone, exhibits little improvement when illite and/or chlorite are added to the model.

For all properties. results using $\mathrm{P}=\mathrm{A} \phi+\mathrm{CX}+\mathrm{D}$ (not discussed here) exhibit fits only slightly better than the results using porosity alone (equation $2 \mathrm{c}$ ), again inicating that chlorite is not a significant controlling factor.

\section{Velocities and Moduli}

(Saturated)

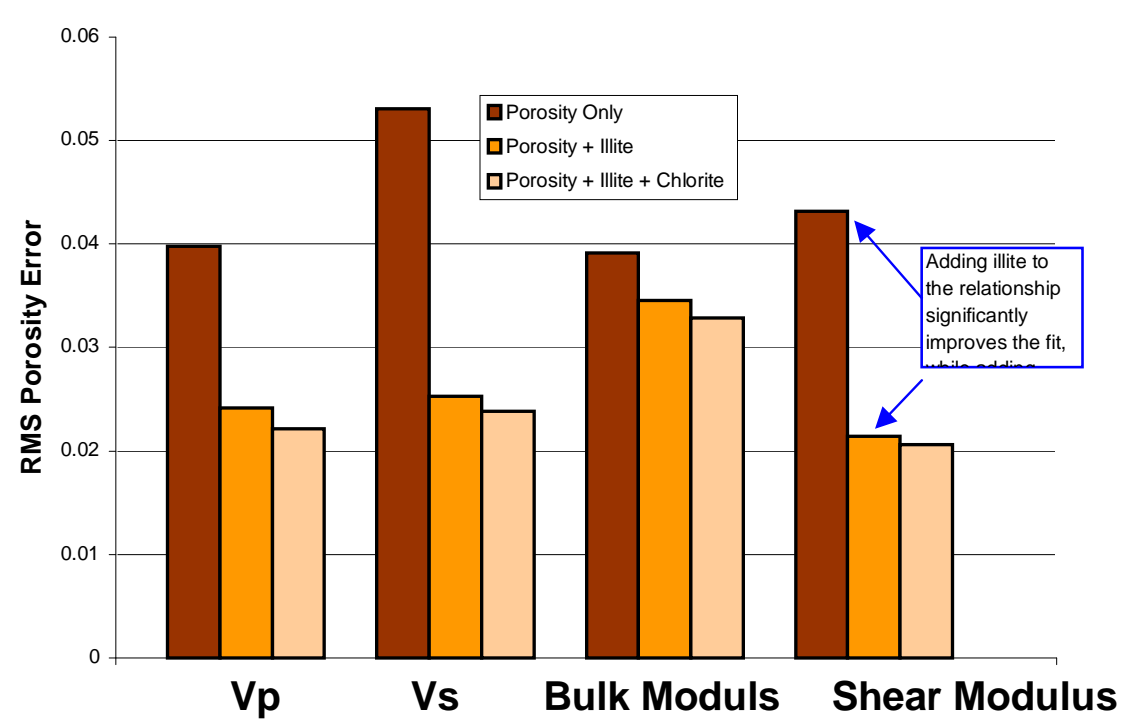

Figure 10: Comparison of RMS porosity errors for fits of saturated velocities and moduli to equations $2(a, b, c)$. For $V_{p}, V_{s}$, and $G_{s a t}$, the addition of illite significantly reduces errors, indicating that illite is a controlling variable.

\subsubsection{The Physical Significance of the Empirical Model}

Previously, we have shown that the measured velocities of individual cores from both the Awibengkok and Geysers geothermal fields can be fit by a modified low frequency poroelastic model derived by adding a shear weakening term to low frequency Biot-Gassmann theory (see also Boitnott and Boyd, 1996; Boitnott and Johnson, 1999). It turns out, as we will now show, that the empirical relationships derived in Table 2 are themselves internally consistent with this same poroelastic model, indicating that the data set is consistent with a generalized model which links velocities and their saturation dependence to porosity and illite content. The resulting model provides a foundation upon which to interpret well logs as well as a matrix model upon which to construct field scale models for seismic properties.

In order to be generally applicable, the model needs definition of four parameters. From a physical modeling point of view, the natural parameter set to choose is $\mathrm{K}_{\mathrm{dry}}, \mathrm{K}_{\mathrm{solid}}, \mathrm{G}_{\mathrm{dry}}$, and $\Delta \mathrm{G}$, since $K_{d r y}, K_{\text {solid }}$, and $G_{d r y}$ do not involve fluid/rock interactions. $K_{d r y}$ and $G_{d r y}$ can be defined 
directly by their best fitting empirical relationships in Table 2 . There is no evidence that $\mathrm{K}_{\text {dry }}$ is influenced by illite or chlorite, so for simplicity we suggest adoption of equation $2 \mathrm{c}$ for $\mathrm{K}_{\mathrm{dry}}$. For the shear modulus, $G_{\text {dry }}$ does appear to have significant illite dependence, but chlorite dependence is not significant, so equation $2 \mathrm{~b}$ is recommended.

Recommendation: The illite dependence of $\mathrm{G}_{\mathrm{dry}}$, combined with the lack thereof for $\mathrm{K}_{\mathrm{dry}}$ is an interesting observation which warrants more study aimed at understanding this observation in the context of a physical model.

\begin{tabular}{|c|c|c|c|c|c|c|}
\hline \multicolumn{7}{|c|}{ Table 2 : Empirical Models of Velocities and Moduli } \\
\hline \multicolumn{7}{|c|}{ Velocities and Moduli : $P=A \phi+B I+C X+D$} \\
\hline Property & Dataset & $\mathbf{A}$ & B & $\mathbf{C}$ & D & RMS Porosity error \\
\hline \multirow{3}{*}{$\begin{array}{l}\text { Dry } V_{p} \\
(m / s)\end{array}$} & \multirow{3}{*}{ Awibengkok and Geysers } & -6940 & & & 5460 & 0.0454 \\
\hline & & -7610 & -1870 & & 5720 & 0.0345 \\
\hline & & -8000 & -1750 & 1320 & 5540 & 0.0316 \\
\hline \multirow{3}{*}{$\begin{array}{l}\text { Dry } V_{\mathrm{s}} \\
(\mathrm{m} / \mathrm{s})\end{array}$} & \multirow{3}{*}{ Awibengkok and Geysers } & -3520 & & & 3270 & 0.0441 \\
\hline & & -3960 & -1230 & & 3440 & 0.0261 \\
\hline & & -4090 & -1190 & 441 & 3370 & 0.0246 \\
\hline \multirow{3}{*}{$\begin{array}{l}\mathrm{K}_{\text {dry }} \\
(\mathrm{GPa})\end{array}$} & \multirow{3}{*}{ Awibengkok and Geysers } & -134 & & & 42.4 & 0.0440 \\
\hline & & -141 & -19.8 & & 45.2 & 0.0396 \\
\hline & & -147 & -18.0 & 19.8 & 42.4 & 0.0373 \\
\hline \multirow{3}{*}{$\begin{array}{l}\mathrm{G}_{\mathrm{dry}} \\
(\mathrm{GPa})\end{array}$} & \multirow{3}{*}{ Awibengkok and Geysers } & -76.5 & & & 29.0 & 0.0309 \\
\hline & & -83.0 & -18.1 & & 31.5 & 0.0196 \\
\hline & & -85.5 & -17.4 & 8.2 & 30.3 & 0.0183 \\
\hline \multirow{3}{*}{$\begin{array}{l}\text { Saturated } V_{p} \\
(\mathrm{~m} / \mathrm{s})\end{array}$} & \multirow{3}{*}{ Awibengkok and Geysers } & -7580 & & & 5620 & 0.0398 \\
\hline & & -8530 & -2360 & & 5940 & 0.0242 \\
\hline & & -8980 & -2300 & 1110 & 5790 & 0.0222 \\
\hline \multirow{3}{*}{$\begin{array}{l}\text { Saturated } V_{\mathrm{s}} \\
(\mathrm{m} / \mathrm{s})\end{array}$} & \multirow{3}{*}{ Awibengkok and Geysers } & -4200 & & & 3180 & 0.0531 \\
\hline & & -4990 & -1970 & & 3450 & 0.0253 \\
\hline & & -5190 & -1940 & 500 & 3380 & 0.0239 \\
\hline \multirow{3}{*}{$\begin{array}{l}\mathrm{K}_{\text {sat }} \\
(\mathrm{GPa})\end{array}$} & \multirow{3}{*}{ Awibengkok and Geysers } & -137 & & & 49.1 & 0.0391 \\
\hline & & -145 & -20.3 & & 51.9 & 0.0346 \\
\hline & & -151 & -19.4 & 14.6 & 49.9 & 0.0329 \\
\hline \multirow{3}{*}{$\begin{array}{l}\mathrm{G}_{\text {sat }} \\
(\mathrm{GPa})\end{array}$} & \multirow{3}{*}{ Awibengkok and Geysers } & -75.1 & & & 27.5 & 0.0432 \\
\hline & & -86.4 & -28.4 & & 31.4 & 0.0214 \\
\hline & & -88.8 & -28.1 & 5.8 & 30.6 & 0.0206 \\
\hline
\end{tabular}


$\Delta \mathrm{G}$ can best be defined empirically by subtracting the equation $2 \mathrm{~b}$ relationships for $\mathrm{G}_{\mathrm{sat}}$ and $\mathrm{G}_{\mathrm{dry}}$ from Table 2, yielding

$$
\begin{gathered}
\Delta \mathrm{G}=\mathrm{A} \phi+\mathrm{BI}+\mathrm{D} \\
\mathrm{A}=-3.4 \\
\mathrm{~B}=-10.3 \\
\mathrm{D}=-0.1
\end{gathered}
$$

Note that $|\mathrm{B}|>|\mathrm{A}|$ and $|\mathrm{D}|<<|\mathrm{BI}|$ for typical I, and thus illite content dominates $\Delta \mathrm{G}$. This is evident in a cross plot of $\Delta \mathrm{G}$ versus illite, which exhibits a well defined trend despite highly variable porosities (see Figure 11). Note also that the Awibengkok and Geysers cores both follow the same trend, suggesting that textural influences are not important for this phenomenon. While the physical mechanism for this shear weakening remains poorly understood, there is ample evidence that the effect is a chemo-mechanical one, as it is not observed in kerosene saturated sample discussed earlier.

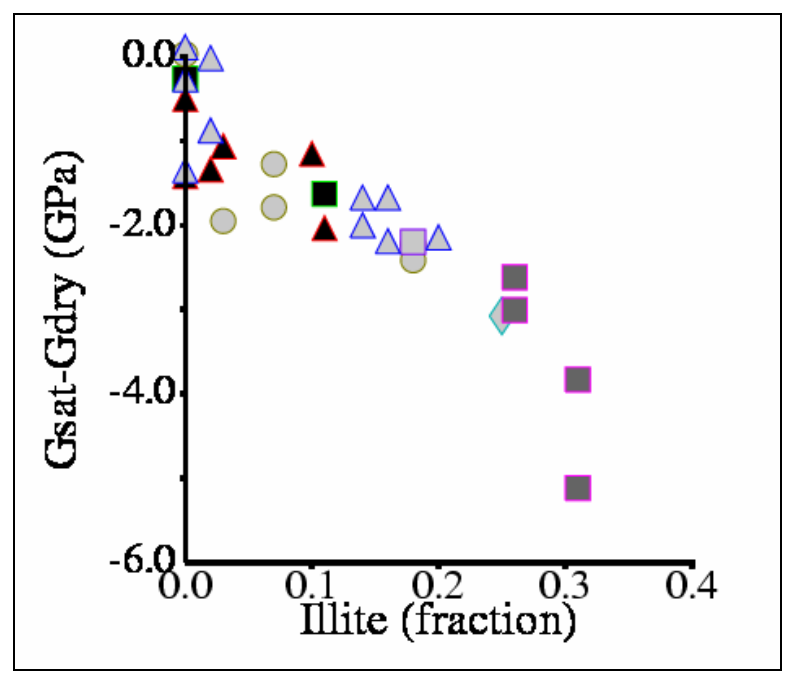

Figure 11: Cross plot of $\Delta \mathbf{G}=\mathbf{G}_{\text {sat }}-\mathbf{G}_{\text {dry }}$ versus weight fraction illite for the Awibengkok and Geysers data sets. Symbols are the same as in Figure 9. A strong linear trend is clearly seen, consistent with the prediction $\Delta G \sim-10.3 I$ using the empirical relations in Table 2. 
For the dynamic bulk modulus, the equation $2 \mathrm{c}$ relationships in Table 2 indicate that

$$
\begin{gathered}
\Delta \mathrm{K}=\mathrm{A} \phi+\mathrm{D} ; \\
\mathrm{A}=3 \\
\mathrm{D}=6.7 .
\end{gathered}
$$

In this case we note that $\mathrm{D}>>\mathrm{A} \phi$ for typical $\phi$, indicating that $\Delta \mathrm{K}$ is nearly constant independent of porosity. While this appears at odds with what might be inferred from equation 1c, taking $\mathrm{K}_{\text {solid }}=58 \mathrm{GPa}$ (a typical value used when modeling data from individual cores), we find that $\Delta \mathrm{K}$ from equation $1 \mathrm{c}$ is predicted to be of the correct magnitude and nearly independent of porosity (see Figure 12). This result indicates that low frequency Biot theory described by equations $1(\mathrm{a}, \mathrm{c})$ is consistent with our empirical relationships for $\mathrm{K}_{\mathrm{dry}}$ and $\mathrm{K}_{\mathrm{sat}}$ in Table 2, providing justification for use of this well studied physical model for these rocks.

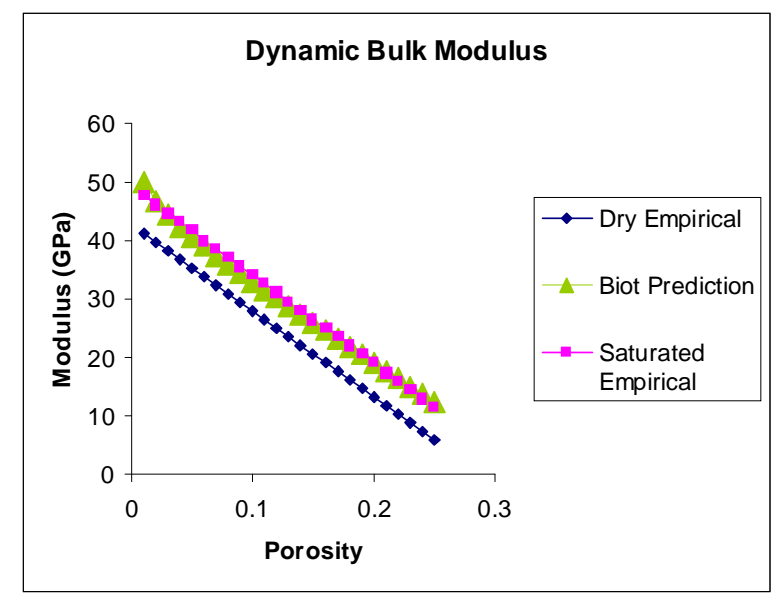

Figure 12: Comparison of $K_{\text {sat }}$ from Table 2 with $K_{\text {sat }}$ predicted from equation $1 c$ using $K_{\text {dry }}$ from Table 2 and $K_{\text {solid }}=58$ GPa.

One noteworthy finding which should serve as the focus of future work involves evidence of textural/mineralogical controls on $\mathrm{Vp} / \mathrm{Vs}$ ratio. It has long been observed that the dynamic bulk modulus of reservoir cores exhibit considerable scatter with respect to a first order linear trend with porosity. The cause of this scatter has not been identified, but it is of great interest because it leads to scatter in the $\mathrm{Vp} / \mathrm{Vs}$ ratio, a seismic property commonly used to infer saturation in a reservoir. One key result which was discovered only recently is that the residual in the bulk modulus with respect to the first order porosity trend, when plotted versus Vp/Vs, results in a separation of samples into logical groups based on lithology and reservoir (see Figure 13). This segregation clearly suggests that bulk modulus variation, and thus Vp/Vs, is controlled in part by textural/and or mineralogical variables linked to lithology. Two types of variation are apparent in the data, one being intra-group variations and the other being intergroup, the later of which appears to lead to systematics between cores from Awibengkok and The Geysers. 
Recommendation: A broader look at mineralogy and texture variations is certainly warranted. Establishing controls on dynamic bulk modulus and $\mathrm{Vp} / \mathrm{Vs}$ will greatly improve our ability to model and interpret seismic and sonic log data from geothermal reservoirs.

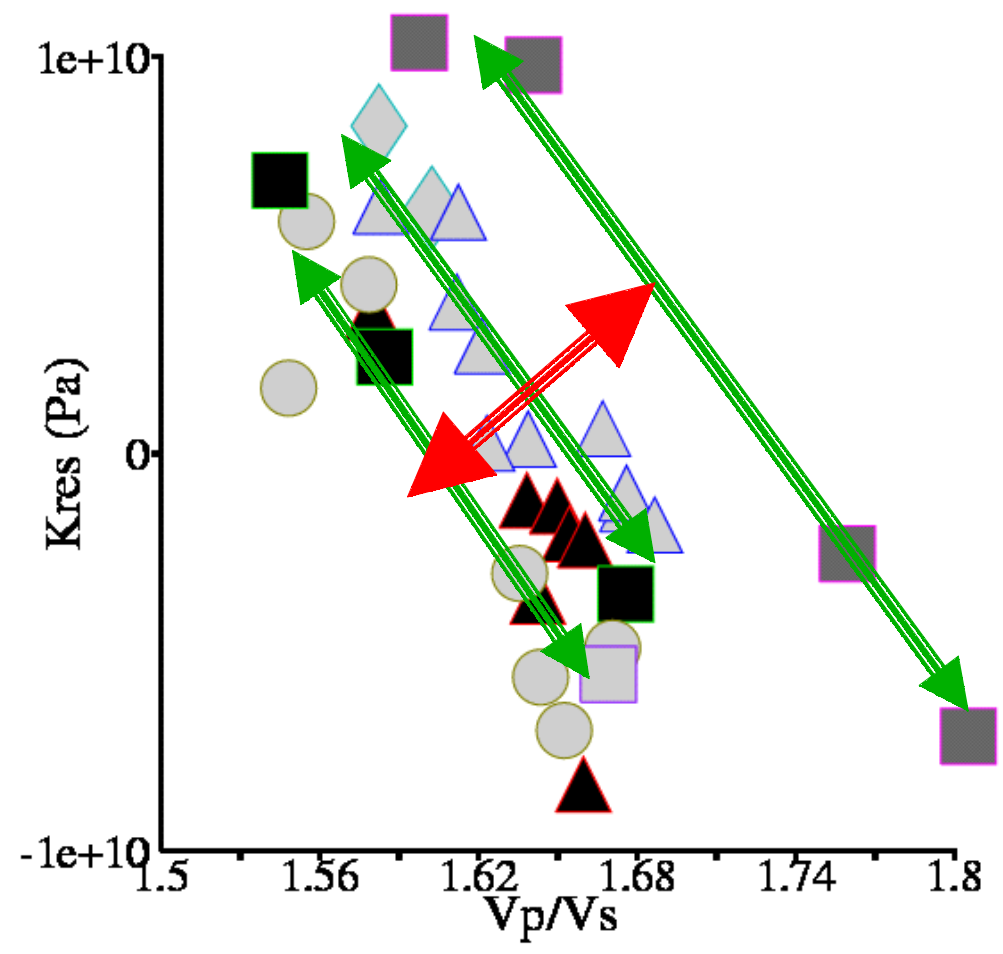

Figure 13: Cross plot of the residual in the bulk modulus (with respect to the predicted modulus based on a simple linear function of porosity) versus the $\mathrm{Vp} / \mathrm{Vs}$ ratio for core plugs from the Awibengkok geothermal field and The Geysers. This plot indicates that $\mathrm{Vp} / \mathrm{Vs}$ variation is linked to scatter in the dynamic bulk modulus, the causes of which are not well understood. Different symbols indicate different lithologies. Both intragroup (green arrows) and intergroup (cross cutting red arrow) variations are noted, providing clues to possible mineralogical and textural controls. 


\subsection{Electrical Properties}

\subsubsection{Overview}

Measurements of electrical impedance were made as a function of pressure, temperature, brine chemistry, and frequency. Based on this data, we have found that in general the electrical properties of a given sample (including both magnitude and frequency dependence) are relatively insensitive to pressure. Temperature dependence approximates that of the temperature dependence of brine, although in some samples a measurable decrease in formation factor with temperature is observed. In contrast, intrinsic variations between samples (even with similar lithology and porosity) are in comparison rather large, reflecting potentially important textural or mineralogic controls. As a result of the apparent simplicity of the pressure and temperature effects, these intrinsic variations should be resolvable in log data, and thus understanding the underlying causes is important and directly applicable to reservoir characterization.

Data relating mineralogy to electrical properties suggests that illite is associated with enhanced conductivity. The data also suggests that chlorite may inhibit conductivity, however we caution that more data is needed to test both these hypotheses. While a general physical model incorporating brine conduction, surface conduction, and polarization of electrically conductive grains has been initiated and appears within reach, this task has not been completed due to lack of funding. Reported here are the general results analyzed in the context of the physical insight that they provide, along with an empirical model for basic electrical properties that can be used for practical, first order analysis of field and log data.

Unlike the results for velocities, a unified empirical model has not been identified to fit the combined data set for The Geysers and Awibengkok samples. While the data from each reservoir follows similar functional form and exhibits dependencies on the same variables, the data favors systematic differences in parameters (such as the Archie cementation exponent) for each reservoir.

\subsubsection{Electrical Impedance of Awibengkok Cores}

\subsubsection{Depth and Lithology:}

The primary brine used for laboratory testing was a $12000 \mathrm{ppm} \mathrm{NaCl}$ brine selected to approximate the salinity and dominant cationic composition of the brine in the Awibengkok reservoir. Electrical impedance data is presented in terms of the formation factor $F$ which is defined as the resistivity of the rock normalized by the resistivity of the pore fluid. A summary plot of formation factors and cementation exponents, $m=\log (F) / \log (\phi)]$, versus porosity $(\phi)$ for the Awibengkok data set is shown in Figure 14. While a clear trend in $\mathrm{F}$ with porosity is present (as is typical of rocks), significant scatter is observed. This scatter can amount to a 50\%variation in porosity for a given $\mathrm{F}$ or a factor of three variation in $\mathrm{F}$ for a given porosity. No systematic trends with depth or lithology are apparent. 


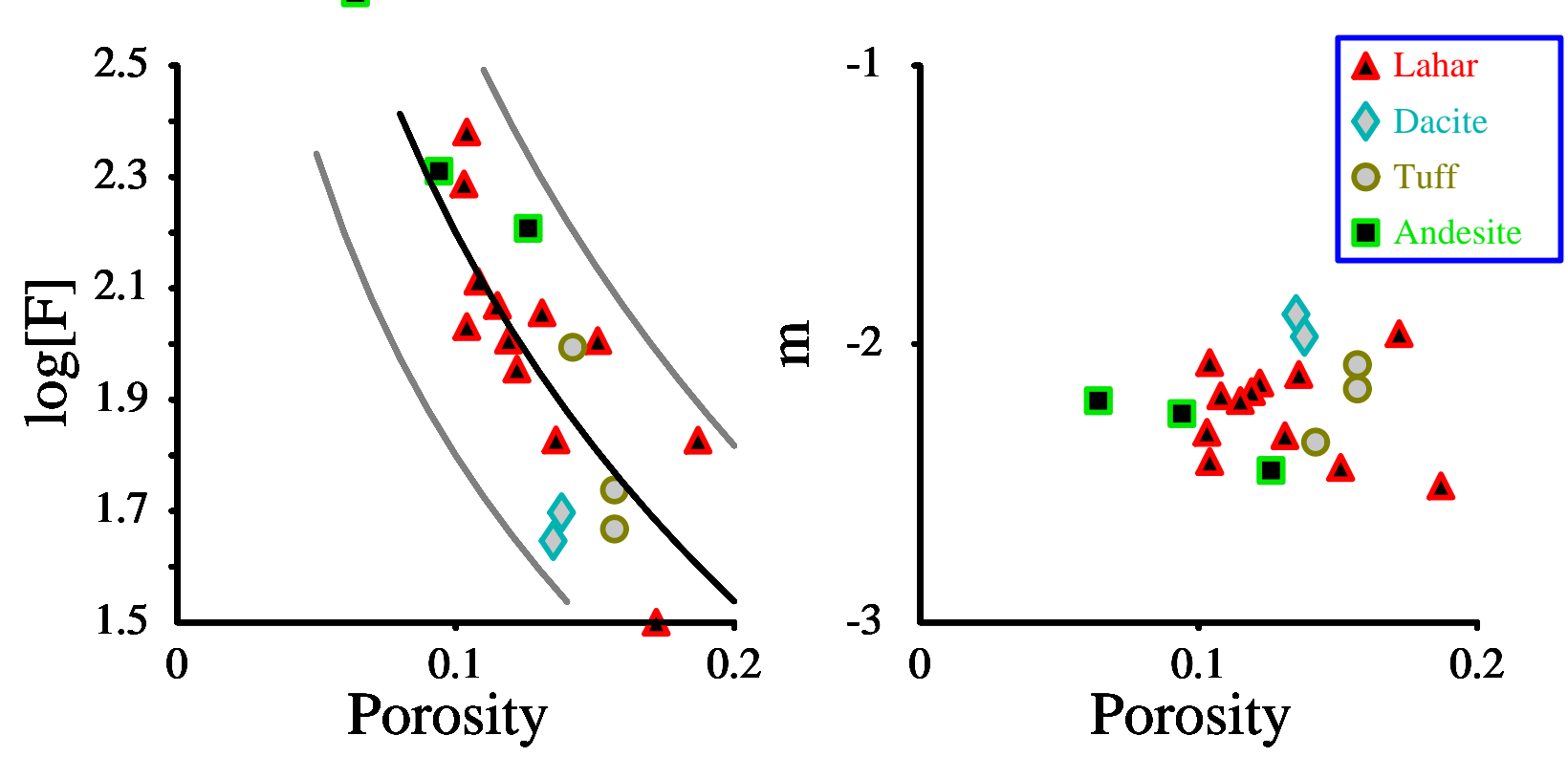

Figure 14: Logarithm of formation factors and cementation exponents versus porosity for brine saturated core plugs from AWI 1-2. The lines in the left hand figure represent $m=-1.8,-2.2,-2.6$ respectively.

\subsubsection{Pressure and Temperature}

The cause of the scatter in the resistivity/porosity relationship is an important issue. Induction log response observed in sidetrack well AWI 1-2 ST\#1 exhibits significant variations in apparent resistivity in sections of the hole with apparently uniform lithology. While the temptation might be to attribute much of the log variation to porosity, the laboratory data suggests that this may not be the case. In comparing laboratory data with logs, we must also take into account environmental effects such as pressure and temperature dependence of the resistivities. Thus we have begun making measurements to populate a data-base which can be used to address the effects of pressure, temperature, brine chemistry, and frequency on the electrical properties of the matrix.

Pressure dependence is in general relatively small, indicating that the observed scatter should be persistent at all depths. The pressure dependence of $F$ from a representative sub-set of cores is shown in Figure 15. The effect of temperature on $\mathrm{F}$ is also found to be relatively small (see Figure 16). The observation that $\mathrm{F}$ is independent of temperature is suggestive of a brine dominated conduction system. Support for this also comes from results on resistivity versus brine concentration, discussed in a latter section. 


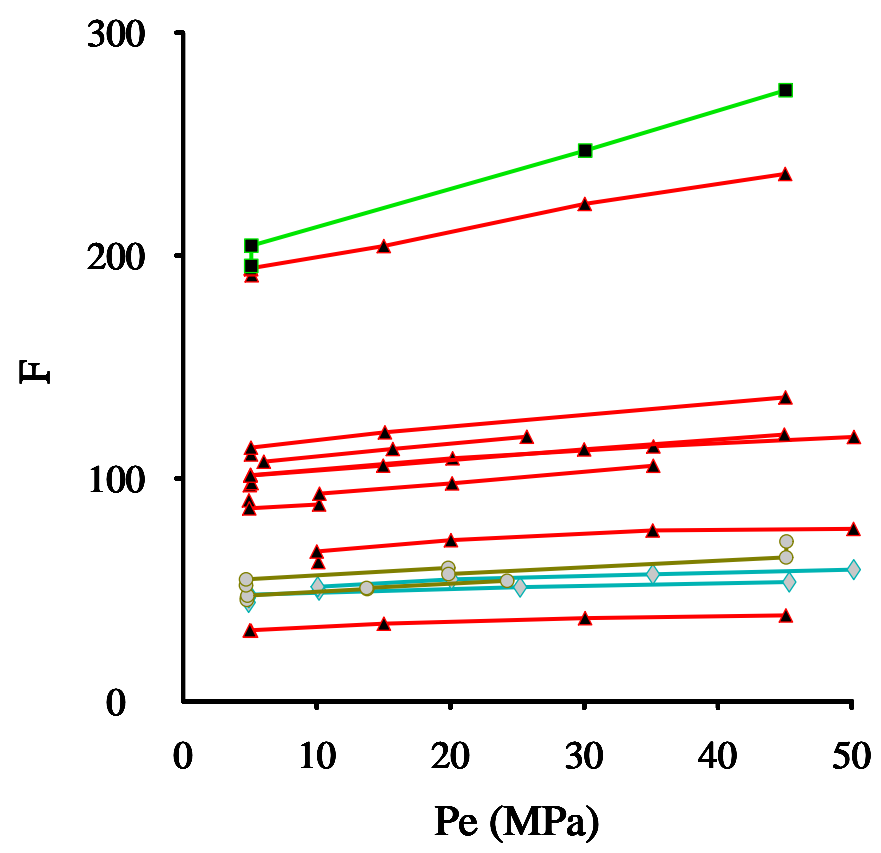

Figure 15: Formation factors versus effective confining pressure for representative samples.

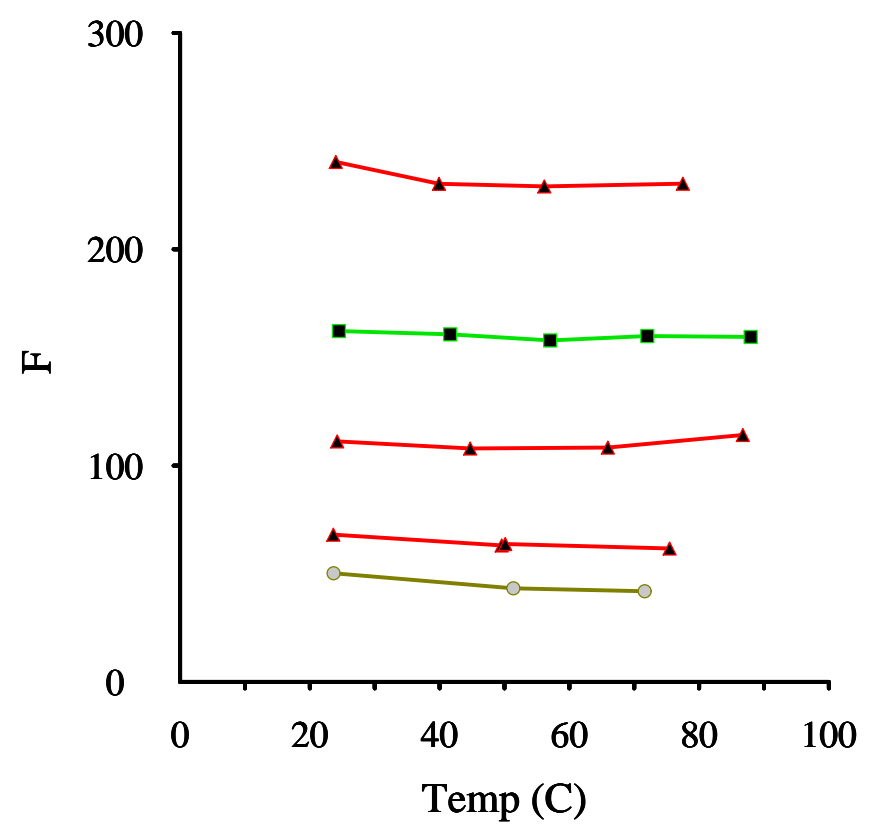

Figure 16: Formation factors versus temperature for representative samples.

\subsubsection{Frequency Dependence}

Frequency dependence is variable and can lead to relatively strong dispersions at logging frequencies. The observed frequency dependence is summarized in Figures 17 and 18. In principle, any heterogeneity in free charge mobility will lead to frequency dependent impedance. In these rocks, the frequency dependence is commonly found to be caused by disseminated 
sulfides and other electrically conductive minerals in the matrix. In many cases, there is a clear association with strong dispersion and the presence of disseminated sulfides in the sample. When the disseminated sulfides are of relatively uniform size distribution, the expected narrow band response is observed. For more complicated size distributions, the frequency dependence is more diffuse, as is expected from theory (see Wong, 1979). Strong dispersions are also seen in some samples without concentrations of opaque minerals, indicating that clay related mechanisms are also present. Regardless of mechanism, the available data suggests that the observed dispersion, which can lead to a $20 \%$ reduction in $\mathrm{F}$ between $1 \mathrm{~Hz}$ and $10 \mathrm{kHz}$, is relatively insensitive to changes in pressure or temperature.
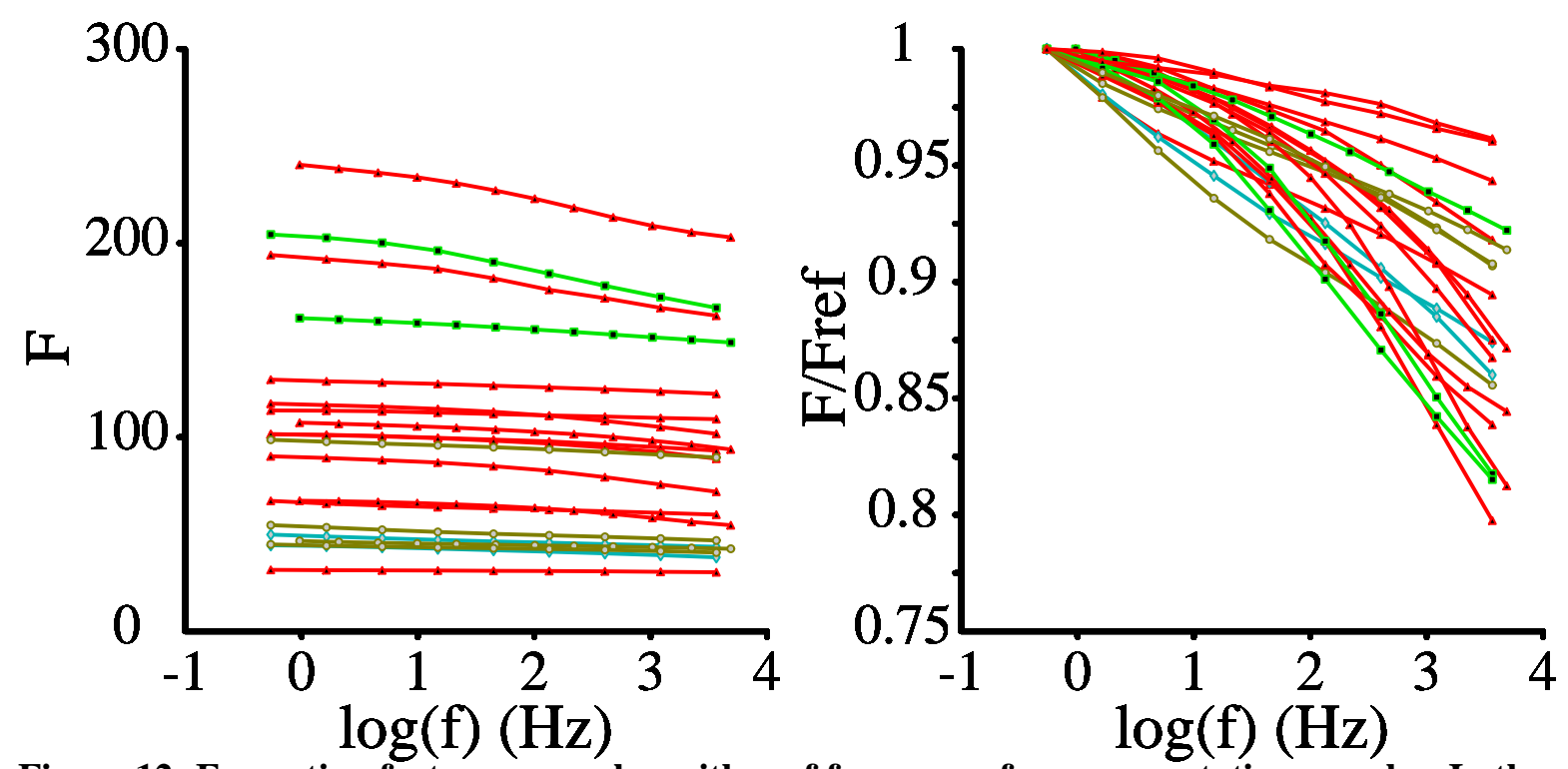

Figure 12: Formation factors versus logarithm of frequency for representative samples. In the right hand figure, the measured F's are normalized by the value of $F$ at $1 \mathrm{~Hz}$. Different colors represent different lithologies. 

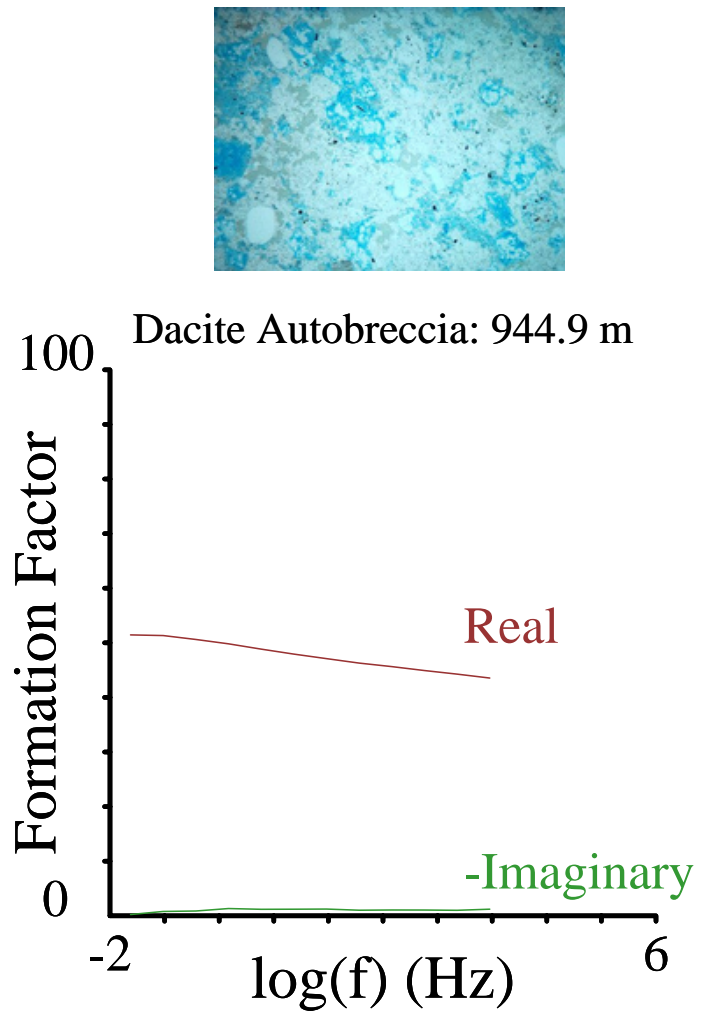
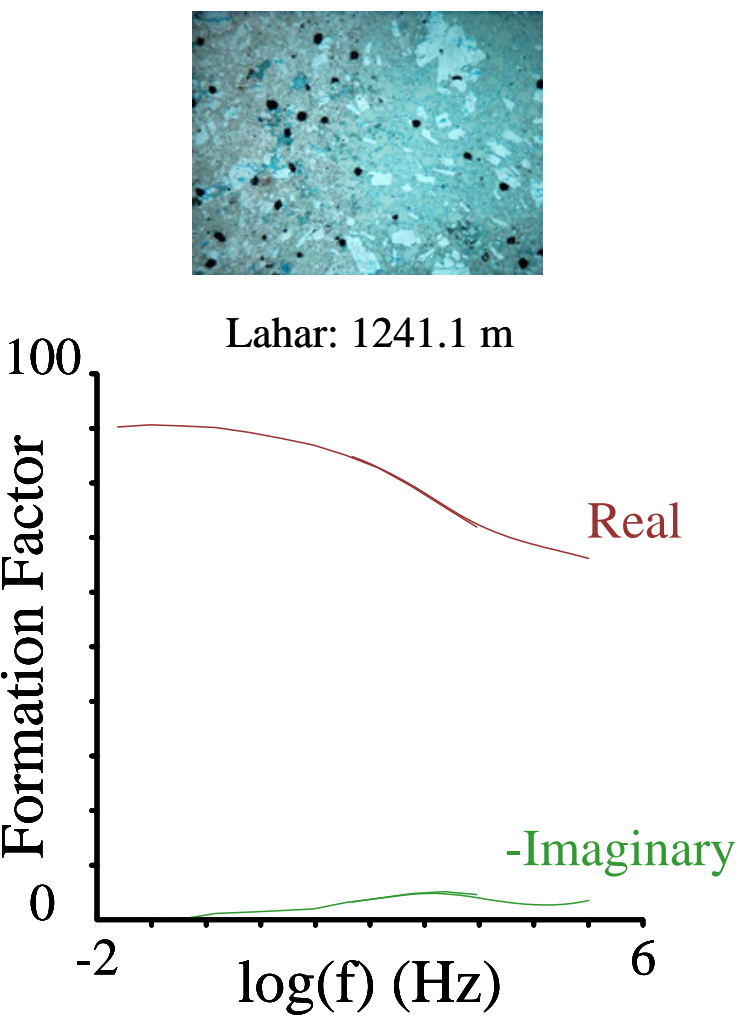

Figure 13: Impedance spectra for two representative samples from AWI 1-2. On the left is the complex Formation Factor for a dacite autobreccia from $944.9 \mathrm{~m}$. On the right is the spectrum for a lahar from 1241.1 m. A plane light photomicrograph of each sample is shown above each plot. Note the prominent bump in the imaginary impedance and the strong dispersion in the real impedance for the lahar sample. This is thought to reflect the presence of disseminated sulfides in the sample.

\subsubsection{The Effect of Brine Chemistry on Electrical Properties}

As discussed in a later section, results analyzed in the context of mineralogic data indicate that illite plays an important role in increasing the conductivity of these samples. One possible explanation is that the enhanced conductivity results from the surface conductivity of illite. Also a possibility is that there is a textural control related to illite, such as a decreased tortuosity as illite content increases. To independently test these ideas, a number of specialized measurements were made to constrain the amount of surface conduction in selected samples. Two types of experiments were performed aimed at characterizing the brine dependence of the sample conductivity.

The first set of experiments involved analysis of closely spaced sub-cores, each saturated with different brines. Three samples of various lithologies were selected, based in part on their visual homogeneity. The sub-cores were oven dried (at $70 \mathrm{C}$ under vacuum for 24 hours) and submerged in jars of either $\mathrm{NaCl}$ or $\mathrm{KCl}$ brines of varying strength. Imbibition of brine was monitored by periodically weighing the samples. After a few days, when the imbibition of the brine had slowed to an undetectable level, the electrical properties of each sample were measured. 
A summary plot of computed sample conductivities versus fluid conductivities is shown in Figure 19. A clear trend with brine concentration is seen, indicating general agreement with a Waxman and Smits [1968] type conductivity relationship. Brine composition does not appear to have a strong influence on electrical properties, with no apparent difference between the $\mathrm{NaCl}$ and $\mathrm{KCl}$ saturated samples. Also included in Figure 19 are results from the routine data set, indicating that the imbibition method of saturation has not biased the result. The results for each sample can be parameterized by the relation

$$
\text { (3) } \mathrm{C}_{\text {sample }}=\mathrm{C}_{\text {surface }}+\mathrm{C}_{\text {brine }} / \mathrm{F}^{*}
$$

where $\mathrm{C}_{\text {sample }}, \mathrm{C}_{\text {surface }}$, and $\mathrm{C}_{\text {brine }}$ are the sample, surface, and brine conductivities respectively, and $\mathrm{F}^{*}$ is a modified formation factor describing the resistivity of the porous system in parallel with a surface conductivity element. Similarly, a surface conductivity corrected Archie exponent $\mathrm{m}^{*}$ can be defined as $\left.\mathrm{m}^{*}=\log \left(\mathrm{F}^{*}\right) / \log (\phi)\right]$.

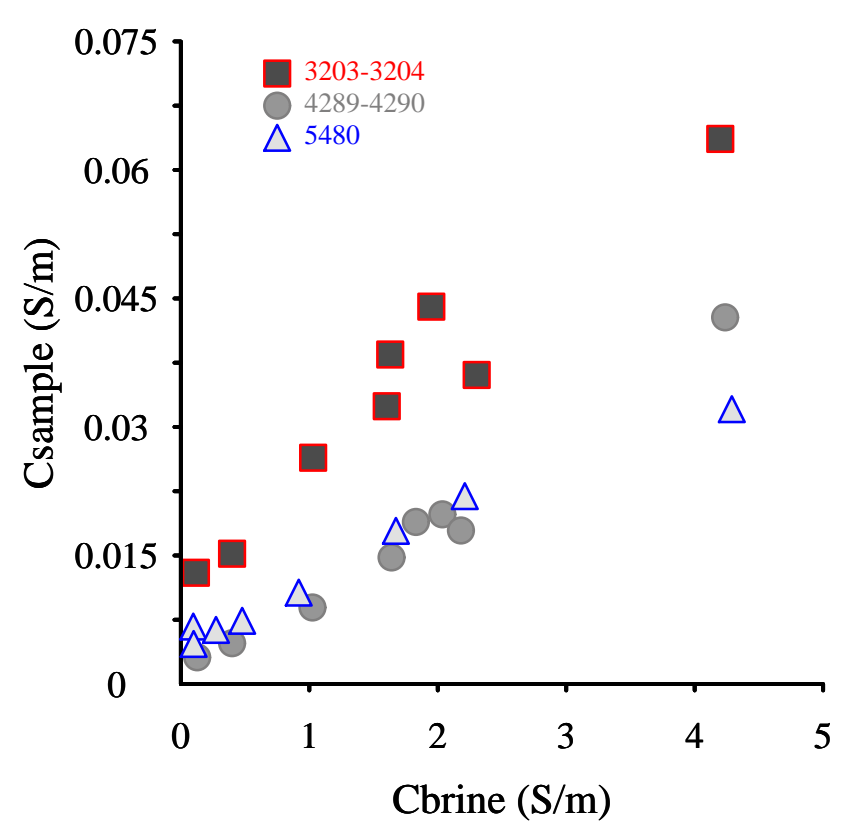

Figure 19: The effect of brine chemistry and strength of the electrical conductivity and formation factor of three hydrothermally altered samples from AWI 1-2.

In order to supplement this data set, a second procedure was used to obtain the same sort of information on individual sub-cores. Saturated samples from the routine data set were submerged in a large volume of tap water, with the tap water being refreshed periodically. The tap water conductivity was monitored to indicate leaching of salts from the samples. Once no further leaching was detected, the samples were retested. Assuming the samples behave according to equation 3 , a constraint on $\mathrm{C}_{\text {surface }}$ is obtained. From these two data sets, $\mathrm{C}_{\text {surface }}, \mathrm{F}^{*}$, and $\mathrm{m}^{*}$ were computed and are presented in Table 3. Plotting $\mathrm{C}_{\text {surface }}$ versus illite content (Figure 20) produces a suggestive trend indicating that a surface conductivity contribution is influenced by illite concentration. Plotting $\mathrm{F}^{*}$ and $\mathrm{m}^{*}$ versus porosity however, we still do not produce well defined trends (Figure 21). This implies that the porosity and/or textural contribution to the sample resistivities is intrinsically variable. A weak decrease in $\mathrm{m}^{*}$ with increasing porosity is suggested by the data. 


\begin{tabular}{|c|c|c|c|c|c|c|}
\hline \multicolumn{7}{|c|}{ Table 3 Electrical Properties of Selected Cores } \\
\hline $\begin{array}{c}\text { Sample } \\
-\end{array}$ & $\begin{array}{c}\text { Porosity } \\
-\end{array}$ & $\begin{array}{l}\text { Illite } \dagger \\
\mathrm{Wt} \%\end{array}$ & $\begin{array}{c}\text { Chlorite } \\
\text { Wt } \%\end{array}$ & $\begin{array}{c}\mathrm{F}^{*} \\
- \\
\end{array}$ & $\begin{array}{c}\mathrm{m}^{*} \\
-\end{array}$ & $\begin{array}{l}\mathrm{C}_{\text {surface }} \\
\mathrm{mS} / \mathrm{m}\end{array}$ \\
\hline 2520_0a & 0.151 & 0 & 13 & 114.6 & -2.51 & 2.69 \\
\hline 2541_7a & 0.187 & 0 & 22 & 71.9 & -2.55 & 3.77 \\
\hline 3035_0a & 0.135 & 23 & 3 & 60.8 & -2.05 & 14.1 \\
\hline $3203-3204 \ddagger$ & 0.157 & 18 & 10 & 60.8 & -2.22 & 13.0 \\
\hline $4125 \_4 a$ & 0.104 & 3 & 19 & 192.0 & -2.31 & 0.85 \\
\hline $4289-4290 \ddagger$ & 0.119 & 2 & 21 & 108.2 & -2.20 & 3.12 \\
\hline $5480 \ddagger$ & 0.110 & 7 & 25 & 126.8 & -2.19 & 5.65 \\
\hline 5513_6a & 0.131 & 10 & 16 & 118.7 & -2.35 & 1.07 \\
\hline
\end{tabular}

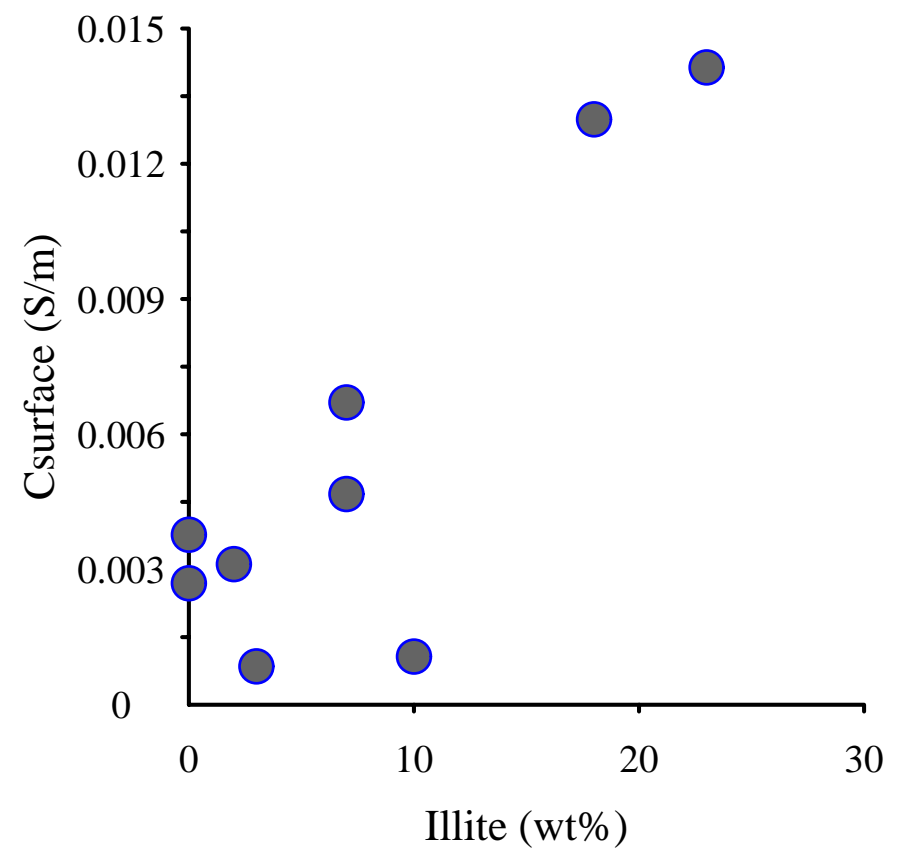

Figure 20: Inferred $C_{\text {surface }}$ versus weight percent illite for selected samples from AWI 1-2 (see Table 3). 

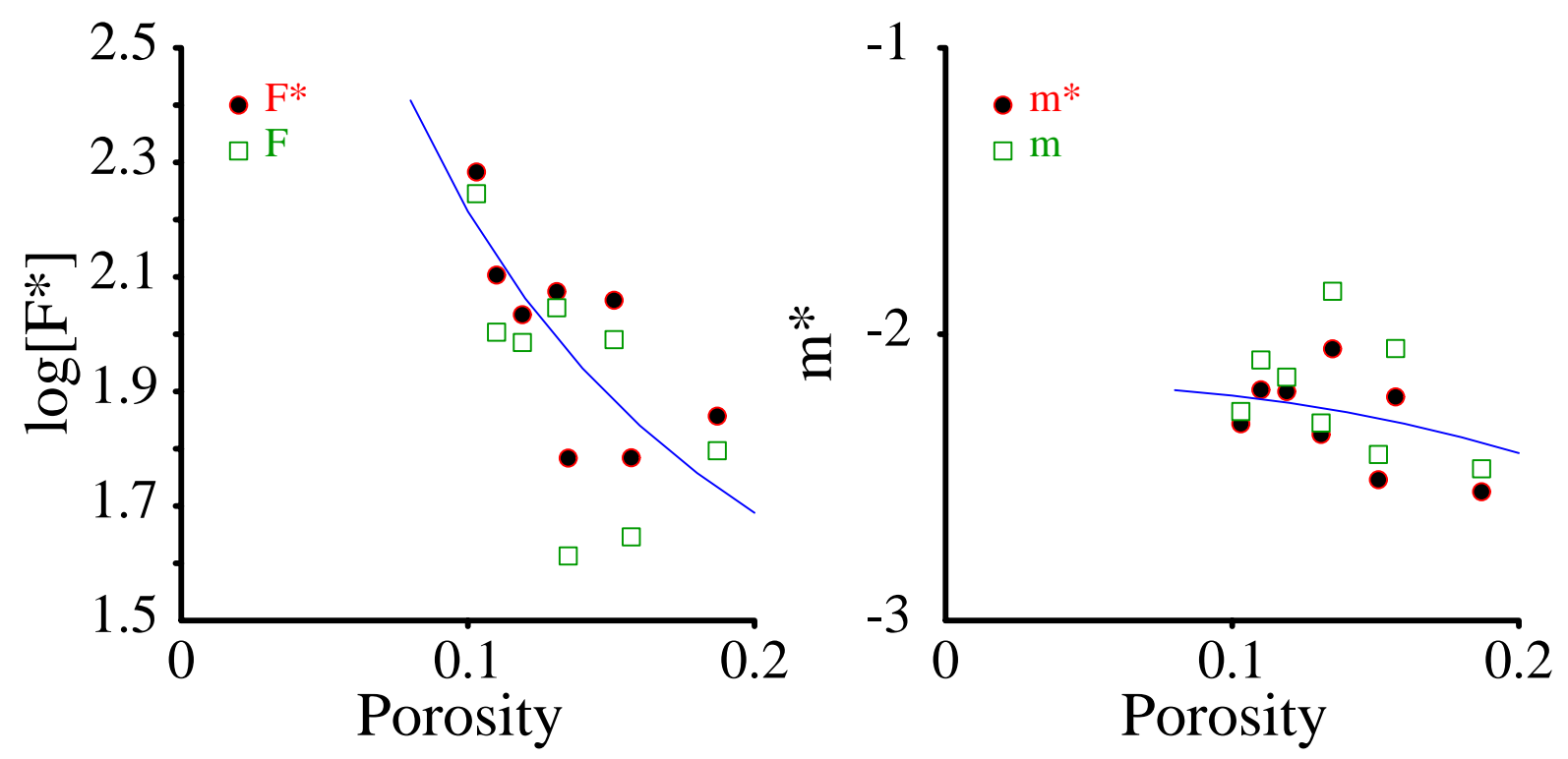

Figure 21: Logarithm of $\mathrm{F}^{*}$ and $\mathrm{m}^{*}$ versus porosity for selected samples from AWI 1-2. Also for reference, $F$ and $m$ are plotted for the same samples (squares) and the curve $F=\phi^{-2.17}+15.9$, which includes the non-mineralogic terms from an exploratory empirical model.

\subsubsection{Empirical Models of Electrical Properties}

\subsubsection{Mineralogic Controls}

Illite and chlorite concentrations for selected samples have been provided by Jeff Hulen at EGI. Cross-plotting various electrical impedance attributes with the available mineralogic data has yielded two suggestive trends. The cementation exponent $m=\log (F) / \log (\phi)$ exhibits weak correlations with illite and chlorite concentration (Figure 22). The data suggests that illite correlates with low $\mathrm{F}$ for a given porosity while chlorite exhibits the opposite association. This would be consistent in part with a modest surface conductivity contribution by illite, however we caution that correlations between mineralogy and other properties (such as porosity) are also

likely and may lead to apparent correlations between parameters having no direct physical connection. 

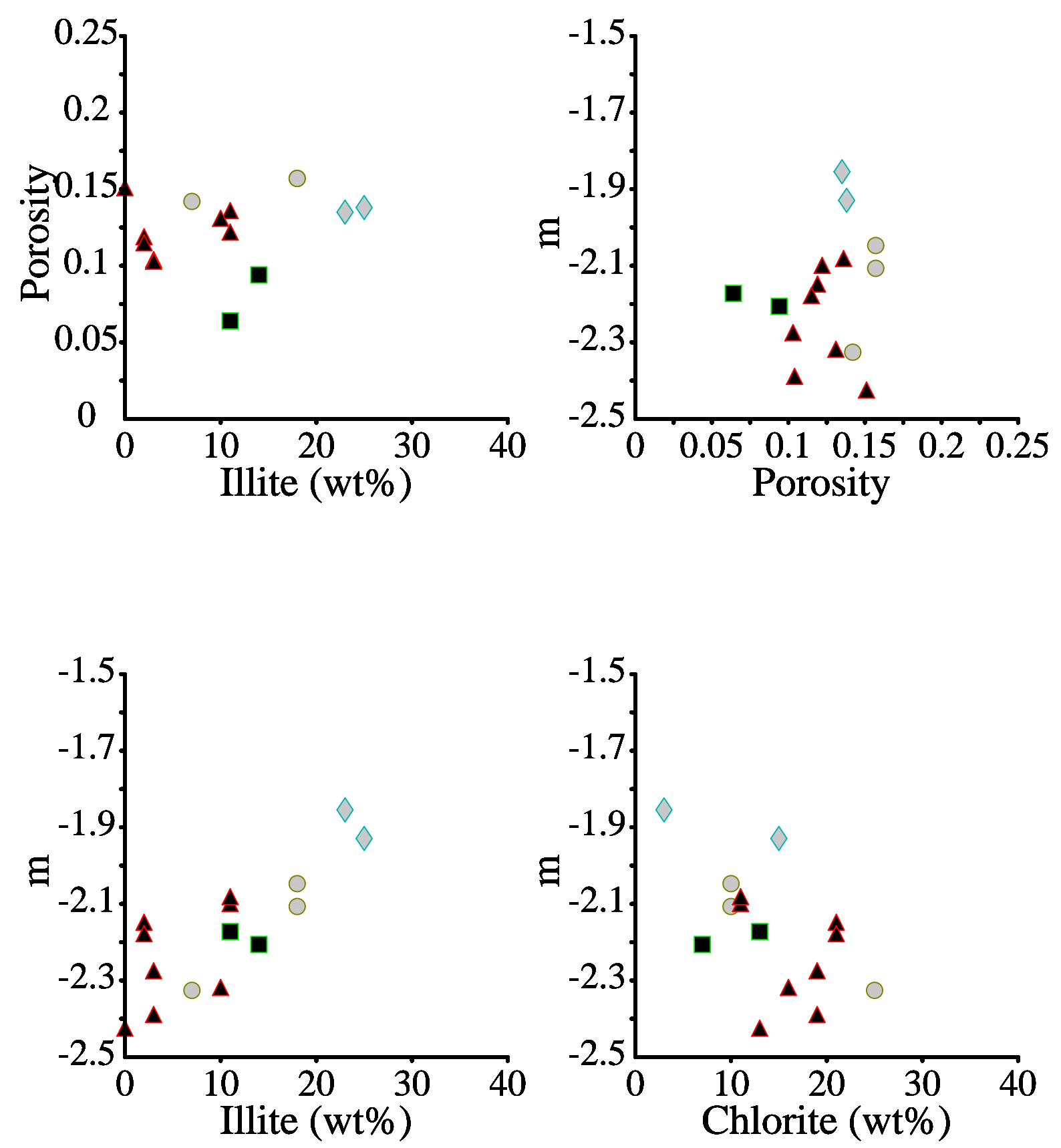

Figure 22: Cross plots of porosity, m, and illite and chlorite concentrations. 
Based on these observations, and recalling that Formation factors (F) of these cores follow a typical but noisy Archie porosity trend, $F=\phi^{\mathrm{m}}$, (Figure 14), a simple empirical relationship was selected of the form

$$
\text { (4) } F=\phi^{m}+B I+C X
$$

Following a similar procedure to that used for the velocities and moduli, we again find that the inclusion of illite in the relationship significantly reduces the RMS porosity error, while the addition of chlorite along with porosity and illite produces no additional advantage (see Figure 4).

\section{Electrical Resistivity}

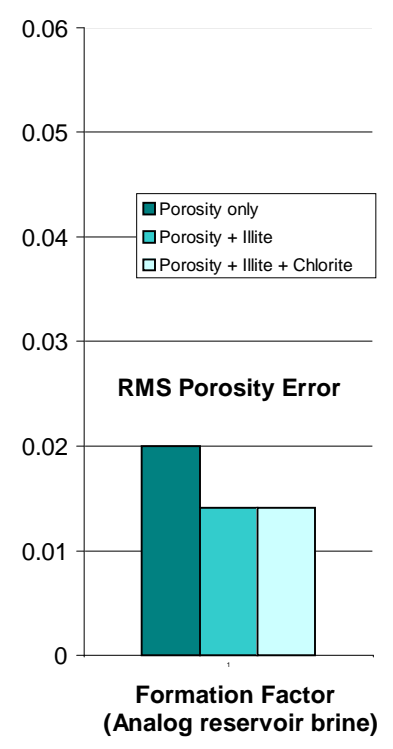

Figure 23: Comparison of RMS porosity errors for fits to equation 4 (see Table 4). As with velocities and moduli, the addition of illite significantly improves the fit, while chlorite has little effect.

\subsubsection{Electrical Properties of The Geysers Matrix}

Near the end of this project, electrical resistivity data was collected on cores from the Geysers Geothermal field. Brine saturated electrical resistivity measurements were made on the same cores used by Boitnott and Boyd, 1996. In Figure 24, the brine saturated resistivity measurements on the Geysers cores are compared with the Awibengkok results. While the NEGU17 and Awibengkok results appear to define a reasonable trend with porosity (approximately linear in $\log (\mathrm{F})$ versus porosity, the SB15D cores follow a notably steeper $\log (\mathrm{F})$ vs. porosity trend. Using the empirical model for $\mathrm{F}$ as a function of porosity and illite content determined for the Awibengkok data set, we find that all of the Geysers cores are systematically shifted to higher F. This indicates that the empirical model based on the Awibengkok data will need to be modified to accommodate the Geysers data set. 
Attempts to combine the Awibengkok and Geysers data sets into a unified empirical model were not successful (see Figure 25 and Table 4). With the combined data set, the RMS porosity errors are consistently worse than for the Awibengkok data set alone, and there is no clear evidence the inclusion of mineralogy provides significantly better fits to the data (i.e. the RMS porosity error improves slightly with each addition of a new free parameter as would be expected for such a small data set). Fitting the Geysers data alone leads to similar conclusions to those made previously based on the Awibengkok data, but requiring different parameters - most notably an $\mathrm{m}$ of- -1.75 as opposed to -2.1 for Awibengkok. For the Geysers data set, the addition of a linear dependence on either chlorite or illite improves the fit. This is in contrast to the Awibengkok data set where only the inclusion of illite dependency made a clear improvement. In addition, the mineralogy terms determined by fitting the Geysers data are much stronger than those determined for the Awibengkok data set. These differences between the two data sets should be studied in more detail.

It is also of interest to note that in previous studies of The Geysers core (Boitnott and Boyd, 1996), a correlation between sample conductivity and shear modulus weakening was observed. In that work, conductivity measurements were made using distilled water as the pore fluid, so that the measured sample conductivities were dominated by surface conductivity. This finding that shear modulus weakening is strongly correlated with illite content, again suggests a correlation between surface conductivity and illite concentration. However, it should be noted that surface conductivities for The Geysers cores are notably less than the inferred surface conductivities of the Awibengkok cores, indicating that textural controls are important.
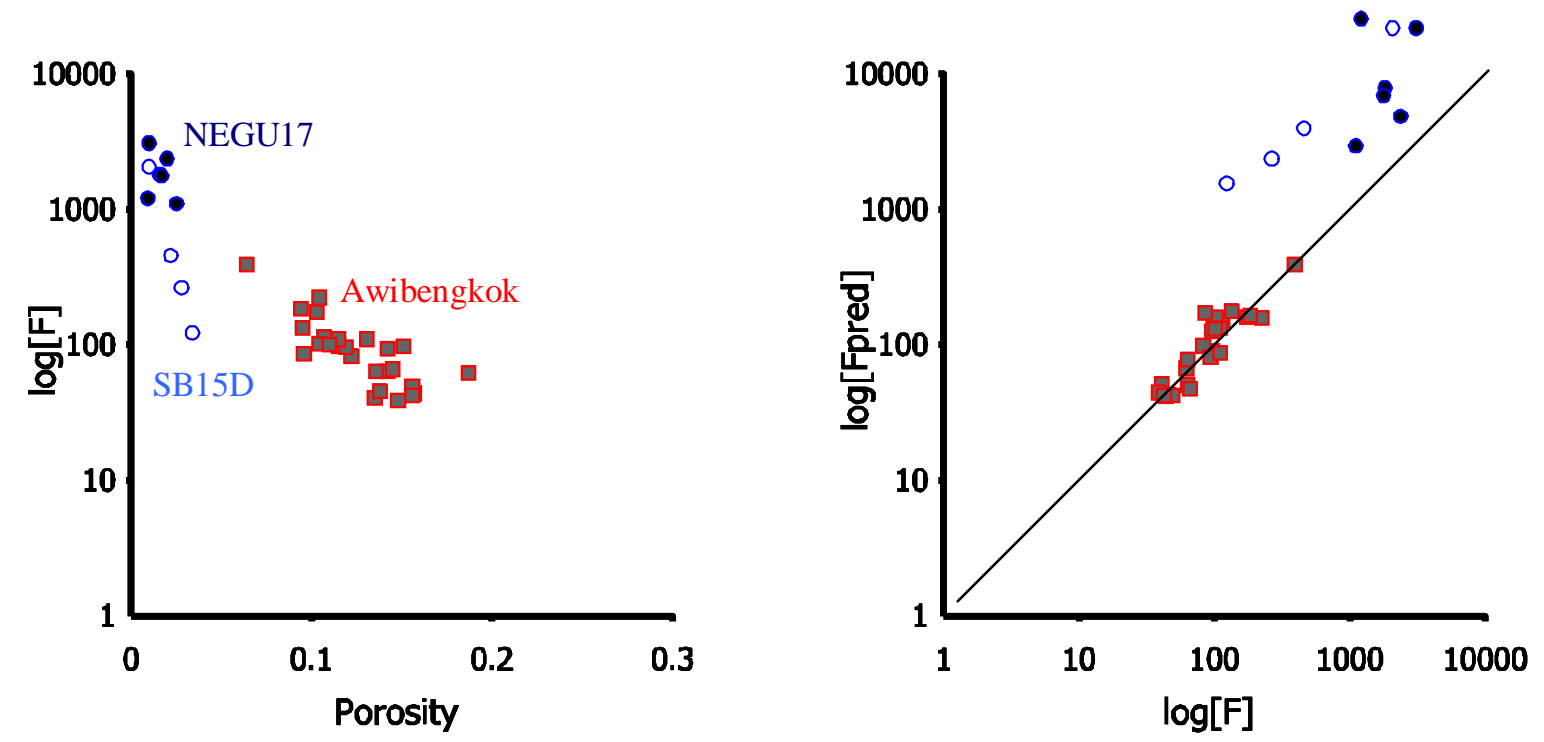

Figure 24: Plot of logarithm of the formation factor (F) versus porosity (left) comparing new data from cores from the Geysers (NEGU17 and SB15D) with the previously reported Awibengkok data. On the right is a comparison of measured versus predicted formation factor using a empirical relationship based on the Awibengkok data. Note that the empirical model, which is based on porosity and illite content, systematically over-predicts F for the Geysers cores. 


\section{Resistivity Empirical Models}

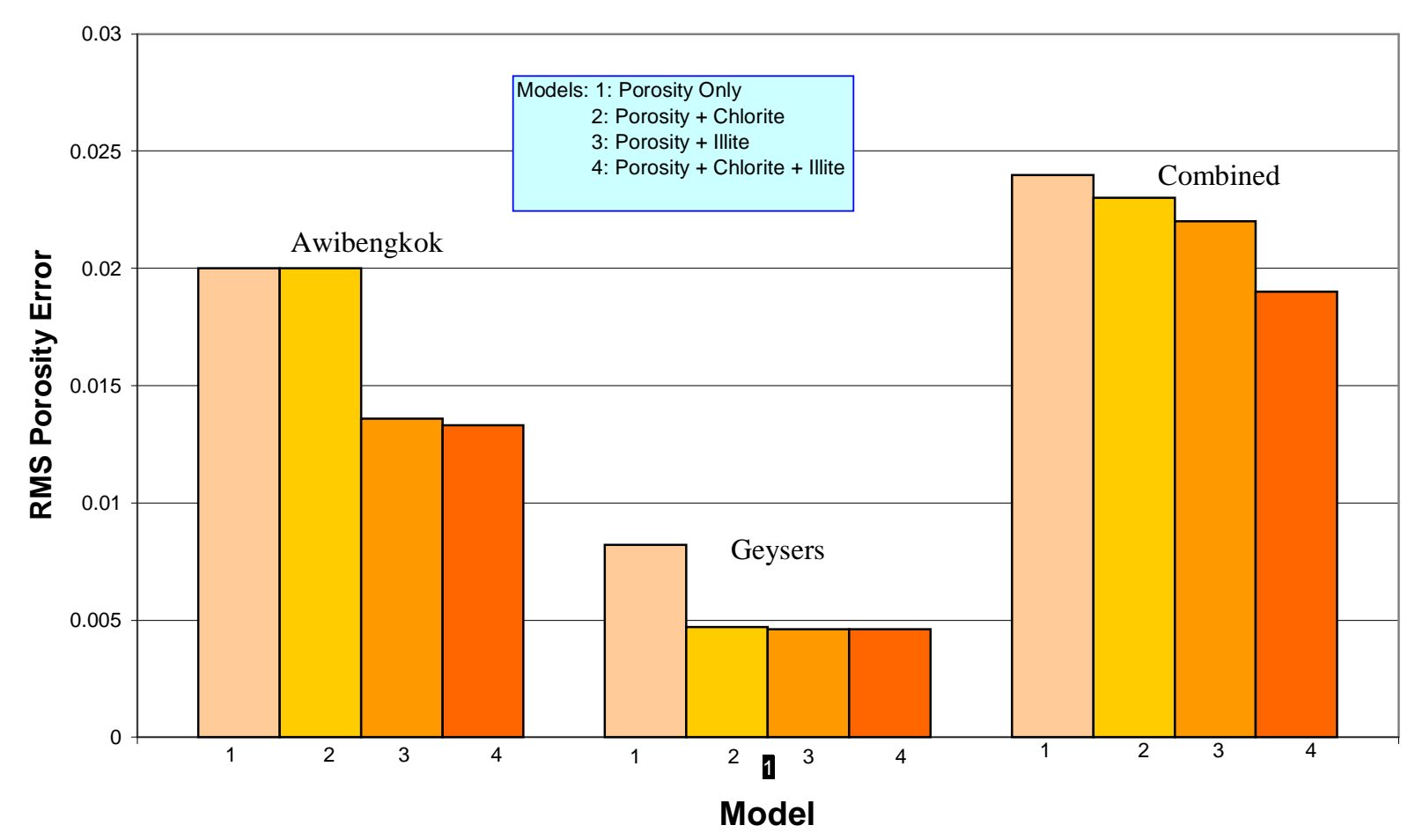

Figure 25: Comparison of fits of formation factor to empirical models of the form in equation 4, for different subsets of the available data. Fitting the Awibengkok data only, the addition of a linear dependence on illite concentration leads to a significant improvement in fit, while the addition of a linear chlorite term does not. Fitting the Geysers data alone, the addition of either illite and/or chlorite dependencies are significant. The combined data set (Awibengkok and Geysers) is not fit as well by the empirical model, with modest improvement in fit upon addition of illite and/or chlotite terms.

\subsubsection{Physical Significance of the Empirical Model}

A simple physical model that results is that of a porous matrix with brine conductivity defined by an Archie relationship $\mathrm{F}^{*}=\phi^{\mathrm{m}^{*}}$ with $\mathrm{m}^{*}$. Based on the Awibengkok data, the available data suggests that $\mathrm{m}^{*}$ may be weakly dependent on porosity. A significant secondary conduction mechanism (presumably surface conduction) is clearly evident and appears to be associated with illite content. There is evidence from both the Awibengkok and Geysers data sets to indicate that the surface conductivity is proportional to the abundance of illite in the sample. However, based on measurements with low conductivity pore fluids, the inferred surface conductivities cannot fully explain the success of the linear illite term in equation 4 in improving the predictions of $\mathrm{F}$. This indicates that while surface conduction enhanced by illite appears to be an important conduction mechanism, there also appears to be a textural component to the illite dependence that plays a more significant role in influencing F. For example, the archie exponent $\mathrm{m}^{*}$ may be a function of illite content, representing a textural (i.e. tortuosity) influence of illite, 
which combined with surface conductivity enhancement, leads to the strong illite dependence indicated by the best fitting empirical model. Clearly more work is needed to better understand these results in the context of a self-consistent physical model.

Recommendation: Extending the data set to include a larger number of samples, combined with more detailed work on physical and electrochemical modeling and more complete petrographic analysis is needed to help address these fundamental issues

\begin{tabular}{|c|c|c|c|c|c|}
\hline \multicolumn{6}{|c|}{ Table 4: Empirical Models of Formation Factor } \\
\hline \multicolumn{6}{|c|}{ Formation Factor : $F=\phi^{m}+B I+C X$} \\
\hline Property & Dataset & $\mathbf{m}$ & B & C & RMS PorosityError \\
\hline \multirow{4}{*}{$\begin{array}{l}\mathrm{F} \\
(12000 \mathrm{ppm} \mathrm{NaCl})\end{array}$} & \multirow{4}{*}{ Awibengkok only } & -2.13 & & & 0.0200 \\
\hline & & -2.13 & & 1.7 & 0.0200 \\
\hline & & -2.25 & -162 & & 0.0136 \\
\hline & & -2.19 & -143 & 61 & 0.0133 \\
\hline \multirow{4}{*}{$\begin{array}{l}\mathrm{F} \\
(12000 \mathrm{ppm} \mathrm{NaCl})\end{array}$} & \multirow{4}{*}{ Geysers only } & -1.58 & & & 0.0082 \\
\hline & & -1.80 & & -1978 & 0.0047 \\
\hline & & -1.78 & -1050 & & 0.0046 \\
\hline & & -1.75 & -1750 & 1440 & 0.0046 \\
\hline \multirow{4}{*}{$\begin{array}{l}\mathrm{F} \\
(12000 \mathrm{ppm} \mathrm{NaCl})\end{array}$} & \multirow{4}{*}{ Awibengkok and Geysers } & -2.07 & & & 0.024 \\
\hline & & -1.98 & & 93 & 0.023 \\
\hline & & -2.15 & -119 & & 0.022 \\
\hline & & -2.02 & -101 & 141 & 0.019 \\
\hline
\end{tabular}

\subsection{Joint Interpretation of Velocities and Electrical Properties}

One potential application of these relationships is for improved log analysis, such as characterization of porosity and illite concentration from resistivity and velocity logs. Figure 26 illustrates saturated $V_{p}$ and formation factor contours based on the empirical relationships of each property for the Awibengkok data set. This graph illustrates some important interrelationships between these two commonly logged properties. At low porosities, formation factor is found to be relatively insensitive to illite content. For saturated matrix, if $\mathrm{F}$ is known, porosity can be inferred directly from $\mathrm{F}$ and velocities can be used to infer illite content. High porosity materials have different systematics owing to the fact that porosity effect on $\mathrm{F}$ decreases at higher porosities while the illite effect retains its strength. In this case, resistivity becomes a poor predictor of porosity, but in combination with velocites, could be used to constrain both porosity and illite. Also of significance at moderate porosities, $\mathrm{F}$ and $\mathrm{V}_{\mathrm{p}}$ contours are relatively parallel, indicative of a regime where porosity and illite cannot be distinguished even using a joint interpretation approach. The Awibengkok reservoir contains a number of units in this regime.

For the Geysers, a similar relationship is observed. For typical matrix porosities of less than 3 percent, the F contours are essentially independent of illite content, crossing the velocity 
contours at significant angle. This again indicates that joint interpretation of $\mathrm{F}$ and velocity may provide information on porosity and illite content, and similarly, the analysis of velocity alone is a poor indicator of porosity.

For both the Awibengkok and Geysers cases, at high porosities the illite term begins to dominate the determination of $\mathrm{F}$ as the linear illite dependence maintains its strength while the power law dependence on porosity becomes weak. In hindsight, this is likely a limitation of our choice of the empirical equation, and extrapolation of these models to porosities higher than observed in the datasets from which they are constrained may not be physical. More work, and more laboratory data are needed to better define the functional dependence of illite and porosity on F. We also suggest that a unified empirical model may be possible by allowing the Archie exponent to be a function of porosity.

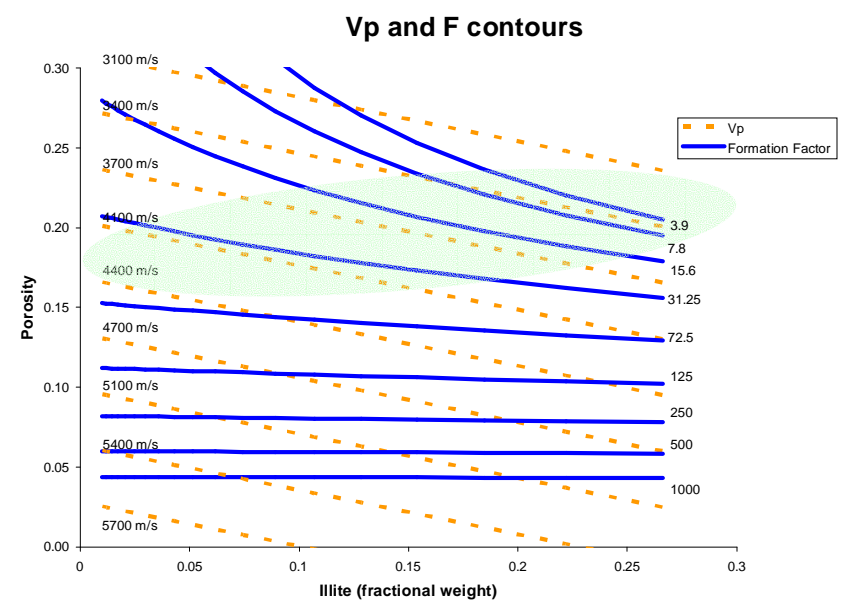

Figure 26: Contours of saturated $V_{p}$ and $F$ for the Awibengkok samples based on Tables 2 and 4. A zone of parallel contours highlighted in green indicates a region where porosity variations cannot be distinguished from illite variations. Below this zone (i.e. low porosity) $F$ is the best indicator of porosity and $V_{p}$ can be used to constrain illite.

\subsection{Core Scale Heterogeneity}

The core from Awibengkok is visibly heterogeneous at scales from a millimeter to a few centimeters. This produces significant challenges for core analysis, owing to the need to rely on a limited number on samples with dimensions on the order of 2 to $5 \mathrm{~cm}$. In order to better understand the importance of this heterogeneity, a series of measurements were made on selected samples to quantifying the degree and character of this heterogeneity. As part of this project, an electrical resistivity probe was developed to measure spatial variability in electrical properties of core samples.. The probe is a four electrode device, which when pressed against the sample, measures the local complex impedance as a function of frequency.

An example resistivity map is shown in Figure 27 along-side a photograph of the core surface (see also Appendix A for more examples). Note that the resistivity maps are rich in detail, showing a wide variety of heterogeneities associated with veins, fractures, and petrographic variations. While some of the heterogeneities correspond to noticeable visual features in the sample, others are less obvious as to their origin.

Results illustrate a wide variety of "anomalies" ranging from conductive or resistive clasts to fractures and porous veins. Importantly, the results illustrate that the samples 
commonly have intrinsic variability on the order of a factor of three or more, with significant correlations at length scales of a few centimeters. This suggests that core scale heterogeneity (and its structural details) may give rise to significant resistivity signatures, and may explain much of the remaining scatter in the laboratory scale data. Viewed in the context of the findings from plug data discussed earlier, we can postulate that resistivity anomalies with $\mathrm{F}>100$ are largely controlled by porosity variations. Illite and porosity are equally likely to contribute significantly to anomalies for $\mathrm{F}<100$.

Another important conclusion of this work is that resistivity variation is a poor indicator of lithology. Somewhat surprisingly, resistivity maps of lahar samples with conspicuous heterogeneity in the form of clasts of various rock types, illustrate that the clasts are not resolved well by resistivity alone. This same conclusion can be drawn from measurements on plugs of various lithologic units (recall Figure 14), where lithologies are shown to span wide ranges of porosity and $\mathrm{F}$.

Complex impedance, however, appears to do a reasonable job in identification of discrete clasts and/or beds in some cases, and thus as resistivity logging tools become more advanced, complex impedance may prove a useful reservoir characterization tool. Furthermore, these observations suggest that for these rocks, porosity may reflect a combination of weathering prior to lithification and degree of hydrothermal alteration, rather than being linked to primary porosity of the host matrix.

For the sample shown in Figure 27, a very large petrographic thin section $(20 \mathrm{~cm}$ by 10 $\mathrm{cm}$ ) was produced of the surface that was mapped, providing a unique opportunity to study the interrelationships between electrical impedance and petrography. In collaboration with Jeff Hulen at EGI, basic petrographic characteristics we mapped at the centimeter scale in the thin section, including mineral abundances and megaporosity. An interactive analysis program was written to allow us to explore for correlations between the various mapped quantities.

Many of these anomalies are quickly explained, such as open cracks associated with veins and the large vein clot which dominates both the visual and electrical images. However, other anomalies do not have obvious explanation. In lower part of Figure 27, the probability density function for electrical impedance is displayed. This grey scale plot presents the frequency of occurrence of a particular resistivity and phase pair in the map data. Dark indicates higher frequency of occurrence. The plot illustrates the broad distribution of impedances represented in the sample, however somewhat of a surprise, the plot indicates that the distribution is dominantly bi-modal, with two fairly concentrated populations of impedances.

Figure 28 highlights the two peaks in the bimodal impedance distribution and displays where those impedances are located in the map view of the sample. One peak occurs at $\mathrm{R}=27$ $\mathrm{ohm} \mathrm{m}$ and Phase $=-0.018 \mathrm{rad}$, while the other occurs at $\mathrm{R}=38 \mathrm{ohm} \mathrm{m}$ and Phase $=-0.022 \mathrm{rad}$. Note the two impedance types are spatially separated in the sample, with the less resistive one being concentrated on the upper third of the sample and the more resistive one being representative of the lower third. This is thought to reflect variation between in electrical properties between beds of slightly different petrographic character. Figure $\mathbf{2 8}$ also highlights a third, central division in the impedance map, characterized by relatively little (i.e. near zero) phase shift and a wide range in resistivity. This central region represents a zone of more intense hydrothermal alterantion and dissolution, apparently associated with a vien and guided by the bedding structure of the unit.

To help identify and quantify petrologic controls for the various impedance types and anomalies, mineral composition was mapped using the large thin section of the sample (work courtesy of Jeff Hulen). Eleven mineral species were mapped at centimeter resolution. Some representative data is shown in Figure 29. The mineralogy maps indicate that the upper and 
lower regions, which were found to be electrical distinct, are mineralogically similar. Two leading possibilities are that porosity or textural differences, likely originating from or reflecting original bedding variations, gives rise to this behavior. The central region is notably low in sericite (dominantly illite) but has normal abundances of chlorite. The low illite content is also likely a relic bedding feature (J. Hulen, personal communication). The central region while low in illite, does not have increased resistivity as might be expected from the plug data. In fact, resistivity is highly variable and spans the range observed in the neighboring beds. This is believed to reflect the complex hydrothermal alteration of this bed, possibly reflecting proximity to the large vein clot. A combination of enhanced microporosity and unevenly distributed pore filling wairakite and carbonate is a possible explanation for the character of this central bed.

A catalog of resistivity maps with the same detail have been collected, but not yet analyzed in any detail (see Appendix A). The maps, two examples of which are shown in Figures 30 and 31, illustrate that a wide variety of electrical impedance "fabrics" are present in these cores. An important conclusion is that the electrical heterogeneity is generally not well correlated with the visible heterogeneity, indicating that the hydrothermal alteration process can significantly overprint the original lithologies. This also indicates that yet to be identified petrographic features influence the electrical properties, consistent with past interpretations that fabric, as opposed to simple mineralogic composition, plays a role in controlling electrical properties. An understanding of these observations should lead to an enhanced understanding of the hydrothermal alteration processes that ultimately control the properties of the matrix material.

Recommendation: A detailed study integrating these observations with petrographic analysis would provide valuable information concerning the fundamental controls on electrical properties. 


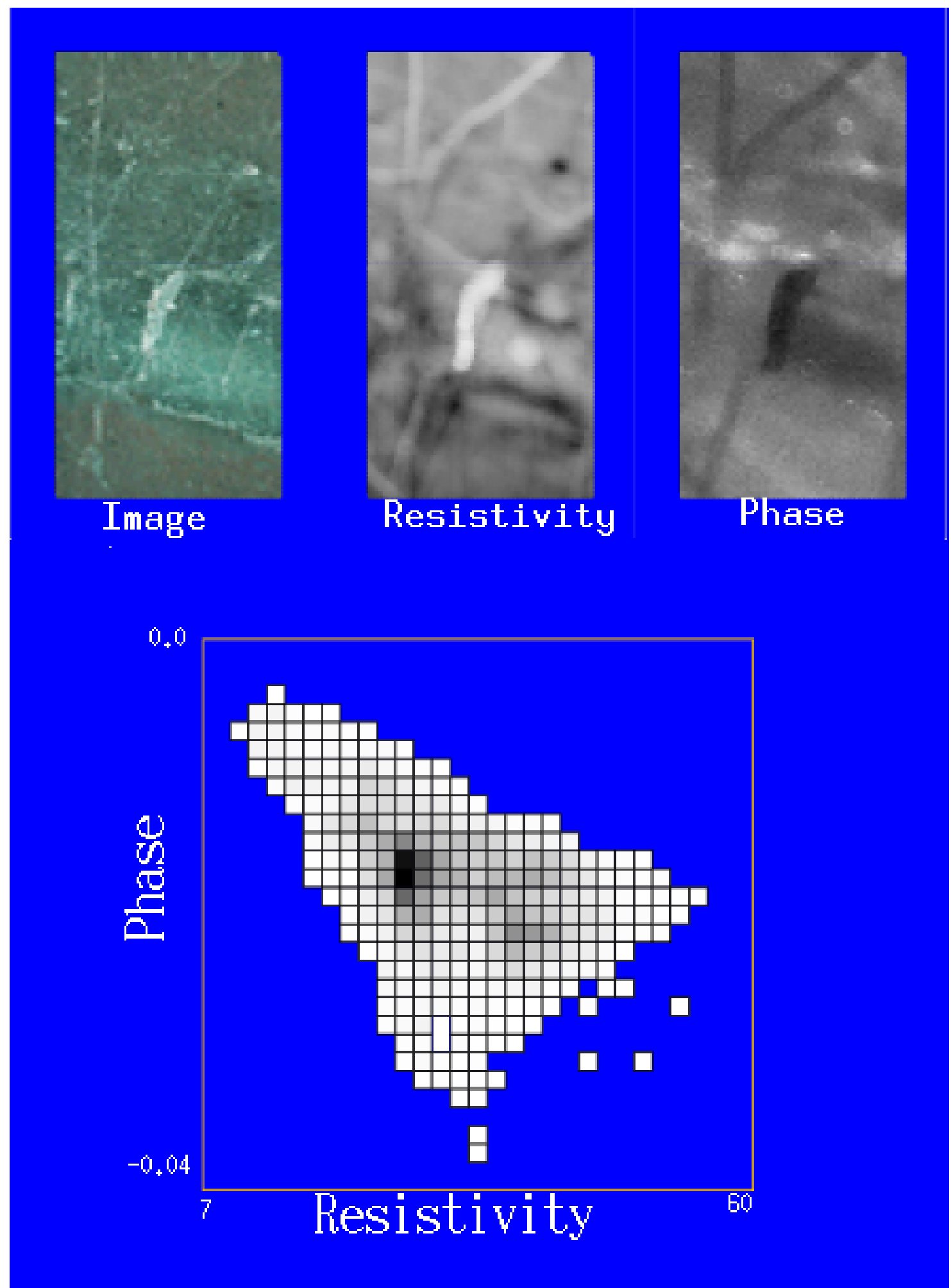

Figure 27: Electrical impedance map of sample 4990, a hydrothermally altered tuff from $1521 \mathrm{~m}$ in AWI 1-2. The upper right is a photograph of the core surface and the upper center and right images are the resistance and phase shift maps (dark indicates high absolute values for resitivity and phase; note that phase shifts are negative, so high absolute phases [dark areas] are areas with the smallest phase shift - i.e. nearest zero). The lower figure represents the distribution of resistances and phases observed in the maps, with dark shading indicating the most common resistivity/phase pairs. 

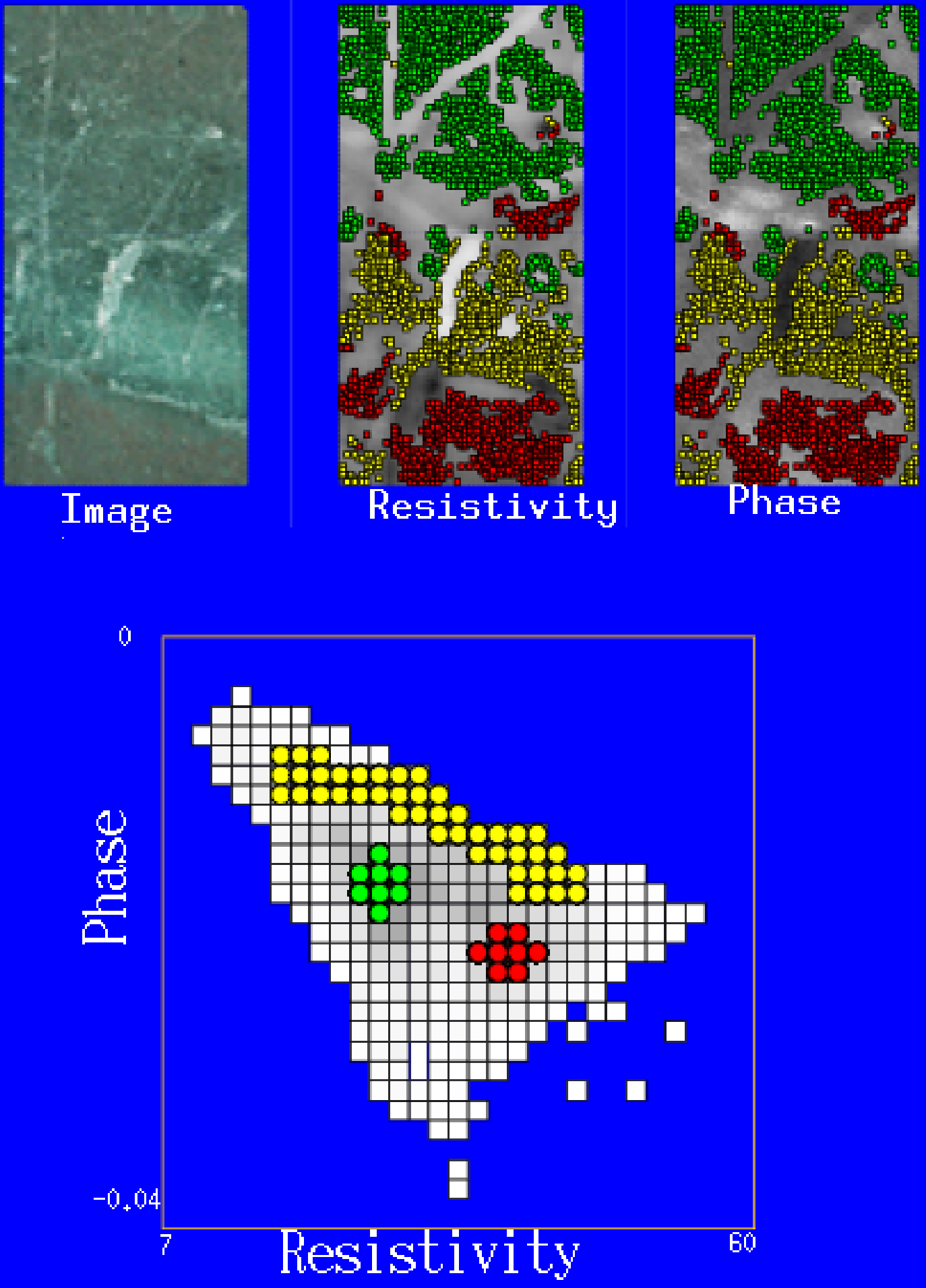

Figure 28: Electrical impedance maps of sample 4990, with three dominant impedance types highlighted. Note that these regions defined in resistivity/phase space map spatially to upper, central, and lower regions of the core. Also note that the central region of the core corresponds to impedances with relatively low (i.e. near zero) phase shift and widely varying resistivity. 


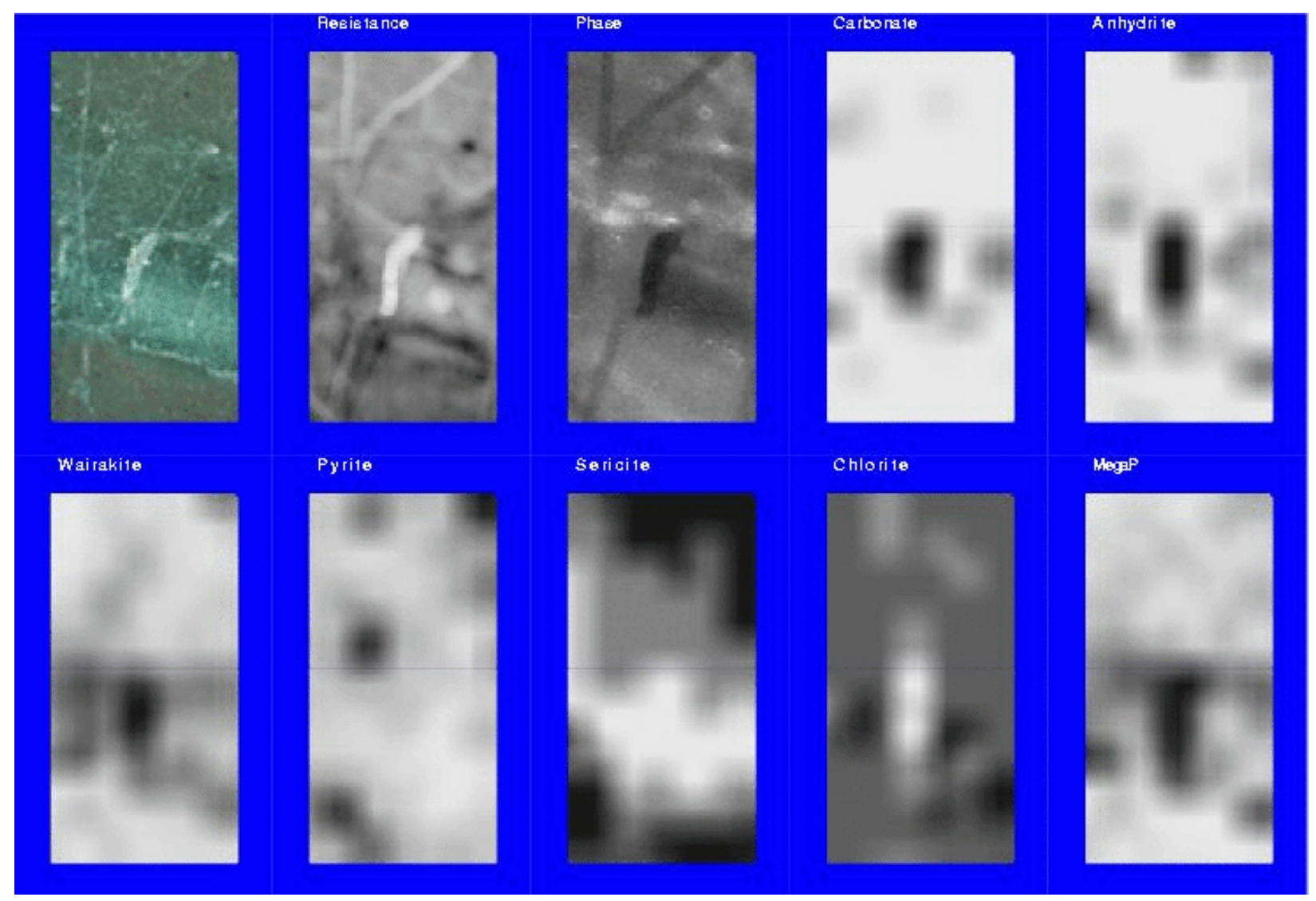

Figure 29: Electrical impedance and mineralogy maps of sample 4990. The mineralogy maps, mapped at the centimeter scale have been smoothed to aid comparison. Dark indicates higher concentration of each quantity. Sericite is thought to be dominantly illite. Note that the central region is characterized by low sericite but that chlorite content of the matrix is relatively uniform. The upper and lower regions, which are electrically distinct, are mineralogically quite similar. 

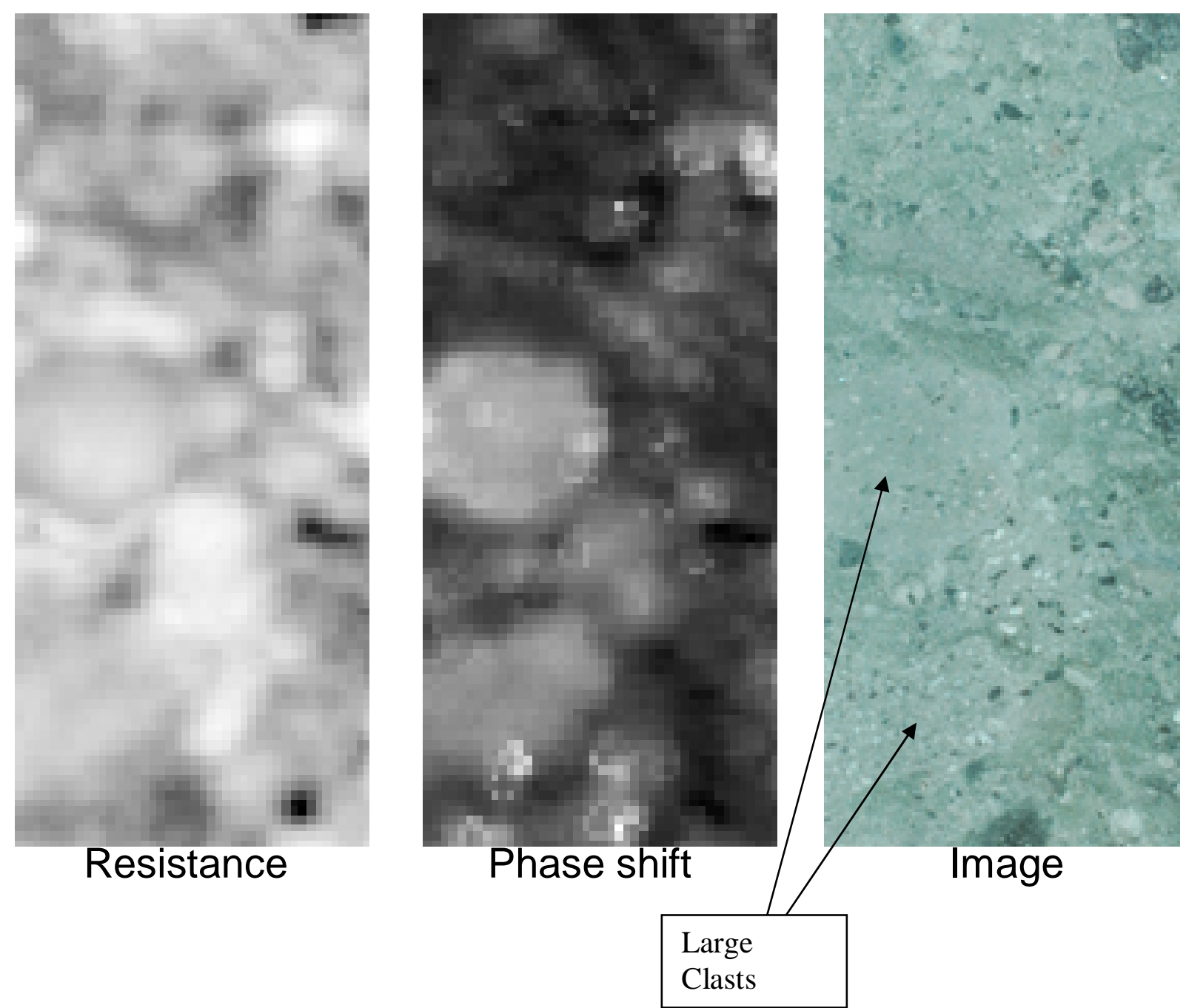

Figure 30: Resistance and phase shift maps, along side a photographic image of a lahar from the Awibengkok geothermal field. Two clasts are highlighted, both of which are easily visible and have a clear phase signal, but are not well resolved by resistance. Careful examination of this data provides a way of comparing the electrical signatures of different clasts which have undergone identical geothermal history, thus providing a unique data set from which to explore the role of original lithology in influencing the electrical properties of the matrix. 


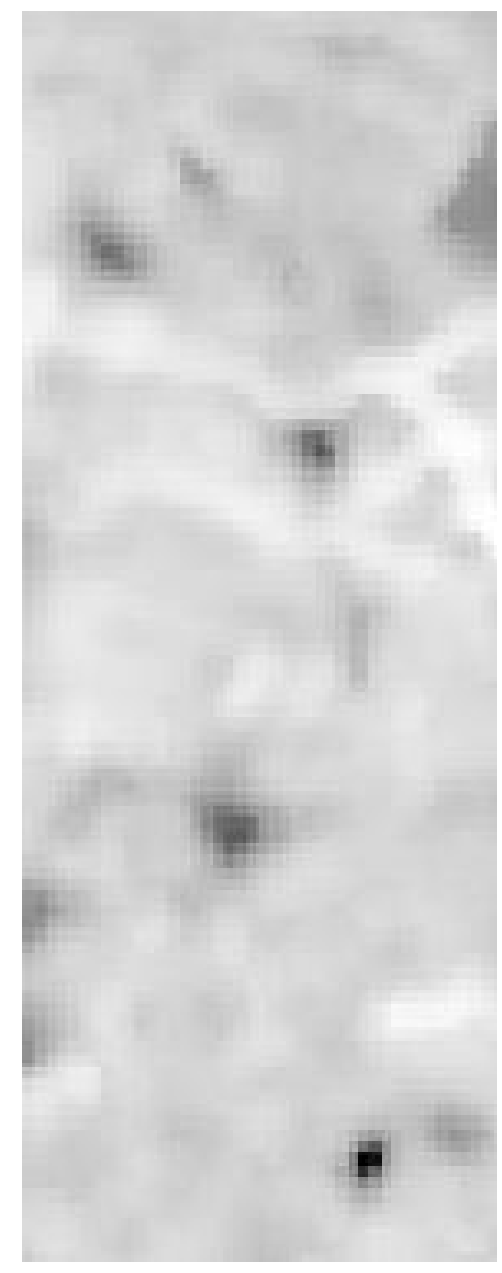

Resistance

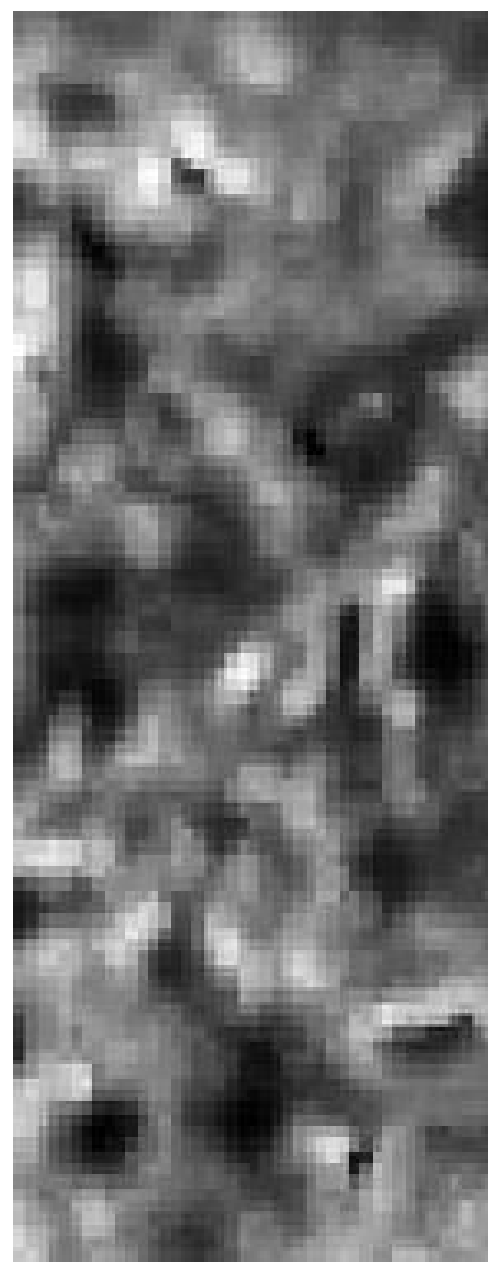

Phase Shift

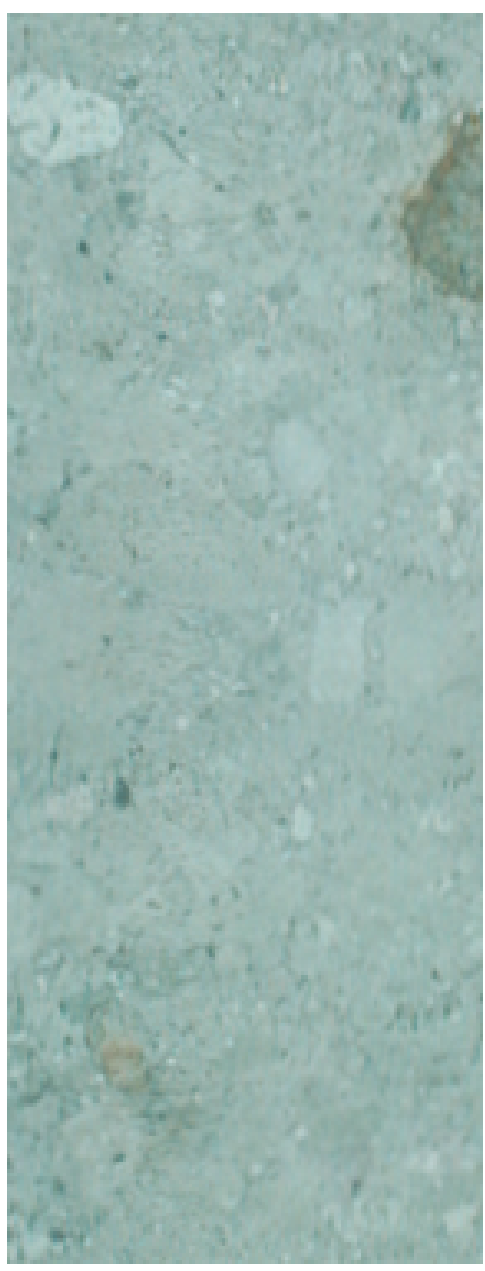

Image

Figure 31: Resistance and phase shift maps, along side a photographic image of a core from the Awibengkok geothermal field. Despite the relative visual uniformity, the phase map is rich in structure, indicating petrophysical detail not expected based on visual inspection. 


\subsection{Some Thoughts Concerning Field Scaling}

The next step in applying this core scale information is to use it to help constrain and interpret field scale data. The usefulness of matrix velocity information in interpreting field scale velocities has been demonstrated previously in Boitnott [1995]. With knowledge of the matrix properties, differences between field scale and matrix scale velocities and resistivities can be interpreted as the effect of the fracture system. This process is greatly simplified by the fact that the effect of pressure on velocities and resistivities of the matrix is in general quite small, indicating that depth dependence (due to pressure) of matrix properties can be largely neglected for most applications.

Field scale seismic tomography data exhibits similar patterns as observed in the matrix, evidence that saturation effects at the Geysers may be influenced by a field scale shear weakening phenomena similar to that observed in the matrix (see Boitnott and Kirkpatrik, [1997]). The mechanical properties of a single fracture are known to be controlled by the morphology of the fracture and the elastic properties of the host matrix. Thus the poroelastic model for the matrix outlined here provides a necessary component of a physical model for fractured rock as well. A fractured rock model for seismic properties linking fracture network geometry and matrix properties using an effective medium approach is currently under development.

Similarly, pressure and temperature dependence of $\mathrm{F}$ is in general relatively small, indicating that the observed systematics should be persistent at all depths. Frequency dependence of resistivity is variable and can lead to relatively strong dispersions at logging frequencies. The available data suggests that the observed dispersion, which can lead to a $20 \%$ reduction in resistivity between $1 \mathrm{~Hz}$ and $10 \mathrm{kHz}$, is relatively insensitive to changes in temperature and pressure. Thus the effects of temperature, pressure and frequency are all second order effects when compared to the observed systematics between $F, \Phi$, and illite, indicating that the empirical relationships presented here are directly relavant to field observations. As with for seismic properties, an effective medium model is now being developed to combine the matrix and fracture system effects on field scale measurements.

\subsection{References}

Boitnott, G. N., and B. Bonner, (1994) Characterization of rock for constraining reservoir scale tomography at the Geysers Geothermal Field, Proceedings, 19th Workshop on Geothermal Reservoir Engineering, SGP-TR-147, 231-236

Boitnott, G. N., (1995) Laboratory measurements on reservoir rocks from The Geysers geothermal field, Proceedings, 20th Workshop on Geothermal Reservoir Engineering, SGP-TR150, 107-114.

Boitnott, G. N., and P. J. Boyd, (1996), "Permeability, Electrical Impedance, and Acoustic Velocities on Reservoir Rocks from The Geysers Geothermal Field," Proceedings, $21^{\text {st }}$ Workshop on Geothermal Reservoir Engineering, SGP-TR-151, 343-350.

Boitnott, G. N. and A. Kirkpatrick, (1997) Interpretation of field seismic tomography at the Geysers geothermal field, California, Proceedings, $22^{\text {nd }}$ Workshop on Geothermal Reservoir Engineering, SGP-TR-155 391-398 
Boitnott, G. N.. and J. Johnson, (1999) Laboratory measurements of ultrasonic velocities on core samples from the Awibengkok geothermal field, Indonesia, GRC Transactions, vol. 23, p. 9-12.

Boitnott, G. N., and J. B. Hulen, (2001), Petrographic controls on electrical properties of core samples from the Awibengkok geothermal field, GRC Transactions, vol 25, p-391-394.

Waxman, M. H., and Smits, L. J. M., (1968) Electrical conductivities in oil-bearing shaly sandstones, Transactions AIME, v. 243, part II, 107-122.

Wong, J., (1979) An Electrochemical model of the induced-polarization phenomenon in disseminated sulfide ores, Geophysics, v. 44, n. 7. 


\subsection{Appendix A}

Following are some additional examples of complex impedance maps collected on samples from the Awibengkok geothermal reservoir, followed by some overview plots detailing the resistivity distributions (distributions of formation factors) and crossplots of resistivity and phase.

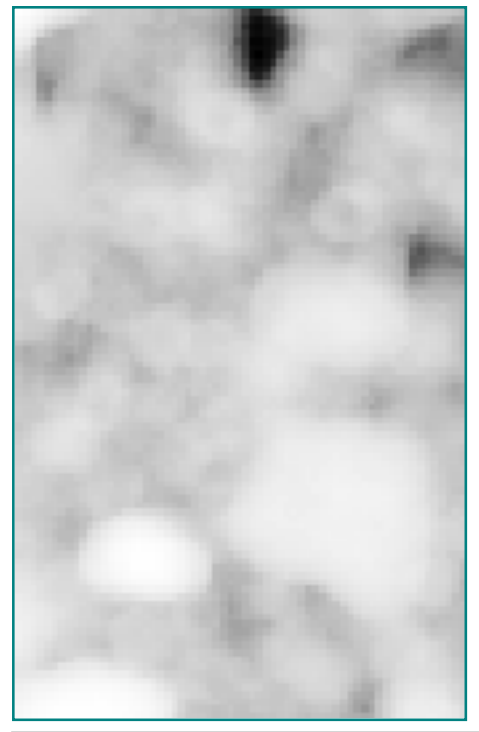

Resistance

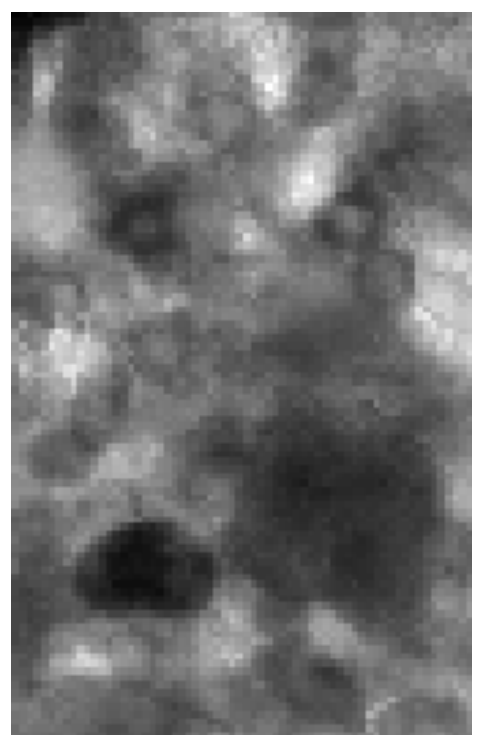

Phase Shift

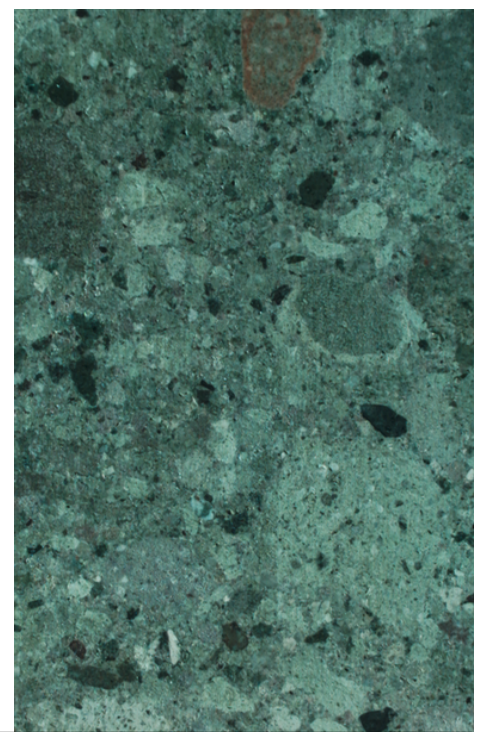

Image

Sample 2541: lahar 


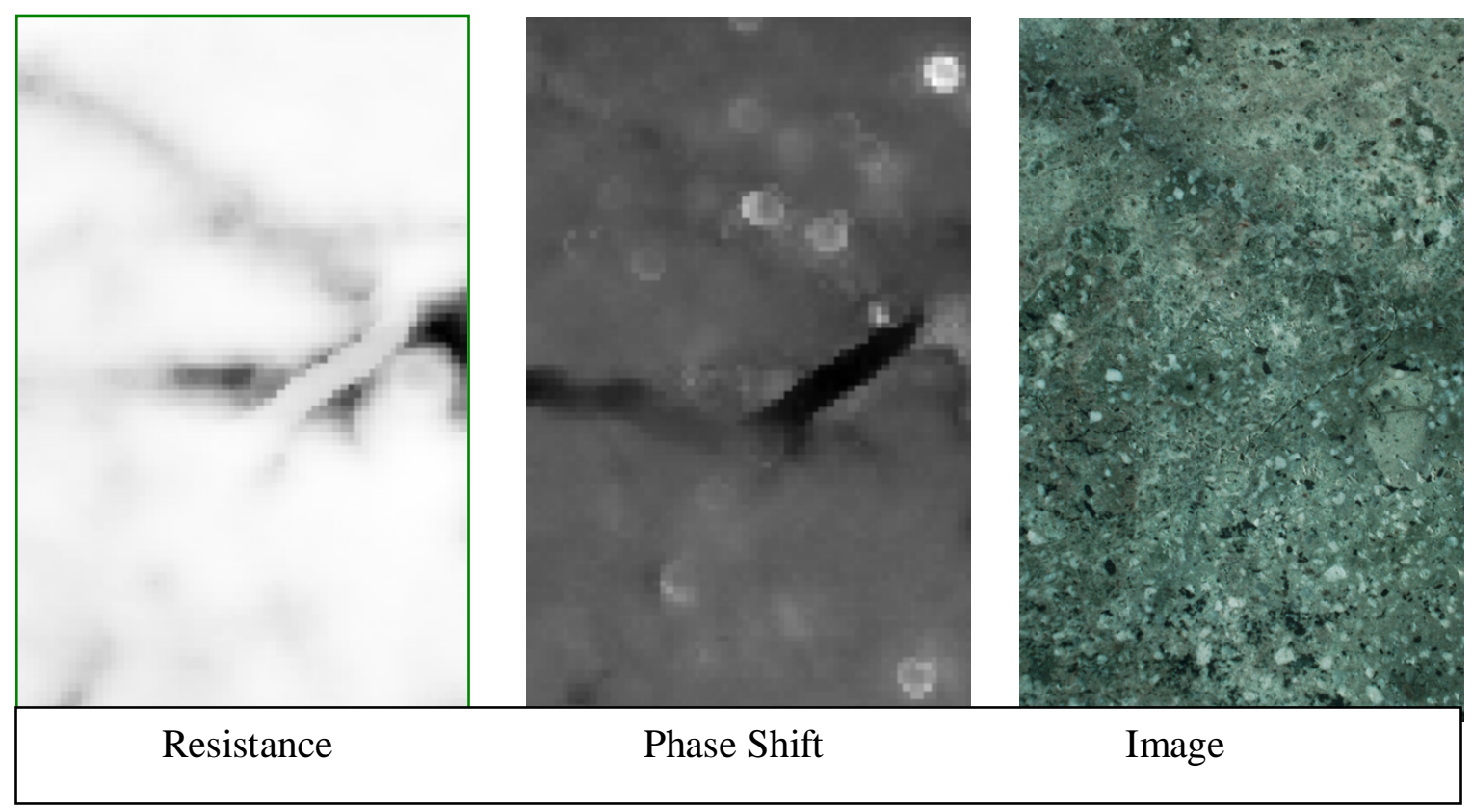

Sample 3099: Dacite Autobreccia

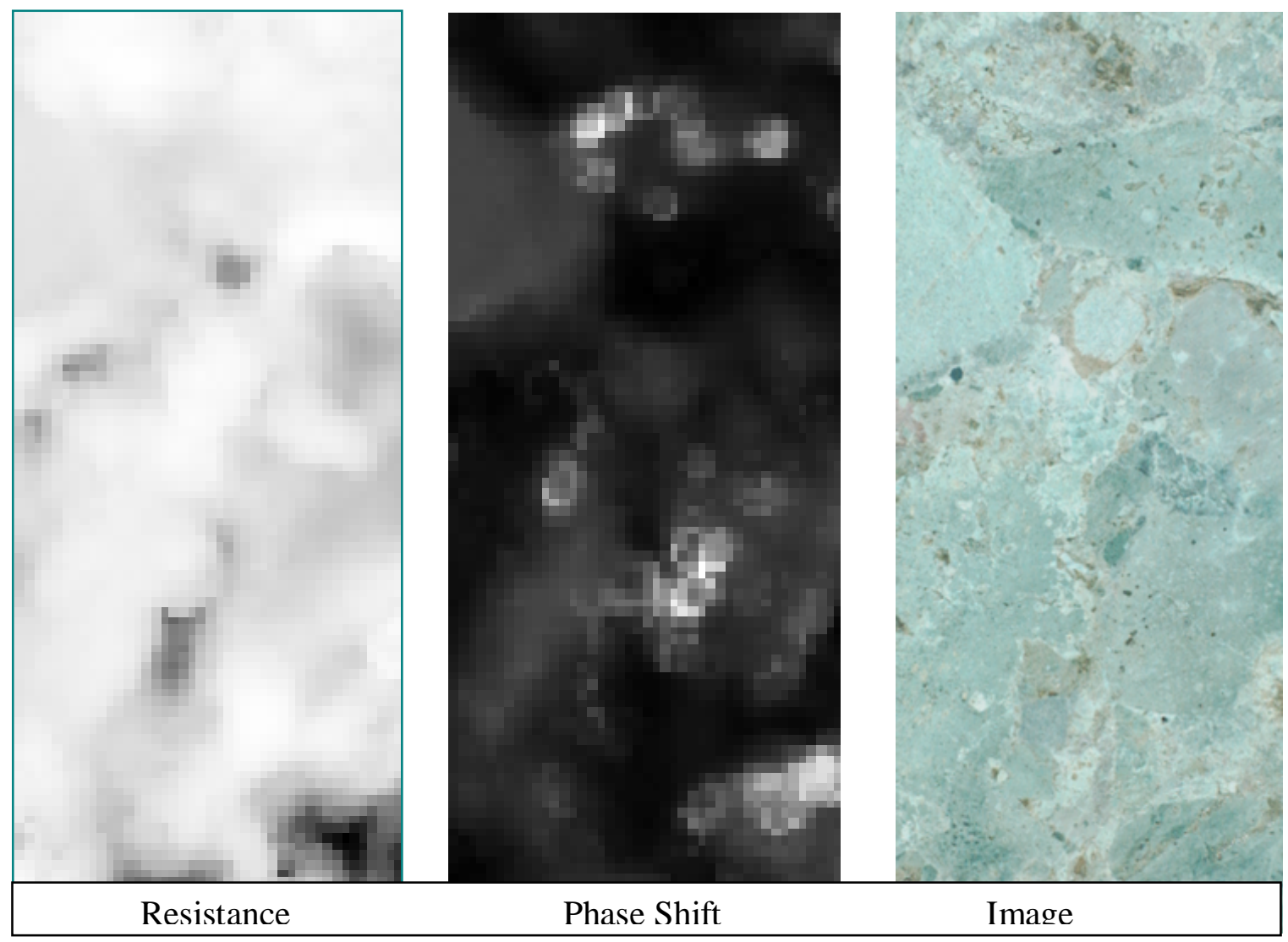

Sample 5105: Lahar 


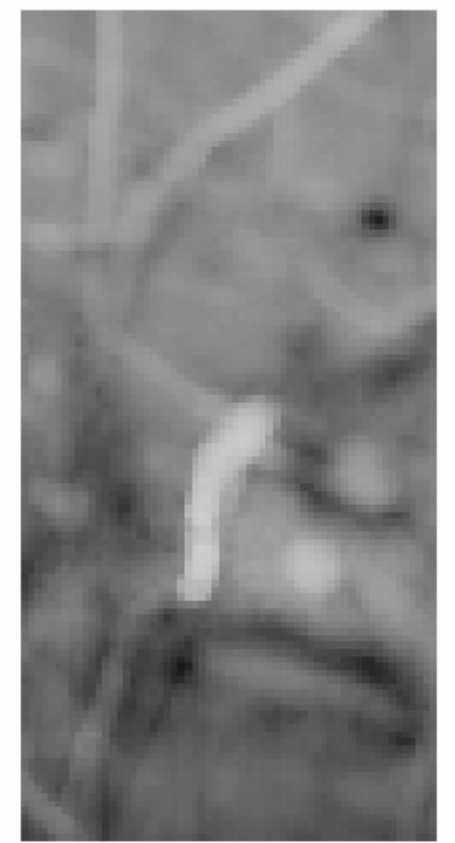

\section{Resistance [ohms]}

0

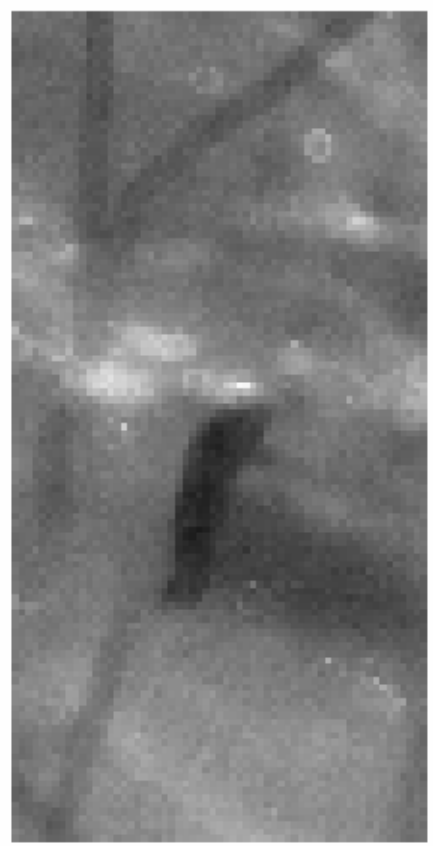

Phase [radians]

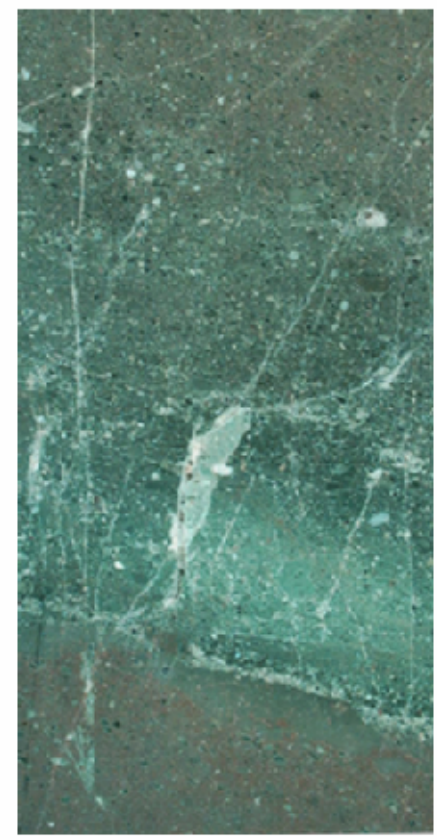

Sample 4990: Tuff 


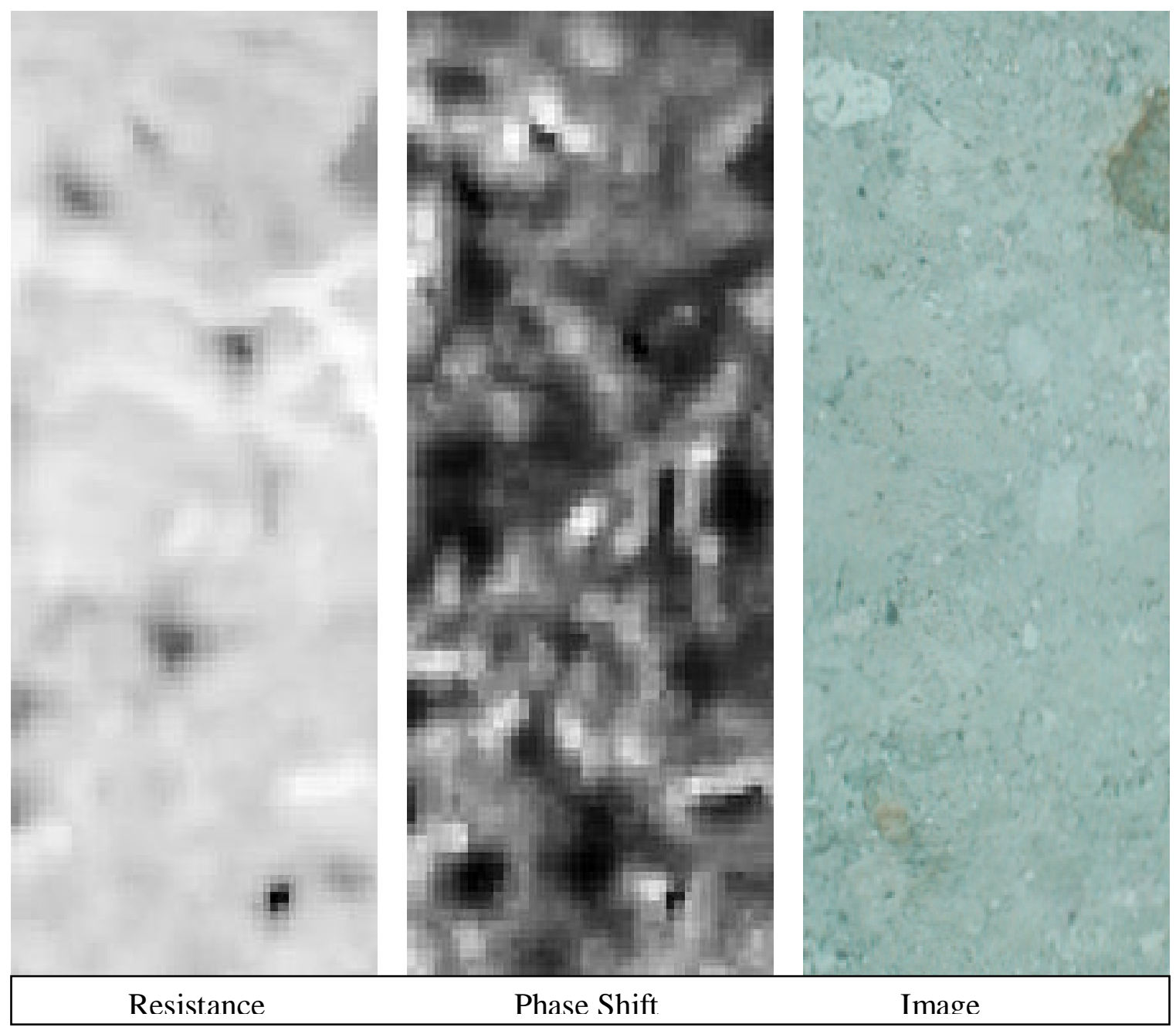

Sample 2571-72 

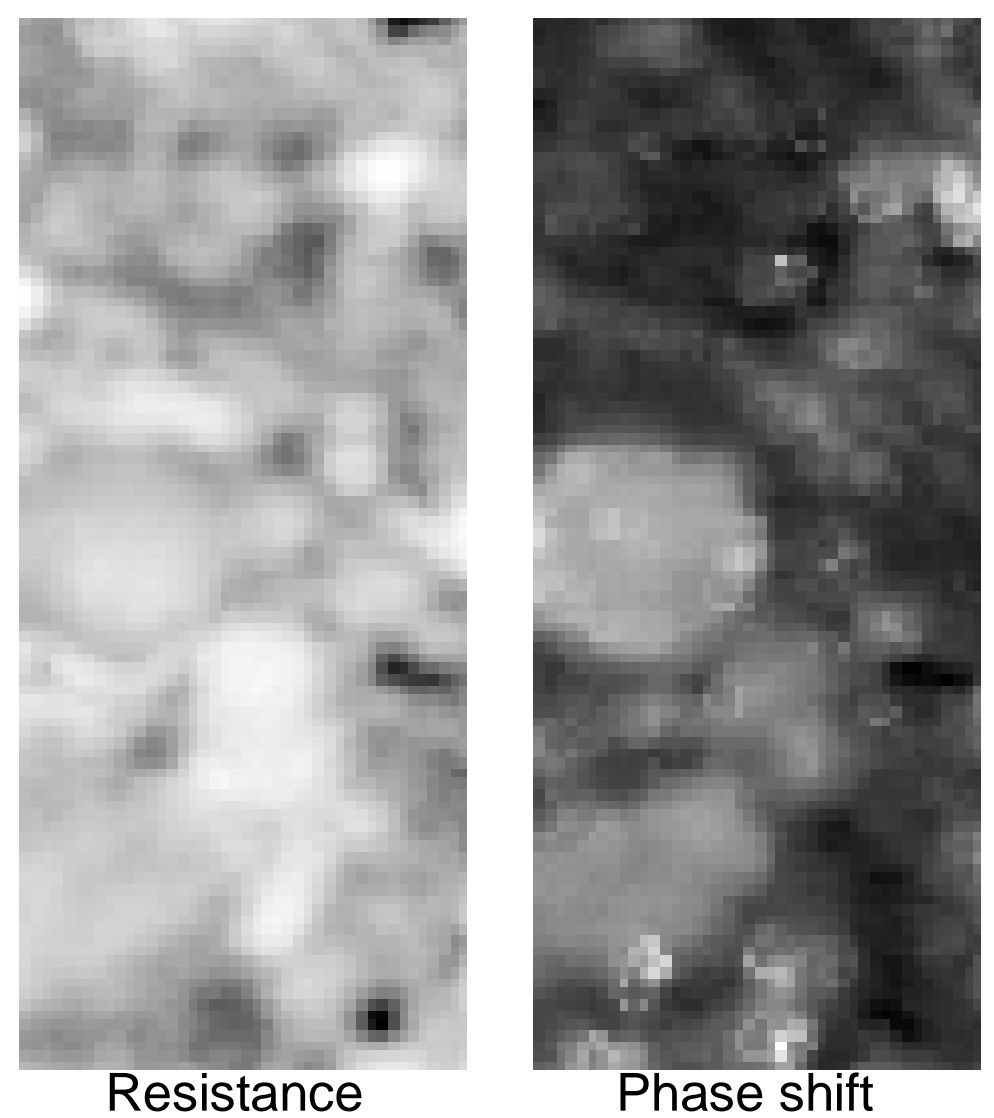

Phase shift

Sample 2561-62: Lahar

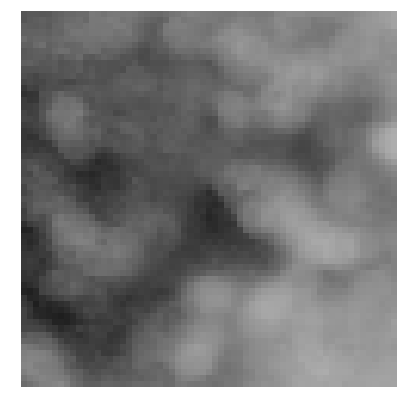

Resistance [ohms]

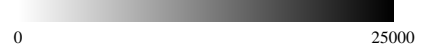

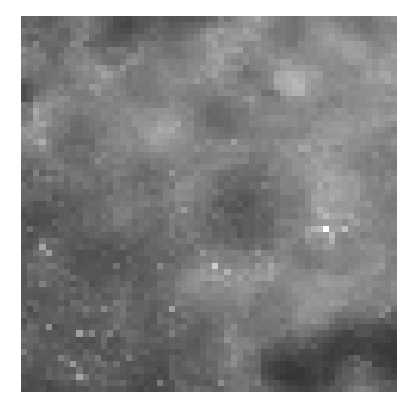

Phase [radians]

$-0.1$

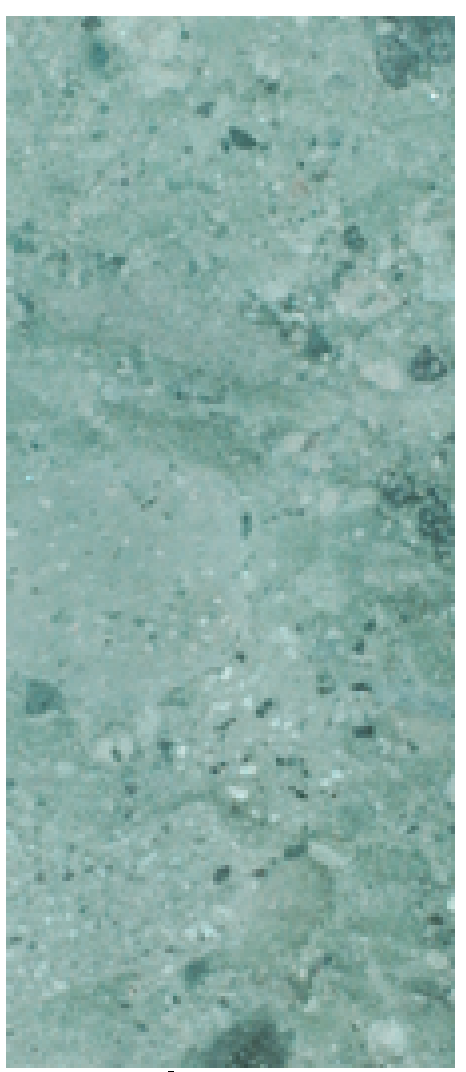

Image

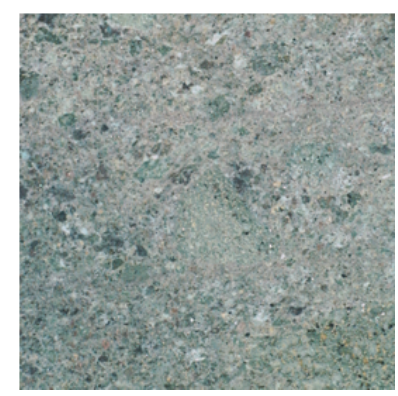

Sample 4125: Lahar 

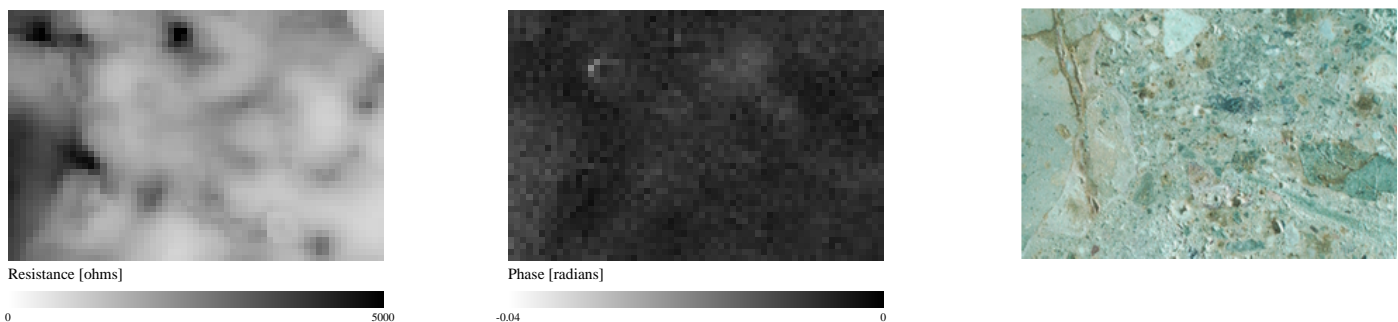

Sample 5091: Lahar 